\title{
EFEITO DO PROCESSO DISPERSIVO EM SUBPOPULAÇÕES DE TAMANHO REDUZIDO DE MILHO (Zea mays L.)
}

\author{
RAIMUNDO NONATO VIEIRA DA CUNHA
}

Tese apresentada à Escola Superior de Agricultura "Luiz de Queiroz", da Universidade de São Paulo, para obtenção do título de Doutor em Agronomia, Área de Concentração: Genética e Melhoramento de Plantas.

P I R A C I C A B A

Estado de São Paulo - Brasil

Janeiro - 2004 


\title{
EFEITO DO PROCESSO DISPERSIVO EM SUBPOPULAÇÕES DE TAMANHO REDUZIDO DE MILHO (Zea mays L.)
}

\author{
RAIMUNDO NONATO VIEIRA DA CUNHA \\ Engenheiro Agrônomo
}

Orientador: Prof. Dr. JOSÉ BRANCO DE MIRANDA FILHO

\begin{abstract}
Tese apresentada à Escola Superior de Agricultura "Luiz de Queiroz", da Universidade de São Paulo, para obtenção do título de Doutor em Agronomia, Área de Concentração: Genética e Melhoramento de Plantas.
\end{abstract}

P I R A C I C A B A

Estado de São Paulo - Brasil

Janeiro - 2004 
Dados Internacionais de Catalogação na Publicação (CIP)
DIVISÃO DE BIBLIOTECA E DOCUMENTAÇÃO - ESALQ/USP

\author{
Cunha, Raimundo Nonato Vieira da \\ Efeito do processo dispersivo em subpopulações de tamanho reduzido de milho \\ (Zea mays L.) / Raimundo Nonato Vieira da Cunha. - - Piracicaba, 2004. \\ $126 \mathrm{p}$. \\ Tese (doutorado) - - Escola Superior de Agricultura Luiz de Queiroz, 2004. \\ Bibliografia.
}

1. Deriva gênica 2. Endogamia 3. Heterose 4. Milho 5. Populações vegetais I. Título

CDD 633.15

\title{
"Permitida a cópia total ou parcial deste documento, desde que citada a fonte - O autor"
}


À minha mãe pela educaşão, confiança e estímulos constantes em todos os momentos da minha vida e aos meus amores, Ana Cristina, Camila e João Vicente pelo apoio, carinho e dedicação em todos esses anos que estamos juntos OFERECSO

Ao meu pai Vicente Celso da Cunha (in memorian) "Da semente à vida Da vida à semente" 


\section{AGRADECIMENTOS}

Ao Professor Dr. José Branco de Miranda Filho, pela orientação segura, confiança e amizade;

Aos Professores Dr.Antônio Augusto Franco Garcia e Dr. Roland Vencovsky do Departamento de Genética da Escola Superior de Agricultura "Luiz de Queiroz" pelo auxílio na interpretação dos dados;

Aos Professores do Departamento de Genética da Escola Superior de Agricultura "Luiz de Queiroz" pelos ensinamentos transmitidos e amizade;

Aos funcionários do Departamento de Genética da Escola Superior de Agricultura "Luiz de Queiroz", pelo auxílio na implantação e condução dos experimentos;

À Empresa Brasileira de Pesquisa Agropecuária - EMBRAPA Amazônia Ocidental, pelo apoio institucional para a realização deste trabalho;

Ao Conselho Nacional de Pesquisa e Desenvolvimento Científico e Tecnológico - CNPq pela bolsa de estudo concedida durante parte do curso;

Aos amigos e colegas pós-graduandos da Escola Superior de Agricultura "Luiz de Queiroz", pelo companheirismo, troca de experiências que em muito contribuiu para o sucesso deste trabalho;

Aos meus familiares, esposa e filhos, mãe, irmãs e irmãos pela paciência, carinho, confiança e apoio decisivos neste período;

E finalmente um agradecimento sincero a todas as demais pessoas que, direta ou indiretamente contribuíram para a realização deste trabalho. 


\section{SUMÁRIO}

Página

LISTA DE FIGURAS ........................................................................... vii

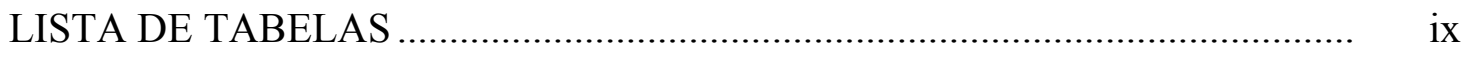

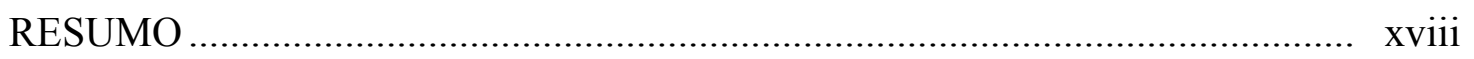

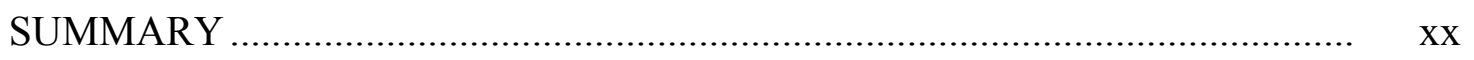

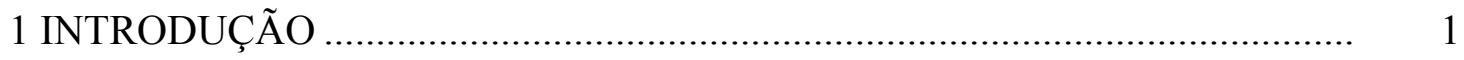

2 REVISÃO DE LITERATURA ................................................................ 3

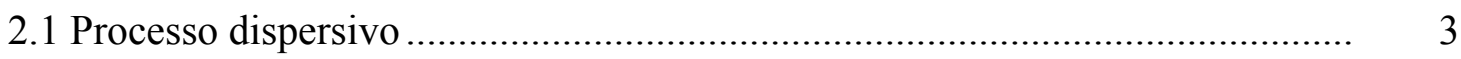

2.2 Variabilidade genética intrapopulacional.................................................... 7

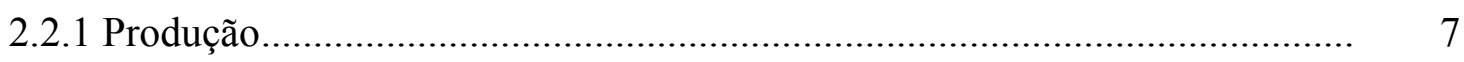

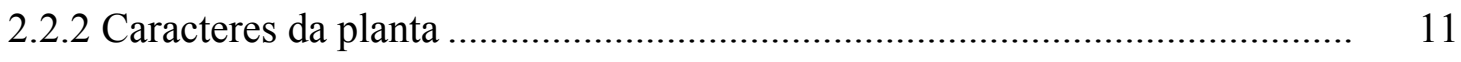

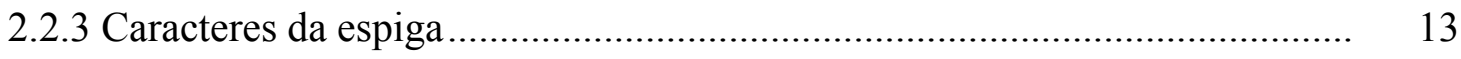

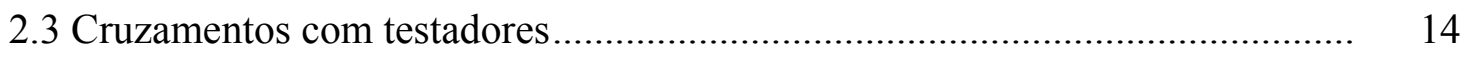

2.3.1 Variância entre famílias ou 'testcrosses' .................................................. 15

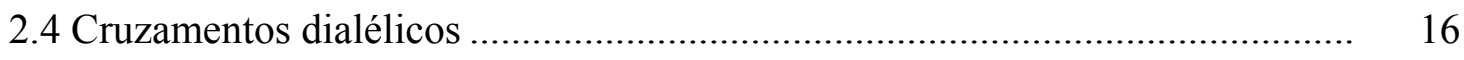

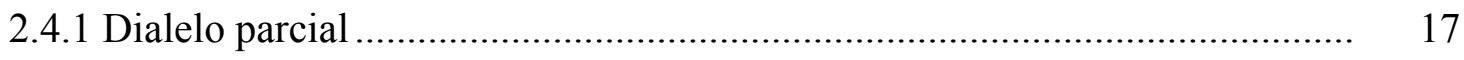

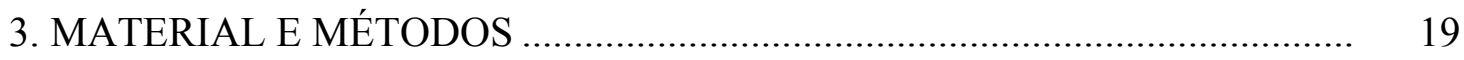

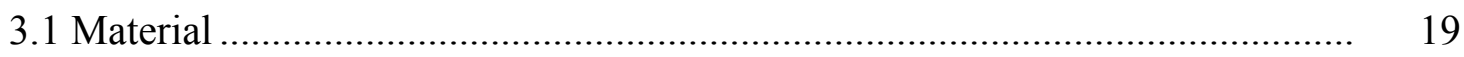

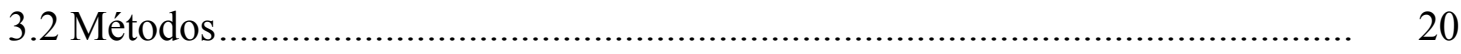

3.2.1 Obtenção dos materiais genéticos e execução experimental......................... 20

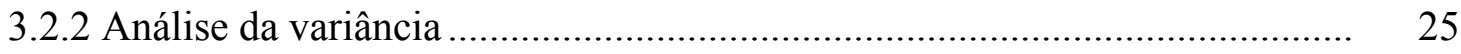

3.2.2.1 Progênies em cadeia ........................................................................... 25

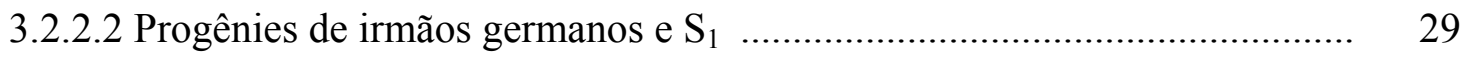


3.2.2.3 Subpopulações de tamanho reduzido ..................................................... 30

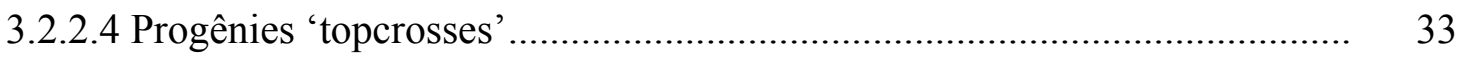

3.2.2.5 Cruzamento dialélico parcial ........................................................... 34

3.2.3 Estimativas de componentes da variância................................................. 37

3.2.3.1 Experimentos com progênies obtidas através de cruzamentos

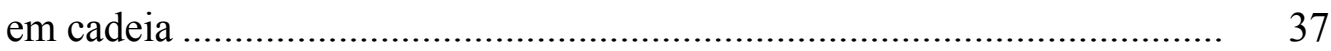

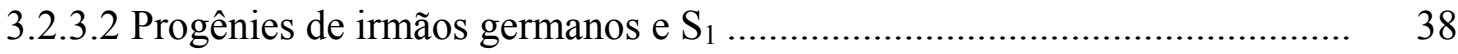

3.2.4 Depressão por endogamia (I) ............................................................. 40

4 RESULTADOS E DISCUSSÃO .............................................................. 41

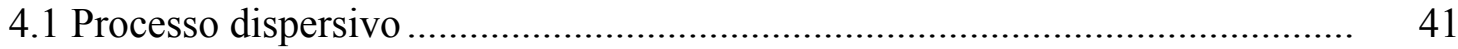

4.1.1 Análise da variância ........................................................................... 42

4.1.2 Valores médios em função do tamanho efetivo e seleção............................. 44

4.1.3 Valores médios das subpopulações, depressão por endogamia e desempenho em relação à testemunha..................................................... 49

4.2 Avaliação da capacidade de combinação das subpopulações em esquema 'topcross' ........................................................................... 56

4.3 Análise de cruzamentos dialélicos ....................................................... 57

4.4 Estimativas de componentes da variância................................................. 58

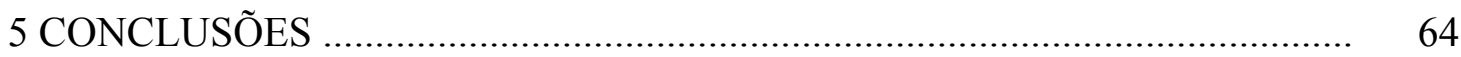

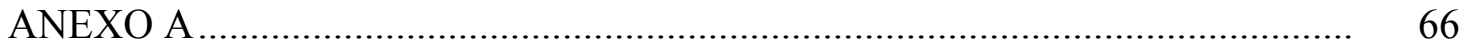

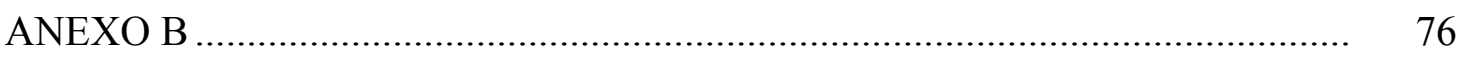

REFERÊNCIAS BIBLIOGRÁFICAS ....................................................... 114 


\section{LISTA DE FIGURAS}

Página

1 Representação diagramática de um esquema de cruzamentos com 3 genitores, representando uma cadeia......................................................... 20

2 Distribuição de valores da variável peso de espigas $\left(\mathrm{kg} / 4 \mathrm{~m}^{2}\right)$ com seleção positiva e negativa, em subpopulações (A) tamanho efetivo 1, (B) tamanho efetivo 2 e (C) tamanho efetivo 3................................ 67

3 Distribuição de valores da variável comprimento da espiga $(\mathrm{cm})$ com seleção positiva e negativa, em subpopulações (A) tamanho efetivo 1, (B) tamanho efetivo 2 e (C) tamanho efetivo 3............................... 68

4 Distribuição de valores da variável diâmetro da espiga $(\mathrm{cm})$ com seleção positiva e negativa, em subpopulações (A) tamanho efetivo 1, (B) tamanho efetivo 2 e (C) tamanho efetivo 3............................... 69

5 Distribuição de valores da variável prolificidade (espigas/pl.) com seleção positiva e negativa, em subpopulações (A) tamanho efetivo 1, (B) tamanho efetivo 2 e (C) tamanho efetivo 3................................. 70

6 Distribuição de valores do caráter altura da planta $(\mathrm{cm})$ com seleção positiva e negativa, em subpopulações (A) tamanho

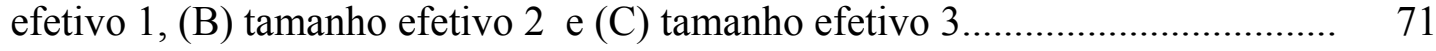

7 Distribuição de valores do caráter altura da espiga $(\mathrm{cm})$ com seleção positiva e negativa, em subpopulações (A) tamanho

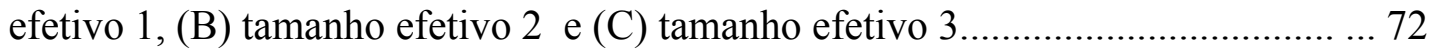

8 Depressão por endogamia para o caráter (A) peso de espigas, (B) comprimento da espiga e (C) diâmetro da espiga 
9 Depressão por endogamia para o caráter (A) prolificidade, (B)

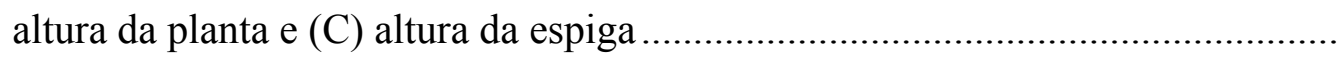

10 Valores médios dos 'topcrosses' em função dos tamanhos efetivos

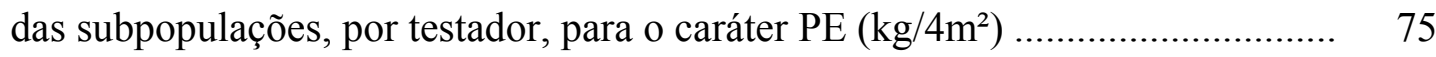

11 Valores médios dos 'topcrosses' em função dos tamanhos efetivos das subpopulações, para o caráter PE $\left(\mathrm{kg} / 4 \mathrm{~m}^{2}\right)$.

12 Valores médios dos 'topcrosses' em função dos tamanhos efetivos das subpopulações, por nível de seleção, para o caráter PE $\left(\mathrm{kg} / 4 \mathrm{~m}^{2}\right)$ 


\section{LISTA DE TABELAS}

Página

1 Estimativas da variância genética aditiva $\left(\hat{\sigma}_{\mathrm{A}}^{2}\right)$ para produção de grãos em diversas populações de milho no Brasil......................................... 9

2 Estimativas da variância genética aditiva $\left(\hat{\sigma}_{\mathrm{A}}^{2}\right)$, em $(\mathrm{cm} / \text { planta })^{2}$, para o caráter comprimento da espiga em diversas populações de milho

3 Médias de três caracteres do composto GN-04 obtidas em Rio Verde-GO, 1999

4 Experimentos instalados nos locais 1 e 2 no ano agrícola $2000 / 2001$

5 Análise agrupada da variância para progênies de cruzamentos em cadeia, para um local, e para todos os caracteres, em nível de totais ou de médias de parcelas e esperança dos quadrados médios expressa em termos de componentes da variância e covariância.

6 Análise agrupada conjunta da variância, para progênies de cruzamentos em cadeia, para todos os caracteres, em nível de totais ou de médias de parcelas e esperança dos quadrados médios, expressa em termos de componentes da variância e covariância, correspondentes às fontes de variação de maior interesse.

7 Estrutura da análise conjunta da variância dos experimentos 5 e 6, para todos os caracteres, em nível de totais ou de médias de parcelas, com os quadrados médios e suas respectivas esperanças. 
8 Estrutura da análise da variância do experimento 7, consistindo de subpopulações de tamanho reduzido, para todas os caracteres, em nível de total ou média de parcela.

9 Estrutura da análise da variância conjunta do experimento 7, para todas as variáveis, em nível de total ou média de parcela.

10 Estrutura da análise da variância do experimento 8 para o caráter peso de espigas, em nível de total de parcela.....

11 Estrutura da análise individual da variância dos experimentos 9, 10 e 11, baseado em um dialelo parcial, de acordo com o modelo sugerido por Miranda Filho \& Geraldi (1984)

12 Quadrados médios da análise da variância conjunta do experimento 7, com subpopulações de tamanho reduzido, para os caracteres peso de espigas (PE), comprimento da espiga (CE), diâmetro da espiga (DE) e prolificidade (PR)

13 Quadrados médios da análise da variância conjunta do experimento 7, com subpopulações de tamanho reduzido, para os caracteres altura da planta (AP) e altura da espiga (AE).

14 Quadrados médios da análise da variância do experimento 7, com subpopulações de tamanho reduzido, para os caracteres peso de espigas (PE), comprimento da espiga (CE), diâmetro da espiga (DE) e prolificidade (PR). ESALQ/Genética, 2003.

15 Quadrados médios da análise da variância do experimento 7, com subpopulações de tamanho reduzido, para os caracteres peso de espigas (PE), comprimento da espiga (CE), diâmetro da espiga (DE) e prolificidade (PR). Anhembi, 2003

16 Quadrados médios da análise da variância do experimento 7, com subpopulações de tamanho reduzido, para os caracteres altura da planta (AP) e altura da espiga (AE), por local.

17 Valores médios do caráter peso de espigas $\left(\mathrm{kg} / 4 \mathrm{~m}^{2}\right)$, dados de dois locais, para o fator de tratamento tamanho efetivo x seleção. 
18 Valores médios do caráter comprimento da espiga ( $\mathrm{cm} / \mathrm{esp}$.), dados de dois locais, para o fator de tratamento tamanho efetivo $\mathrm{x}$ seleção

19 Valores médios do caráter variável diâmetro da espiga ( $\mathrm{cm} / \mathrm{esp}$.), dados de dois locais, para o fator de tratamento tamanho efetivo $\mathrm{x}$ seleção

20 Valores médios do caráter prolificidade (esp./pl), dados de dois locais, para o fator de tratamento tamanho efetivo x seleção.

21 Valores médios do caráter altura da planta $(\mathrm{cm} / \mathrm{pl})$, dados de dois locais, para o fator de tratamento tamanho efetivo x seleção

22 Valores médios do caráter altura da espiga $(\mathrm{cm} / \mathrm{pl})$, dados de dois locais, para o fator de tratamento tamanho efetivo x seleção.

23 Valor médio $(\bar{X})$, depressão por endogamia (I) e relação valor médio/testemunha $(\bar{X} / T)$ para os caracteres peso de espigas $(\mathrm{PE})$, comprimento da espiga (CE) e diâmetro da espiga (DE), obtidos em 30 subpopulações de tamanho efetivo reduzido, com seleção. ESALQ/Genética, 2003

24 Valor médio $(\bar{X})$, depressão por endogamia (I) e relação valor médio/testemunha $(\bar{X} / T)$ para os caracteres prolificidade $(P R)$, altura da planta (AP) e altura da espiga (AE), obtidos em 30 subpopulações de tamanho efetivo reduzido, com seleção. ESALQ/Genética, 2003.

25 Valor médio $(\bar{X})$, depressão por endogamia (I) e relação valor médio/testemunha $(\bar{X} / T)$ para os caracteres peso de espigas $(\mathrm{PE})$, comprimento da espiga (CE) e diâmetro da espiga (DE), obtidos em 30 subpopulações de tamanho efetivo reduzido, com seleção. Anhembi, 2003

26 Valor médio $(\bar{X})$, depressão por endogamia (I) e relação valor médio/testemunha $(\bar{X} / T)$ para os caracteres prolificidade $(P R)$, 
altura da planta (AP) e altura da espiga (AE), obtidos em 30 subpopulações de tamanho efetivo reduzido, com seleção. Anhembi, 2003

27 Valor médio $(\bar{X})$, depressão por endogamia (I) e relação valor médio/testemunha $(\bar{X} / \mathrm{T})$, dados de dois locais, para os caracteres peso de espigas (PE), comprimento da espiga (CE) e diâmetro da espiga (DE), obtidos em 30 subpopulações de tamanho efetivo reduzido, com seleção

28 Valor médio $(\overline{\mathrm{X}})$, depressão por endogamia $(\mathrm{I})$ e relação valor médio/testemunha ( $\bar{X} / T)$, dados de dois locais, para os caracteres prolificidade (PR), altura da planta (AP) e altura da espiga (AE), obtidos em 30 subpopulações de tamanho efetivo reduzido, com seleção

29 Valor médio $(\bar{X})$ de 5 subpopulações, agrupadas de acordo com o tamanho efetivo e a seleção, depressão por endogamia (I) e a relação valor médio/testemunha $(\bar{X} / T)$ obtidos para os caracteres peso de espigas (PE), comprimento da espiga (CE) e diâmetro da espiga (DE). ESALQ/Genética, 2003

30 Valor médio $(\bar{X})$ de 5 subpopulações, agrupadas de acordo com o tamanho efetivo e a seleção, depressão por endogamia (I) e a relação valor médio/testemunha $(\bar{X} / T)$ obtidos para os caracteres prolificidade (PR), altura da planta (AP) e altura da espiga (AE). ESALQ/Genética, 2003.

31 Valor médio $(\bar{X})$ de 5 subpopulações, agrupadas de acordo com o tamanho efetivo e a seleção, depressão por endogamia (I) e a relação valor médio/testemunha $(\bar{X} / T)$ obtidos para os caracteres peso de espigas (PE), comprimento da espiga (CE) e diâmetro da espiga (DE). Anhembi, 2003 
32 Valor médio $(\bar{X})$ de 5 subpopulações, agrupadas de acordo com o tamanho efetivo e a seleção, depressão por endogamia (I) e a relação valor médio/testemunha $(\bar{X} / T)$ obtidos para os caracteres prolificidade (PR), altura da planta (AP) e altura da espiga (AE). Anhembi, 2003

33 Valor médio $(\bar{X})$ de 5 subpopulações, com dados de dois locais, agrupadas de acordo com o tamanho efetivo e a seleção , depressão por endogamia (I) e a relação valor médio/testemunha $(\bar{X} / T)$, obtidos para os caracteres peso de espigas (PE), comprimento da espiga (CE) e diâmetro da espiga (DE)

34 Valor médio $(\bar{X})$ de 5 subpopulações, com dados de dois locais, agrupadas de acordo com o tamanho efetivo e a seleção, depressão por endogamia (I) e a relação valor médio/testemunha $(\bar{X} / T)$, obtidos para os caracteres prolificidade $(\mathrm{PR})$, altura da planta (AP) e altura da espiga (AE)

35 Quadrados médios da análise da variância do experimento 8, com progênies 'topcrosses', para o caráter peso de espigas (PE). ESALQ/Genética, 2003

36 Médias, capacidade geral de combinação (CGC) e capacidade específica de combinação (CEC) dos cruzamentos 'topcrosses' das subpopulações com o híbrido P 3041 (1) e o composto GN03 (2), para o caráter peso de espigas $\left(\mathrm{kg} / 4 \mathrm{~m}^{2}\right)$. ESALQ/Genética, 2003 .

37 Quadrados médios da análise da variância de tabelas dialélicas referentes às subpopulações de tamanho efetivo $1\left(\mathrm{~N}_{1}\right), 2\left(\mathrm{~N}_{2}\right)$ e 3 $\left(\mathrm{N}_{3}\right)$, para o caráter produção de grãos (PG). Guaíra - SP, 2003

38 Estimativa da heterose específica $\left(\mathrm{s}_{\mathrm{ij}}\right)$, do efeito de subpopulações $\left(s_{i}\right.$ e $\left.s_{j}\right)$, do efeito heterótico de subpopulações $\left(h_{i}\right.$ e $\left.h_{j}\right)$, da média de grupos de subpopulações (u), do desvio entre grupos de 
subpopulações (d) e da heterose média $(\bar{h})$ para o caráter produção de grãos $\left(\mathrm{kg} / 4 \mathrm{~m}^{2}\right)$, analisado segundo o esquema de cruzamento dialélico parcial de subpopulações de tamanho efetivo

1. Guaíra - SP, 2003

39 Estimativa da heterose específica $\left(\mathrm{s}_{\mathrm{ij}}\right)$, do efeito de subpopulações $\left(s_{i}\right.$ e $\left.s_{j}\right)$, do efeito heterótico de subpopulações $\left(h_{i}\right.$ e $\left.h_{j}\right)$, da média de grupos de subpopulações (u), do desvio entre grupos de subpopulações (d) e da heterose média $(\bar{h})$ para o caráter produção de grãos $\left(\mathrm{kg} / 4 \mathrm{~m}^{2}\right)$, analisado segundo o esquema de cruzamento dialélico parcial de subpopulações de tamanho efetivo

2. Guaíra - SP, 2003

40 Estimativa da heterose específica $\left(\mathrm{s}_{\mathrm{ij}}\right)$, do efeito de subpopulações $\left(s_{i}\right.$ e $\left.s_{j}\right)$, do efeito heterótico de subpopulações $\left(h_{i}\right.$ e $\left.h_{j}\right)$, da média de grupos de subpopulações (u), do desvio entre grupos de subpopulações (d) e da heterose média $(\bar{h})$ para o caráter produção de grãos $\left(\mathrm{kg} / 4 \mathrm{~m}^{2}\right)$, analisado segundo o esquema de cruzamento dialélico parcial de subpopulações de tamanho efetivo

3. Guaíra-SP, 2003.

41 Produção de grãos (t/ha, média de 4 repetições) para dois grupos de subpopulações de tamanho efetivo 1 e combinações híbridas. Guaíra - SP, 2003

42 Produção de grãos (t/ha, média de 4 repetições) para dois grupos de subpopulações de tamanho efetivo 2 e combinações híbridas. Guaíra -SP, 2003.

43 Produção de grãos (t/ha, média de 4 repetições) para dois grupos de subpopulações de tamanho efetivo 3 e combinações híbridas. Guaíra -SP, 2003

44 Quadrados médios da análise da variância agrupada dos experimentos 1, 2, 3 e 4, com progênies obtidas através de 
cruzamentos em cadeia, para os caracteres peso de espigas (PE), comprimento da espiga (CE), diâmetro da espiga (DE) e prolificidade (PR). ESALQ/Genética, 2003

45 Quadrados médios da análise da variância agrupada dos experimentos 1, 2, 3 e 4, com progênies obtidas através de cruzamentos em cadeia, para os caracteres altura da planta (AP) e altura da espiga (AE). ESALQ/Genética, 2003.

46 Quadrados médios da análise da variância agrupada dos experimentos 1, 2, 3 e 4, com progênies obtidas através de cruzamentos em cadeia, para os caracteres peso de espigas (PE), comprimento da espiga (CE), diâmetro da espiga (DE) e prolificidade (PR). Anhembi, 2003

47 Quadrados médios da análise da variância agrupada dos experimentos $1,2,3$, e 4, com progênies obtidas através de cruzamentos em cadeia, para os caracteres altura da planta (AP) e altura da espiga (AE). Anhembi, 2003

48 Quadrados médios da análise da variância agrupada conjunta dos experimentos 1, 2, 3 e 4, com progênies obtidas através de cruzamentos em cadeia, para os caracteres peso de espigas (PE), comprimento da espiga (CE), diâmetro da espiga (DE) e prolificidade (PR).

49 Quadrados médios da análise da variância agrupada conjunta dos experimentos 1, 2, 3 e 4, com progênies obtidas através de cruzamentos em cadeia, para os caracteres altura da planta (AP) e altura da espiga (AE). 106

50 Quadrados médios da análise da variância conjunta do experimento 5, com progênies de irmãos germanos, para os caracteres peso de espigas (PE), comprimento da espiga (CE), diâmetro da espiga (DE) e prolificidade (PR)... 
51 Quadrados médios da análise da variância conjunta do experimento 5, com progênies de irmãos germanos, para os caracteres altura da planta (AP) e altura da espiga (AE)

52 Quadrados médios da análise da variância conjunta do experimento 6 , com progênies $\mathrm{S}_{1}$, para as variáveis peso de espigas (PE), comprimento da espiga (CE), diâmetro da espiga (DE) e prolificidade (PR)

53 Quadrados médios da análise da variância conjunta do experimento 6 , com progênies $S_{1}$, para as variáveis altura da planta (AP) e altura da espiga (AE).

54 Estimativas da variância genética $\left(\hat{\mathrm{S}}_{\mathrm{gc}}^{2}\right)$, da variância genética $\operatorname{aditiva}\left(\hat{\mathrm{S}}_{\mathrm{A}}^{2}\right)$ e da variância genética dominante $\left(\hat{\mathrm{S}}_{\mathrm{D}}^{2}\right)$ para seis caracteres do composto GN-04, com base na análise agrupada da variância dos experimentos 1, 2, 3, e 4, com progênies de cruzamentos em cadeia, em dois locais.

55 Estimativas da variância genética $\left(\hat{\mathrm{S}}_{\mathrm{gc}}^{2}\right)$, variância genética $\operatorname{aditiva}\left(\hat{\mathrm{S}}_{\mathrm{A}}^{2}\right)$ e variância genética dominante $\left(\hat{\mathrm{S}}_{\mathrm{D}}^{2}\right)$ de seis caracteres do composto GN-04, com base na análise agrupada conjunta da variância dos experimentos 1, 2, 3, e 4, com progênies de cruzamentos em cadeia.

56 Estimativas da variância genética $\left(\hat{\mathrm{S}}_{\mathrm{ig}}^{2}\right)$ e variância genética aditiva $\left(\hat{\mathrm{S}}_{\mathrm{A}}^{2}\right)$ de seis caracteres do composto GN-04, com base na análise conjunta da variância do experimentos 5, com progênies de irmãos germanos.

57 Estimativas da variância genética $\left(\hat{\mathrm{S}}_{\mathrm{s} 1}^{2}\right)$ e variância genética $\operatorname{aditiva}\left(\hat{\mathrm{S}}_{\mathrm{A}}^{2}\right)$ de seis caracteres do composto GN-04, com base na 
análise conjunta da variância do experimentos 6 , com progênies

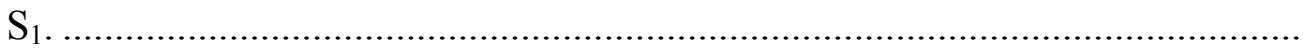




\title{
EFEITO DO PROCESSO DISPERSIVO EM SUBPOPULAÇÕES DE TAMANHO REDUZIDO DE MILHO (Zea mays L.)
}

\author{
Autor: RAIMUNDO NONATO VIEIRA DA CUNHA \\ Orientador: Prof. Dr. JOSÉ BRANCO DE MIRANDA FILHO
}

\section{RESUMO}

O composto GN-04 foi utilizado no presente trabalho, tendo por objetivo: a) avaliar o efeito do processo dispersivo em subpopulações de milho com diferentes tamanhos efetivos, e submetidas previamente à seleção divergente para alta e baixa produção; b) avaliar a capacidade de combinação e o potencial heterótico dessas subpopulações e c) estimar componentes da variância genética no composto GN-04, usando o esquema de cruzamento em cadeia. Um lote do referido composto foi plantado visando à obtenção de três diferentes progênies: $S_{1}$, por autofecundação; irmãos germanos, cruzamento planta a planta e cruzamentos em cadeia, seguindo o esquema $1 \mathrm{x}$ $2,2 \times 3$ e $3 \times 1$. Foram obtidas 77 progênies $S_{1}, 75$ de irmãos germanos e 72 cadeias, contituidas de três cruzamentos. As progênies de cada tipo foram avaliadas em ensaios distintos, em dois locais, de acordo com o delineamento em blocos casualizados, com três repetições. Os caracteres avaliados foram: altura da planta (AP), altura da espiga $(\mathrm{AE})$, comprimento da espiga (CE), diâmetro da espiga (DE), peso de espigas (PE) e prolificidade (PR). Com base nos valores médios do caráter PE, foram selecionadas 10 progênies de irmãos germanos, 10 de $S_{1}$ e 10 cadeias, sendo cada grupo de materiais constituído das cinco progênies ou cadeias mais produtivas, e das cinco menos produtivas. A recombinação das progênies selecionadas ou cadeias ensejou a obtenção 
de subpopulações com diferentes tamanhos efetivos: $\mathrm{N}_{1}, \mathrm{~N}_{2}$ e $\mathrm{N}_{3}$, que correspondem a taxas de endogamia de $50 \%, 25 \%$ e $17 \%$, para $\mathrm{S}_{1}$ 's, irmãos germanos e cadeias, respectivamente. Essas subpopulações foram avaliadas posteriormente com base no seu desempenho per se e em cruzamentos 'topcrosses' e dialélicos. Os resultados desta avaliação mostraram que o tamanho reduzido das subpopulações provocou o surgimento de valores médios inferiores ou superiores à média estimada da população original, em conseqüência da deriva genética. Os valores médios de todos os caracteres foram afetados pela redução no tamanho efetivo das subpopulações, em conseqüência da depressão por endogamia, a qual se expressou com mais intensidade no caráter PE: em subpopulações com $\mathrm{N}_{3}$ e $\mathrm{N}_{1}$, no nível de seleção positiva, o efeito da depressão foi de $5,20 \%$ e $20,07 \%$, respectivamente, e no nível de seleção negativa, 15,98\% e 55,76\%, respectivamente. A seleção divergente entre subpopulações resultou em diferenciação genética suficiente para expressar heterose em cruzamentos entre subpopulações com o mesmo tamanho efetivo. As estimativas da variância aditiva do composto GN-04, com base na análise da variância conjunta dos experimentos com progênies de cruzamentos em cadeia, para os caracteres PE, CE, DE, PR, AP e AE foram, respectivamente: 128,00 $(\mathrm{g} / \mathrm{pl})^{2}, 1,490(\mathrm{~cm} / \mathrm{esp} .)^{2}, 0,1704(\mathrm{~cm} / \mathrm{esp} .)^{2}, 0,0200$ (esp./pl) $)^{2}, 256,55(\mathrm{~cm} / \mathrm{pl})^{2}$ e 136,80 $(\mathrm{cm} / \mathrm{pl})^{2}$. Estimativas negativas da variância aditiva foram obtidas para os caracteres $\mathrm{CE}$, DE, AP e AE; para os caracteres PE e PR as estimativas foram 185,00 (g/pl) ${ }^{2}$ e 0,0188 (esp./pl) ${ }^{2}$, respectivamente. $\mathrm{O}$ delineamento de cruzamentos em cadeia de tamanho 3, tendo em vista a facilidade de execução, pode ser uma alternativa a delineamentos de execução mais complexa para estimar componentes da variância. 


\title{
DISPERSIVE PROCESS EFFECT IN REDUCED SIZE SUBPOPULATIONS OF MAIZE (Zea mays L.)
}

\author{
Author: RAIMUNDO NONATO VIEIRA DA CUNHA \\ Adviser: Prof. Dr. JOSÉ BRANCO DE MIRANDA FILHO
}

\section{SUMMARY}

The composite GN-04 was used in the present work with the objetives: a) evaluation of the effect of the dispersive process in subpopulations of maize with different effective sizes, and submitted to divergent selection for higth and low yield; $b$ ) evaluation of the combining ability and heterotic potential of the subpopulations; and c) to estimate components of the genetic variance in the composite GN-04, using chain crosses. A pollination block of the base population was planted for the development of three different progenies: $\mathrm{S}_{1}$ progenies obtained by selfing, full-sib progenies obtained by plant-to-plant crosses, and chain crosses following the scheme: 1 × 2, 2 × 3 e $3 \times 1$. The numbers of progenies were: $77 \mathrm{~S}_{1^{\prime}}$ s, 75 full-sibs and 72 chains represented by three crosses in each chain. The progenies from each type were evaluated in different experiments in two locations following the randomized complete block design with three replications. The following traits were analysed: plant height (AP), ear height (AE), ear length (CE), ear diameter (DE), ear weight (PE) and prolificacy (PR). Observed means of PE were used for selection of 10 full-sib progenies, $10 \mathrm{~S}_{1^{\prime} \text { s }}$ progenies and 10 complete chains, each group being represented by five high yielding and five low yielding progenies or chains. The recombination of the selected progenies or chains, individually, led to the development of subpopulations with different effective sizes: $\mathrm{N}_{1}, \mathrm{~N}_{2}$ and $\mathrm{N}_{3}$, 
corresponding to inbreeding rates of $50 \%, 25 \%$ and $17 \%$ for $\mathrm{S}_{1 ' s}$, full-sibs and chain crosses, respectively. The subpopulations were later evaluated based on their performance per se, in the topcrosses and in diallel crosses. Results showed that the reduced size of the subpopulations led to changes in the means of the evaluated traits, which were smaller or higher than the original means as a consequence of genetic drift. On the average, all traits showed a decrease in the mean as a consequence of inbreeding depression. The most depressive trait was PE and the depression effects in subpopulations with $\mathrm{N}_{3}$ and $\mathrm{N}_{1}$ were $7.17 \%$ and $22.94 \%$ in the positive selection and $16.85 \%$ and $55.91 \%$ in the negative selection. The divergent selection among subpopulations led to a genetic differentiation sufficient for the expression of heterosis in crosses between subpopulations in the same level of effective size. The estimates of the additive genetic variance in the composite GN-04 were obtained from the analysis of chain crosses. The estimates for the traits $\mathrm{PE}, \mathrm{CE}, \mathrm{DE}, \mathrm{PR}, \mathrm{AP}$ and $\mathrm{AE}$ were, respectively: $128.00(\mathrm{~g} / \mathrm{pl})^{2}, 1.490(\mathrm{~cm} / \mathrm{esp} .)^{2}, 0.1704(\mathrm{~cm} / \mathrm{esp} .)^{2}, 0.0200$ (esp./pl) $)^{2}$, $256.55(\mathrm{~cm} / \mathrm{pl})^{2}$ and $136.80(\mathrm{~cm} / \mathrm{pl})^{2}$. Negative estimates of the dominance variance were obtained for the traits $\mathrm{CE}, \mathrm{DE}, \mathrm{AP}$ and $\mathrm{AE}$; for the traits $\mathrm{PE}$ and PR, the estimates were $185.00(\mathrm{~g} / \mathrm{pl})^{2}$ and $0.0188(\mathrm{esp} . / \mathrm{pl})^{2}$, respectively. The mating design based on chain crosses with size 3 was considered feasible and easy to be used and can be a reliable alternative as compared with other more complex designs. 


\section{INTRODUÇÃO}

Em uma grande população, na ausência de seleção, mutação e migração, as freqüências alélicas e genotípicas permanecem constantes de geração para geração, não havendo, portanto, tendência de que suas propriedades genéticas se modifiquem. Contudo, em pequenas populações, e com as restrições já referidas, essa propriedade de estabilidade não se mantém e as freqüências gênicas estão sujeitas a flutuações aleatórias, causadas pela amostragem de gametas. Estes, que transmitem genes para a geração seguinte, carregam amostras de genes da geração paternal, e, se a amostra não for grande, as freqüências gênicas estarão sujeitas a modificações entre uma geração e a seguinte. Essa mudança aleatória nas freqüêncais gênicas denomina-se de processo dispersivo (Falconer \& Mackay, 1995).

As conseqüências do processo dispersivo, destacando-se dentre estas a deriva genética, diferenciação entre subpopulações e incremento dos homozigotos, foram descritas tendo como pressuposto uma 'população idealizada'. Sucintamente, esta consiste de uma grande população, panmitica, que se subdividiu em um grande número de subpopulações com um número constante $\mathrm{N}$ de indivíduos que se acasalam por geração; mudanças sistemáticas nas freqüências alélicas estão excluídas.

As condições impostas à população idealizada são pouco prováveis de ocorrer em populações reais. Para contornar esse problema surgiu o conceito de tamanho efetivo da população ou número efetivo $(\mathrm{N})$, cuja definição, como descrita por Kimura \& Crow (1963), é o número em uma população idealizada em que cada indivíduo tem um igual número de progênie esperada.

Em programas de seleção recorrente, o número de progênies recombinadas em cada ciclo, juntamente com a estrutura de reprodução da população, 
relacionam-se diretamente ao tamanho efetivo. Portanto, como o número de progênies recombinadas para dar origem à população melhorada geralmente não é muito grande, espera-se que ocorra deriva genética, a qual pode afetar o desempenho da população per se, e limitar a resposta à seleção devido à diminuição da variabilidade genética. Seleção e deriva, para a maioria dos caracteres em milho, constituem-se em dois processos importantes, atuando na alteração da média da população melhorada em direções opostas através dos ciclos: a seleção, se efetiva, tende a aumentá-la, enquanto a deriva genética tende a diminuí-la, devido à depressão por endogamia (Helms et al., 1989).

Tendo em vista a importância do processo dispersivo em todas as etapas do melhoramento genético de milho, o presente estudo teve por objetivo: a) avaliar o efeito do mesmo em subpopulações de milho com diferentes tamanhos efetivos, e submetidas previamente à seleção divergente para alta e baixa produção; b) avaliar a capacidade de combinação e o potencial heterótico dessas subpopulações; c) estimar componentes da variância genética no composto GN-04 que originou essas subpopulações, usando o esquema de cruzamentos em cadeia. 


\section{REVISÃO DE LITERATURA.}

\subsection{Processo dispersivo}

Em uma grande população panmitica, e na ausência de migração, seleção ou mutação, as freqüências gênicas e genotípicas permanecem inalteradas de geração para geração. Entretanto, isto não se verifica em pequenas populações, pois as freqüências gênicas estão sujeitas a flutuações aleatórias decorrentes da amostragem dos gametas: estes levam para a próxima geração apenas uma amostra dos genes dos pais, e se a amostra for pequena, as freqüências gênicas são passíveis de mudar de uma geração para outra, e a esta mudança aleatória nas freqüências gênicas é que se denomina processo dispersivo, o qual apresenta quatro importantes conseqüências: deriva genética, diferenciação entre subpopulações, uniformidade dentro de subpopulações e incremento dos homozigotos (Caballero, 1994; Falconer \& Mackay, 1996).

De acordo com Falconer \& Mackay (1996), a análise simplificada do processo dispersivo toma por base uma "população ideal”, qual seja, uma grande população, cujos cruzamentos ocorrem de forma aleatória; posteriormente essa população subdivide-se em um grande número de subpopulações (linhagem). Todas as linhas constituem a população inteira e cada linha é uma pequena população em que as freqüências gênicas estão sujeitas ao processo dispersivo. Várias condições ou restrições são impostas à população ideal:

1) Cruzamentos são restritos aos membros da mesma linhagem, ou seja, a migração é excluída;

2) As gerações são distintas e não se sobrepõem; 
3) O número de indivíduos que se acasala em cada linhagem é o mesmo em todas as gerações;

4) Dentro de cada linhagem os cruzamentos são aleatórios, admitindo-se autofecundação também de forma aleatória;

5) A seleção não é permitida em qualquer estádio;

6) A mutação é negligenciável.

Três importantes estudos, todos com Drosofila melanogaster, que comprovam os efeitos da deriva em pequenas populações, foram realizados por Kerr \& Wright (1954a), Wright \& Kerr (1954) e Kerr \& Wright (1954b). No primeiro, Kerr \& Wright (1954a) avaliaram 96 subpopulações constituídas de 8 indivíduos tomados ao acaso (quatro machos e quatro fêmeas). Cada subpopulação possuía um gene para cerdas 'forked' e o seu alelo selvagem (normal), ambos com freqüência 0,5. Após 16 gerações de cruzamentos aleatórios os alelos estavam segregando apenas em 26 das subpopulações, sendo que o alelo 'forked' havia se fixado em 29 e o selvagem em 41 das subpopulações. A taxa de fixação de ambos os alelos alcançou equilíbrio a partir da quarta geração em torno de $8,9 \%$.

No segundo, Wright \& Kerr (1954) estudaram a oscilação do gene bar em 108 subpopulações de D. melanogaster, cada uma de tamanho 8 (quatro machos e quatro fêmeas), durante dez gerações. Iniciando com uma freqüência gênica de 0,50 , uma aparente estabilidade na dispersão das freqüências gênicas ocorreu na quarta geração, com uma taxa de fixação de $22 \%$ para o tipo selvagem e $0,7 \%$ para o tipo bar. Após dez gerações, 95 subpopulações haviam fixado alelo selvagem e 3 o tipo bar , o que demonstra que houve uma forte seleção contra o gene bar. No terceiro, Kerr \& Wright (1954b) estudaram a oscilação dos genes aristapedia e spineless em 113 subpopulações dessa mesma espécie, sendo iguais ao estudo anterior o número de gerações e o tamanho efetivo das subpopulações. A freqüência média do gene aristapedia oscilou de 0,50 na geração 1 a 0,3544 na geração 5 , e nas últimas três gerações a freqüencia média foi de 0,4032. A variância alcançou 0,0235 na segunda geração e flutuou em torno deste valor nas gerações seguintes. Além da rápida 
estabilização na distribuição das freqüências gênicas, os autores concluem que houve uma forte pressão de seleção contra os homozigotos.

Estudos com pequenas populações de milho também já foram realizados. Paterniani (1995) estudou o efeito da redução do tamanho de duas populações $F_{2}$ de milho (A e B), com freqüência gênica igual a 0,50 para os locos segregantes da coloração de grãos, com proporção mendeliana de 3 amarelas (Y): 1 branca (y). Na avaliação da primeira geração de amostragem $(\mathrm{N}=5)$, as freqüencias gênicas se mantiveram próximas ao valor esperado no processo dispersivo $\left[\mathrm{E}(\mathrm{p})=\mathrm{p}_{0}=0,50\right]$; na segunda geração de amostragem $(\mathrm{N}=5)$, houve aumento significativo na freqüencia do alelo Y. A redução do tamanho efetivo populacional levou à fixação deste alelo em duas das 29 subpopulações da população base B.

Moreira (1999) avaliou os efeitos da deriva genética em subpopulações com tamanho efetivo igual a 5, em duas gerações de amostragem. Efeitos significativos da deriva genética foram detectados para os caracteres produção de grãos, altura da planta, altura da espiga, prolificidade e relação altura da espiga/altura da planta, sendo que o caráter produção de grãos foi o mais afetado. Corrales Blandón (1996) também avaliou os efeitos da deriva genética em subpopulações com tamanho efetivo igual a 5 em duas gerações de amostragem. Visto que a amostragem provocou depressão por endogamia, e o surgimento de subpopulações com médias per se, estimativas da capacidade geral de combinação ou de variância genética aditiva, similares ou superiores à da população paternal, o autor conclui que a mesma poderia ser utilizada como técnica auxiliar em programas de melhoramento com diversas finalidades: produzir endogamia, liberar variabilidade genética e promover o acúmulo diferenciado de fatores genéticos favoráveis entre as subpopulações.

Em populações não estruturadas e que não obedecem exatamente às condições referidas anteriormente, a deriva genética é quantificada por um único parâmetro, o tamanho efetivo populacional, o qual pode ser calculado ou estimado de dados laboratoriais ou de campo, e predito sob várias circunstâncias (Caballero, 1994). O conceito de tamanho efetivo populacional foi definido por Wright (1931), como "o número de indivíduos de uma população ideal que sofre os mesmos efeitos de 
endogamia e/ou da variância da freqüência gênica que uma dada população real, com sistema de acasalamento conhecido, ao longo das gerações”. Falconer \& Mackay (1996), o definem como "o número de indivíduos que daria origem à variância amostral, ou taxa de endogamia, se eles se reproduzissem à maneira da população idealizada”.

Os conceitos e conseqüências do tamanho efetivo de populações têm sido amplamente abordados na literatura (Baker \& Kurnow, 1969; Vencovsky, 1978; Hallauer \& Miranda Filho, 1995; Souza Júnior et al., 2000). Com populações de tamanho finito há o risco de que um alelo venha a ser fixado por acaso, mesmo havendo alelos mais favoráveis presentes na população. Tem-se demonstrado, tanto teórica quanto empiricamente, que problemas associados com a fixação de alelos indesejáveis devido à deriva genética, afetam a resposta e o limite de seleção (Baker \& Curnow, 1969).

Em milho, o melhoramento de populações via seleção recorrente pode ser conduzido pela utilização de diversos tipos de progênie que, por serem obtidas através de diferentes sistemas de cruzamento, resultam em diferentes tamanhos efetivos. Para as progênies mais usuais, têm-se os seguintes valores de $\mathrm{N}$ : meios irmãos: 4N; irmãos germanos: $2 \mathrm{~N} ; \mathrm{S}_{1}: \mathrm{N}$; sendo $\mathrm{N}$ o número de progênies intercruzadas na fase de recombinação, considerando-se que as progênies tem grande número de indivíduos (Vencovsky, 1978). Tradicionalmente, melhoristas de milho têm recombinado entre 10 e 25 indivíduos (progênies) em programas de seleção recorrente. Nos casos em que apenas 10 linhas foram recombinadas, a deriva mostrou-se um importante fator na limitação da resposta à seleção (Smith, 1983, 1984; Helms et al., 1989). Entretanto, Garay et al. (1996), relataram que a recombinação de 10 linhagens, em experimentos que faziam uso da seleção recorrente, não se constituiu em fator importante na limitação da resposta à seleção. Hallauer (1992), revisando a literatura sobre tamanho efetivo populacional, sugeriu que aproximadamente 25 a 35 progênies deveriam ser recombinadas em programas de seleção recorrente em milho.

Mais recentemente, Weyhrich et al. (1998) compararam a resposta à seleção de progênies $S_{1}$ em quatro programas: $5-S_{1}, 10-S_{1}, 20-S_{1}$ e $30-S_{1}$, o que significa 5, 10, 20 ou 30 progênies recombinadas. A intensidade de seleção foi a mesma em todos 
os programas: $20 \%$. Constataram que a produção de grãos aumentou significativamente em todos os programas, com exceção do 5 - $\mathrm{S}_{1}$, que decresceu de forma significativa. Os autores concluem que a deriva é o fator mais importante na alteração das freqüências alélicas quando menos do que 10 linhagens são recombinadas, não parecendo uma vantagem, se os objetivos são de curto prazo, recombinar mais do que 10 linhagens por ciclo de seleção. Guzman \& Lamkey (2000), realizaram um estudo cujo objetivo foi (i) avaliar o desempenho da população BS11, ciclo $0\left(\mathrm{C}_{0}\right)$ e ciclo $5\left(\mathrm{C}_{5}\right)$, em quatro programas de seleção de progênies $S_{1}$ com diferentes tamanhos efetivos $(5,10,20$ e 30), mas com uma intensidade de seleção comum de $20 \%$, e (ii) comparar a variância genética aditiva entre as populações $\mathrm{C}_{0}$ e $\mathrm{C}_{5}$. Cinco ciclos de seleção foram conduzidos, usando-se na fase de recombinação 5, 10, 20 ou 30 linhagens. Cento e trinta linhagens $\mathrm{S}_{1}\left(\mathrm{C}_{5}\right)$, de cada uma das populações selecionadas, e 100 linhagens $\mathrm{S}_{1}, \mathrm{C}_{0}$, foram cruzadas em esquema topcross com $\mathrm{BS} 11, \mathrm{C}_{0}$. Os quatro programas de seleção resultaram em incremento significativo na produção de grãos, redução de umidade e acamamento. Quanto à produção, o programa $10-\mathrm{S}_{1}$ apresentou o mais alto ganho/ciclo, seguido pelo $30-\mathrm{S}_{1}$, enquanto que o $5-\mathrm{S}_{1}$ teve mais alto ganho do que o $20-\mathrm{S}_{1}$. A variância genética aditiva não mudou significativamente. Estes resultados sugerem pouca ou nenhuma vantagem em usar tamanhos efetivos maiores para manter a variabilidade genética em seleção recorrente de curto prazo.

\subsection{Variabilidade genética intrapopulacional}

\subsubsection{Produção}

No melhoramento de populações, para que se obtenha ganhos com seleção, a condição básica é que as populações base que serão exploradas apresentem variabilidade genética, e as estimativas das variâncias genéticas devido ao efeito médio e de dominância dos genes auxiliam na escolha do método de seleção.

A decomposição da variância genética de uma população foi introduzida por Fisher (1918) em estudos sobre correlação e covariação entre parentes. Este autor 
mostrou que a variância genética de uma população panmítica pode ser decomposta em três componentes: 1) variância genética aditiva, que está associada aos efeitos médios dos genes; 2) variância genética dominante, que está associada aos efeitos das interações intra-alélicas e, 3) variância genética epistática, que é devido aos efeitos das interações interalélicas. Demonstrou, também, que a covariância genética entre parentes é função de quantidades diferentes destes componentes da variância genética, dependendo do tipo de parentesco (Souza Júnior, 1988).

Uma teoria geral para a interpretação genética da covariância entre parentes foi dada por Cockerham (1954) e Kempthorne (1954, 1955), incluindo a decomposição da variância epistática em partes componentes.

Cockerham (1963) apresentou uma série de esquemas de cruzamento para estimação de variância genética. O procedimento geral em qualquer um deles é analisar estatísticamente os resultados de cruzamentos apropriados e interpretá-los de acordo com os componentes de variância das fontes de variação do delineamento. Dentre os esquemas mais utilizados, destacam-se aqueles sugeridos por Comstock e Robinson (1948), denominados de Delineamento I e Delineamento II: o primeiro corresponde a um esquema hierárquico em que as progênies avaliadas resultam de cruzamentos de diversas plantas, tomadas como machos, cada uma cruzada com várias plantas (diferentes para cada macho), tomadas como fêmeas. O Delineamento II corresponde a um esquema de classificação cruzada, onde um conjunto de plantas tomadas como machos são cruzadas com um outro conjunto de plantas tomadas como fêmeas. Hallauer \& Miranda Filho (1995) apresentaram uma análise detalhada dos procedimentos genético-estatísticos para a estimação dos componentes da variância em populações de milho, e um levantamento das estimativas das variâncias genéticas em nível intrapopulacional. No Brasil, predominam os trabalhos envolvendo progênies de meios irmãos, as quais permitem estimar a variância genética aditiva, a herdabilidade e, conseqüentemente, o progresso esperado por seleção (Souza Júnior, 1983). Um resumo das estimativas obtidas pelo Instituto de Genética da Escola Superior de Agricultura “Luiz de Queiroz” é apresentado por Ramalho (1977) e ampliado por Sampaio (1986). Dando seqüência a este levantamento, Vencovsky et al. (1988) verificaram que a média 
das estimativas da variância genética aditiva para o caráter produção de grãos foi de 309 (g/planta $)^{2}$, com um intervalo de variação de 41 a 753 . Algumas estimativas recentes da variância genética aditiva são apresentadas na tabela a seguir:

Tabela 01. Estimativas da variância genética aditiva $\left(\hat{\sigma}_{\mathrm{A}}^{2}\right)$ para produção de grãos em diversas populações de milho no Brasil

\begin{tabular}{lcl}
\hline Populações & $\hat{\sigma}_{\mathrm{A}}^{2}(\mathrm{~g} / \mathrm{pl} .)^{2}$ & Referências \\
\hline Compostos GN & 502,10 a 761,70 & Nass \& Miranda Filho (1999) \\
NAP-PM & 91,11 & Costa et al. (2000) \\
IAC V3 & 623,30 & Paterniani et al. (2000) \\
Caraíba & 278,28 & Mesquita et al. (2000) \\
Samambaia & 283,58 & Mesquita et al. (2000) \\
BR 5011 Sertanejo & 171,80 a 865,00 & Carvalho et al. (2000) \\
Composto Flintisa & 595,92 & Anjos \& Andrade (2000) \\
Populações GO & 199,83 a 306,05 & Silva (2001) \\
\hline Populações brasileiras & $309,00^{1}$ & Vencovsky et al. (1988) \\
\hline
\end{tabular}

${ }^{1}$ Valor médio de 58 estimativas

Harland (1946) propôs uma metodologia pela qual cruzamentos aos pares eram testados em ensaios com repetições, seguido de seleção das melhores progênies e recombinação das sementes remanescentes destas. Famílias de irmãos germanos também têm sido utilizadas na estimação de variâncias genéticas, mas em freqüência bem menor do que com progênies de meios irmãos. Isto se deve, sobretudo, à impossibilidade de efetuar-se a decomposição da variância genética em seus componentes principais, sem que se adote hipóteses que dificilmente ocorrerão na prática. Nass (1992) relatou estimativas de variância genética em três populações de milho, as quais variaram de $86,14$ a 109,58 (g/planta) $)^{2}$ Frank \& Hallauer (1999), trabalhando com seis populações 
de milho, relataram estimativas da variância genética cuja amplitude variou de 54,41 a $69,95$ (g/planta $)^{2}$.

Lonnquist (1961) sugeriu, em vez de cruzamentos planta a planta, que as progênies de irmãos germanos fossem obtidas através de cruzamentos em cadeia. Observa-se que, neste caso, um mesmo genótipo é avaliado através de duas progênies distintas, meios irmãos e irmãos germanos, ao passo que nos cruzamentos planta a planta os genótipos são avaliados através de uma única progênie. A dupla avaliação de um genótipo contribui para uma maior precisão das estimativas e aumenta o ganho com seleção, sendo o método recomendado para populações que já tenham sido submetidas a outros ciclos de seleção. O autor comparou os dois métodos de obtenção de progênies de irmãos germanos, realizando um ciclo de seleção divergente para produção de grãos. Para o caso de progênies de irmãos germanos obtidas através de cruzamentos planta a planta, obteve ganhos de $+3,5 \%$ e $-6,1 \%$ com seleção para aumentar e diminuir o caráter. Para aquelas obtidas através do cruzamento em cadeia obteve ganhos de + 10,6\% e - 4,9\%, respectivamente. Valois (1982) e Valois \& Miranda Filho (1984) observaram que a variabilidade entre progênies de irmãos germanos e o progresso esperado com seleção foram inferiores no esquema de cruzamento em cadeia, em relação ao esquema usual. Miranda Filho (1982) desenvolveu as expressões para obtenção de componentes da variância genética, segundo o esquema de cruzamentos em cadeia, as quais foram utilizadas por Benitez Torres (1986) para estimação de parâmetros genéticos em duas populações de milho. Para os três caracteres avaliados, o autor relatou que os valores encontrados foram da mesma magnitude àqueles obtidos por autores que utilizaram outros delineamentos genéticos.

Progênies endogâmicas obtidas através de autofecundações sucessivas também têm sido bastante utilizadas no melhoramento de populações. A utilização desse tipo de progênie justifica-se quando se trata de caracteres de baixa herdabilidade, pois a endogamia favorece um aumento na variância genética entre progênies (Paterniani \& Miranda Filho, 1987). Outro aspecto favorável da utilização de progênies endogâmicas, diz respeito à possibilidade de se eliminar genes deletérios e, conseqüentemente, populações melhoradas pela avaliação desse tipo de progênie apresentarão menor 
depressão por endogamia (Hallauer, 1980). A variabilidade entre progênies endogâmicas, originárias de uma amostragem de plantas $\mathrm{S}_{0}$ da população de referência, também pode ser usada para estimar variabilidade genética (Hallauer \& Miranda Filho, 1995). Estes autores, em uma extensa revisão sobre o assunto, reportaram estimativas da variância genética aditiva para produção de grãos, obtidas com progênies $\mathrm{S}_{1}$, oscilando de 120,7 a 389,0 (g/planta) ${ }^{2}$. Gul Zaffar \& Shafiq (2001), estudando o potencial para o melhoramento de um composto, encontraram um valor expressivo para a variância aditiva de 380,21 (g/planta $)^{2}$.

\subsubsection{Caracteres da planta}

Os caracteres altura da planta e da espiga são importantes no melhoramento de milho, uma vez que a redução dos mesmos pode conferir vantagens tais como, maior resistência ao acamamento, facilidade de colheita e plantio mais denso (Sampaio, 1986).

Santos (1985) reportou estimativas da variância genética aditiva, em populações brasileiras, oscilando entre 176,56 a $668(\mathrm{~cm} / \text { planta })^{2}$ e 46,14 a 584,00 $\left(\mathrm{cm} /\right.$ planta $^{2}$ para altura da planta e altura da espiga, respectivamente. Hallauer \& Miranda Filho (1995), a partir de vários trabalhos executados nas condições ecológicas dos Estados Unidos, reportaram estimativas médias de 212,9 e 152,70 (cm/planta) ${ }^{2}$ para altura da planta e da espiga, respectivamente. Estas estimativas evidenciaram que, para os caracteres em questão, os efeitos de aditividade dos genes são mais importantes que os de dominância.

Arias \& Souza Júnior (1998), estudando as populações BR-105 e BR-106, estimaram a variância genética aditiva para altura da planta e da espiga, cujos valores respectivos obtidos foram 185,74 e 127,45 (cm/planta) ${ }^{2}$, para a população BR-105, e 109,31 e 74,04 (cm/planta $)^{2}$, para a população BR-106. Wolf et al. (2000), analisando uma população $F_{2}$, reportaram para altura da planta uma estimativa da variância genética aditiva de $180,01(\mathrm{~cm} / \text { planta })^{2}$ e, para altura da espiga, 136,65 (cm/planta $)^{2}$. 
Outro caráter importante é o número de espigas por planta ou prolificidade, como é mais conhecido na literatura.

A capacidade de produzir mais de uma espiga por planta tem-se mostrado altamente correlacionada com o rendimento de grãos. Acredita-se que a seleção do milho pelo homem foi direcionada para uma espiga por planta para facilitar a colheita e aumentar o tamanho da espiga. Os materiais tropicais possuem uma adequada variabilidade genética para incrementar a prolificidade sob seleção, sendo possível a utilização de métodos simples de seleção massal, com controle em ambos os sexos (Paterniani, 1990).

De acordo com Fancelli \& Dourado Neto (2001), o número de grãos por planta e por unidade de área constituem-se de grande importância para o rendimento da cultura do milho. A obtenção do maior número de grãos possível é função da população e do número de espigas encontradas por planta (prolificidade) e por área.

As estimativas de componentes da variância genética para o caráter prolificidade tendem a ser muito influenciadas pelo ambiente. Mariani \& Desidério (1975) e Ordas \& Stucker (1977) relataram que em baixas densidades a variância aditiva foi bem maior que a dominante, ao passo que em altas densidades a diferença entre as estimativas decresceu. Soares Filho (1987) obteve valores da variância genética aditiva entre $4,1 \times 10^{-3}$ e $37,5 \times 10^{-3}$ (espigas $\left./ \mathrm{pl}\right)^{2}$, trabalhando com duas populações em dois ambientes. Hallauer \& Miranda Filho (1995), com base em 39 estimativas, relataram um valor médio da variância aditiva de 45,9 x $10^{-3}$ (espigas/pl) ${ }^{2}$. Miranda Filho \& Andrade (1996), avaliando a população ESALQ - PB1, relataram que a estimativa da variância aditiva foi $17,7 \times 10^{-3}$ (espigas/pl) ${ }^{2}$.

Alves et al. (2002) estimaram componentes da variância genética nos ciclos de seleção 0 e 5 da população CMS - 39 para vários caracteres, dentre os quais, prolificidade. A estimativa da variância aditiva foi $36,0 \times 10^{-3}$ e $24,0 \times 10^{-3}$ (espigas/pl) ${ }^{2}$ nos ciclos 0 e 5 , respectivamente. 


\subsubsection{Caracteres da espiga}

Vários caracteres componentes da produção de grãos podem ser mensurados a partir da espiga, mas, no presente estudo, apenas comprimento da espiga e diâmetro da espiga serão considerados.

Quanto ao comprimento da espiga, Hallauer \& Miranda filho (1995) relataram estimativa média no valor de $152,4 \times 10^{-2}(\mathrm{~cm} / \text { espiga })^{2}$ para a variância genética aditiva. Santos (1985), em uma extensa revisão sobre o assunto, relatou estimativas no intervalo de $90,00 \times 10^{-2}$ a $352,40 \times 10^{-2}$ (cm/espiga) ${ }^{2}$. Nass (1992), analisando quatro compostos, relatou estimativas para a variância genética aditiva, cujo menor valor foi de 1,43 e o maior, 4,15 (cm/espiga $)^{2}$.

A tabela 02, a seguir, sumariza alguns resultados obtidos para o comprimento da espiga, referentes à estimativa da variância genética aditiva.

Tabela 02. Estimativas da variância genética aditiva $\left(\hat{\sigma}_{\mathrm{A}}^{2}\right)$, em $(\mathrm{cm} / \mathrm{planta})^{2}$, para o caráter comprimento da espiga em diversas populações de milho

\begin{tabular}{lcl}
\hline Populações & $\hat{\sigma}_{\mathrm{A}}^{2}(1)$ & Referências \\
\hline American Early (dens. baixa) & 265,20 & Galal et al. (1977) \\
American Early (dens. alta ) & 134,40 & Galal et al. (1977) \\
BS10 x BS11 & 160,00 & Obilana et al. (1979) \\
ESALQ-PB1 x Entrelaçado 1 (S 1$)$ & 259,67 & Nass (1992) \\
ESALQ-PB1 x Entrelaçado 1 (IG) & 415,13 & Nass (1992) \\
Variedade 'Ribadumia' & 91,00 & Malvar et al. (1996) \\
Variedade 'Tuy' & 37,00 & Malvar et al. (1996) \\
B73 x Mol17 (F $\left.\mathrm{F}_{2}\right)$ & 60,00 & Wolf et al. (2000) \\
Composto & 54,00 & Gul Zaffar \& Shafiq (2001) \\
\hline
\end{tabular}

${ }^{1}$ Estimativas multiplicadas por $10^{-2}$ 
Em se tratando do caráter diâmetro da espiga, Santos (1985), analisando três populações, relatou estimativas para a variância genética aditiva entre $5,00 \times 10^{-2} \mathrm{e}$ $8,14 \times 10^{-2}$ (cm/espiga) ${ }^{2}$. Nass (1992), trabalhando com duas populações semi-exóticas, obteve estimativas entre $18,85 \times 10^{-2}$ e $5,51 \times 10^{-2}(\mathrm{~cm} / \text { espiga })^{2}$. Hallauer \& Miranda Filho (1995) encontraram um valor médio de 4,60 x 10 $0^{-2}(\mathrm{~cm} / \text { espiga })^{2}$, com base em 35 estimativas. Wolf et al. (2000), analisando uma população $F_{2}$, relataram uma estimativa no valor de $2,15 \times 10^{-2}$ (cm/espiga $)^{2}$.

\subsection{Cruzamentos com testadores}

O êxito de um programa de melhoramento genético depende da capacidade de identificação de genótipos superiores presentes na população sob seleção. Esta superioridade pode estar presente na condição do genótipo per se, quando então se procurará manter sua combinação gênica na reprodução, ou poderá estar no potencial que este genótipo evidencia através da capacidade de determinar características favoráveis na sua descendência (Allard, 1960). Os primeiros registros sobre teste de progênie em milho remontam a 1896, quando Hopkins iniciou um programa de seleção para conteúdo de óleo e proteína.

Davis (1927), citado por Hallauer \& Miranda Filho (1995), sugeriu o uso do procedimento 'topcross', o qual consiste em um tipo de teste de progênie visando avaliar a capacidade de combinação de linhagens endogâmicas em um programa de melhoramento de milho híbrido.

O uso de 'testcross' (ou topcross) no melhoramento de milho tem um dos seguintes objetivos: 1) avaliação da capacidade de combinação de linhas endogâmicas em um programa de melhoramento de híbrido, ou 2) avaliação do valor genético de genótipos (plantas) para o melhoramento de populações. Em ambas as circunstâncias, o problema da escolha do testador é essencialmente o mesmo, ou seja, encontrar um testador que forneça a melhor discriminação entre genótipos de acordo com os propósitos da seleção (Hallauer \& Miranda Filho, 1995). 
Hull (1945) discutiu teoricamente sobre o valor relativo de testadores com constituições genéticas diferentes. Concluiu que um testador com maior freqüência de alelos recessivos resulta em uma menor média e maior variância entre os híbridos. Assim sendo, se os alelos recessivos são em grande parte indesejáveis na expressão de caracteres quantitativos, um testador com valor genético mais baixo seria mais eficiente, no sentido de maior poder de discriminação entre os genótipos da população. Neste sentido, o uso de testadores elite pode levar à identificação de pares de linhagens com elevado grau de complementação gênica, mas não necessariamente à avaliação do potencial genético intrínseco da linhagem.

A controvérsia na escolha do testador relaciona-se ao fato de que um determinado material pode ser um bom testador em uma circunstância, mas não o ser em outra. Neste aspecto, algumas variações são consideradas, tais como a base genética do testador (ampla vs. estreita), o grau de parentesco com o material a ser avaliado (aparentado vs. não aparentado), valor genético intrínseco (padrão elevado vs. padrão regular ou inferior) ( Miranda Filho \& Gorgulho, 2001).

\subsubsection{Variância entre famílias ou testcrosses}

Rawlings \& Thompson (1962), acrescentaram importantes contribuições ao estudo de testadores analisando dois grupos de linhagens de milho, supondo cada grupo como testador do grupo contrastante. Os aspectos teóricos, utilizados como base para explicar os resultados, representam basicamente uma extensão da hipótese de Hull (1945). Assim, para um único loco, a variância entre híbridos 'topcross' é representada por

$$
\sigma_{\mathrm{t}}^{2}=\frac{1}{2} \mathrm{p}(1-\mathrm{p})(1+\mathrm{F})[\mathrm{a}+(1-2 \mathrm{r}) \mathrm{d}]^{2}
$$

sendo p e F a freqüência alélica e o coeficiente de endogamia na população base; $r$ é a freqüência alélica no testador; $a$ e $d$ representam desvios do homozigoto favorável e do heterozigoto, respectivamente, em torno da média dos homozigotos. 
Miranda Filho \& Vencovsky (2001), mostraram que quando o testador é uma linha pura (completamente homozigótica), a variância que se expressa entre famílias 'testcrosses' é $\sigma_{\mathrm{t}}^{2}=\frac{1}{4} \sigma_{\mathrm{A} 12}^{2}, \sigma_{\mathrm{t}}^{2}=\frac{1}{2} \sigma_{\mathrm{A} 12}^{2}$, ou $\sigma_{\mathrm{t}}^{2}=\frac{1}{4}\left(1+\mathrm{F}_{\mathrm{A}}\right) \sigma_{\mathrm{A} 12}^{2}$, dependendo se a população base é não endógama $(\mathrm{F}=0)$, totalmente endógama $(\mathrm{F}=1)$ ou parcialmente endógama $\left(0<\mathrm{F}_{\mathrm{A}}<1\right)$, respectivamente.

A literatura sobre o uso de testadores no melhoramento de híbridos ou populações de milho é muito vasta e uma ampla revisão sobre o assunto pode ser encontrada em Hallauer \& Miranda Filho (1995).

\subsection{Cruzamentos dialélicos}

Os cruzamentos dialélicos referem-se a todos os cruzamentos possíveis entre um grupo de $n$ linhagens ou variedades. A partir de uma tabela dialélica, são analisados, geralmente, os dados dos $n$ parentais e dos $n(n-1) / 2$ híbridos entre eles, estimando-se os parâmetros genéticos das variáveis observadas (Miranda Filho, 1974). Sprague \& Tatum (1942) utilizaram esse esquema de cruzamento para definir os termos capacidade geral de combinação (CGC) e capacidade específica de combinação (CEC).

Hayman (1954) apresentou um método que, a partir de um conjunto fixo de linhagens, possibilita medir a variância genética aditiva e de dominância e também como detectar a interação gênica não alélica. Embora eficiente, o método é bastante rigoroso nas suas pressuposições, sendo indicado somente para linhas puras. Griffing (1956) denomina de cruzamento dialélico aquele pelo qual um grupo de $n$ linhas puras é escolhido e cruzamentos são feitos entre elas. Este procedimento dá origem a um máximo de $n^{2}$ combinações. Estas são avaliadas em experimentos com repetições e as médias dos tratamentos, representando as combinações mencionadas, são utilizadas para formar uma tabela dialélica $n \times n$. Este trabalho inclui um detalhado exame do conceito de capacidade de combinação e oito diferentes análises a partir da consideração de quatro sistemas de cruzamentos dialélicos, com tratamentos fixos ou aleatórios. 
Gardner e Eberhart (1966), propuseram um outro modelo dialélico, o qual se aplica a um conjunto fixo de variedades. Este modelo é capaz de fornecer informações detalhadas das variedades e seus híbridos $\left(F_{1}\right)$, obtendo-se os efeitos de variedade e heterose, sendo esta última ainda decomposta em heterose média, varietal e específica. Eberhart e Gardner (1966), apresentaram um modelo mais amplo que pode incluir outros tipos de populações $\left(\mathrm{F}_{2}\right.$, retrocruzamentos, autofecundação) para o estudo da heterose e seus componentes, e efeitos epistáticos. Vencovsky (1970), mostrou aspectos importantes no que concerne à utilização, análise e interpretação do modelo Gardner e Eberhart (1966). Neste estudo, o autor define procedimentos para uso do modelo com outras finalidades além daquelas referentes apenas aos híbridos. Uma expressão foi desenvolvida para estimar a média de uma variável, em compostos de variedades possíveis de serem formados com os genitores envolvidos no dialelo.

Os esquemas de análise dos dialelos completos têm sido amplamente utilizados no melhoramento de milho. Discussões teóricas e dados experimentais podem ser encontrados em revisões apresentadas por Vencovsky (1970); Miranda Filho (1974); Miranda Filho \& Vencovsky (1984); Souza Júnior (1981) e Hallauer \& Miranda Filho (1995).

\subsubsection{Dialelo parcial}

Para a cultura do milho, os modelos dialélicos propostos tem sido de grande importância na avaliação de linhagens e populações, notadamente aqueles de Griffing (1956) e Gardner \& Eberhart (1966). Todavia, a utilização destes modelos apresenta alguns inconvenientes na execução dos experimentos, pois à medida que aumenta o número de parentais envolvidos, o número de combinações tende a aumentar drasticamente (Hallauer \& Miranda Filho, 1995).

Vencovsky (1987) denominou de cruzamento dialélico parcial à situação em que um grupo de linhagens ou materiais é cruzado com outro grupo, em todas as combinações; um grupo podendo ser do tipo dente e o outro do tipo flint, por exemplo. Miranda Filho \& Gorgulho (2001) afirmam que os dois grupos de linhagens ou 
genótipos envolvidos nos cruzamentos são distintos ou não relacionados, diferindo portanto dos esquemas propostos por Comstock \& Robinson (1948) e Cockerham (1963), que se referem a dois grupos tomados aleatoriamente da mesma população base. Miranda filho \& Geraldi (1984) propuseram um modelo para análise de dialelos parciais entre grupos distintos de variedades, que consiste em uma adaptação do modelo proposto por Gardner e Eberhart (1996). A metodologia foi aplicada por Lima (1982), Dantas (1992), Belluci (1994), Gorgulho (1997), e Astete Maldonado (2001) na avaliação do potencial heterótico de grupos de variedades ou progênies. Geraldi \& Miranda Filho (1988) apresentaram dois modelos para análise de cruzamentos dialélicos parciais entre dois grupos distintos de variedades, sendo um, denominado de 'parcialST', baseado nos conceitos de capacidade geral e específica de combinação de Sprague e Tatum (1942); e o outro modelo, designado de 'parcial-G2', é baseado no método 2 de Griffing (1956). Os autores apresentam também, fórmulas para estimação dos efeitos e para obtenção das somas de quadrados na análise da variância para ambos os modelos. 


\section{MATERIAL E MÉTODOS}

\subsection{Material}

Em 1993/94, o Departamento de Genética da ESALQ/USP iniciou uma pesquisa sobre resultados de cruzamentos dialélicos no Brasil visando à síntese de novos compostos. Os pais foram selecionados com base nos valores médios de rendimento, capacidade de combinação e heterose. $\mathrm{O}$ intercruzamento desses materiais resultou em quatro compostos assim denominados: GN-01, GN-02, GN-03 e GN-04.

No presente estudo foi utilizado o composto GN-04, o qual foi constituído a partir das populações CMS 50, BR 106, Cunha, Sintético Elite e Saracura. $\mathrm{Na}$ Tabela 03, a seguir, apresentam-se os valores médios de algumas características agronômicas importantes do referido composto.

Tabela 3. Médias de três caracteres do composto GN-4 obtidas em Rio Verde-GO, 1999

\begin{tabular}{lcc}
\hline Caracteres & Unidade & Valor \\
\hline Produção de espigas & $\mathrm{t} / \mathrm{ha}$ & 8,49 \\
Altura da planta & $\mathrm{cm} / \mathrm{pl}$. & 205,10 \\
Altura da espiga & $\mathrm{cm} / \mathrm{pl}$. & 103,60 \\
\hline
\end{tabular}

Fonte: Adaptada de Nass e Miranda Filho (1999)

Os materiais avaliados foram 30 subpopulações de tamanho reduzido, 60 famílias 'topcrosses', resultantes dos cruzamentos dessas subpopulações com dois 
testadores, 75 híbridos obtidos através de cruzamentos dialélicos entre essas subpopulações, 77 progênies $S_{1}, 75$ de irmãos germanos e 216 progênies de cruzamentos em cadeia.

\subsection{Métodos}

\subsubsection{Obtenção dos materiais genéticos e execução experimental}

Um lote do composto GN-04 foi instalado em março de 2000 na área experimental da ESALQ visando à obtenção,através de polinizações controladas, de três tipos de materiais: progênies $S_{1}$, de irmãos germanos e progênies de cruzamentos em cadeia, segundo o esquema 1 x 2, 2 × 3 e 3 x 1 (Figura 1). No laboratório, procedeu-se à seleção das espigas isentas de doenças e pragas, o que resultou em 77 progênies $S_{1}, 75$ de irmãos germanos e 72 cadeias, as quais são compostas de três progênies, que apresentam relações de parentesco de irmãos germanos e meios irmãos.

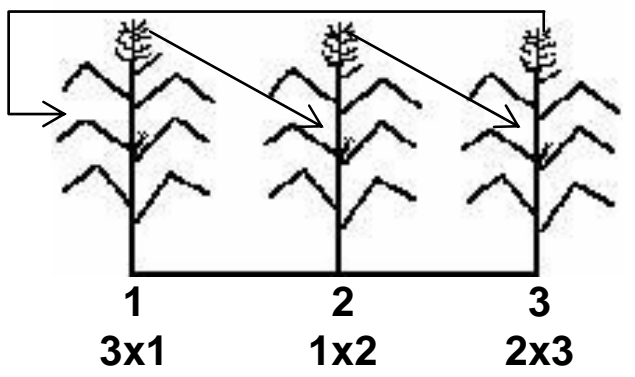

Figura 1 - Representação diagramática de um esquema de cruzamentos com 3 genitores, representando uma cadeia

A avaliação desses materiais iniciou-se em novembro de 2000, sendo instalados seis experimentos na área experimental da ESALQ/Genética (L1) e Anhembi (L2), ambas pertencentes ao Município de Piracicaba. Os experimentos de 1 a 4 foram constituídos com progênies de cruzamentos em cadeia, o experimento 5, com progênies de irmãos germanos e o experimento 6 , com progênies $S_{1}$. Para todos eles utilizou-se o 
delineamento experimental em blocos casualizados, com três repetições dos tratamentos em ambos os locais. O espaçamento foi de 1,00 m entre filleiras e 0,20 m entre plantas, o que corresponde a um estande de 50.000 plantas/ha. A unidade experimental constituiuse de uma fileira de $4 \mathrm{~m}$, perfazendo um total de 20 plantas após desbaste. Na Tabela 4 , a seguir, mais informações são apresentadas sobre esses experimentos:

Tabela 4. Experimentos instalados nos locais 1 e 2 no ano agrícola 2000/2001

\begin{tabular}{c|c|c|c}
\hline $\begin{array}{c}\text { Experimento } \\
\left(\mathrm{N}^{\text {o }}\right)\end{array}$ & Tratamento & Testemunha $^{1}$ & Material genético \\
\hline 01 & $51(17)$ & AG 6018 & $\begin{array}{c}\text { Progênies de } \\
\text { cruzamentos em cadeia. }\end{array}$ \\
02 & $48(16)$ & “ & “ \\
03 & $51(17)$ & “ & “ \\
04 & $66(22)$ & “ & Progênies de IG \\
05 & 75 & “ & Progênies S $\mathrm{S}_{1}$ \\
06 & 77 & “ & \\
\hline
\end{tabular}

${ }^{1}$ Híbrido simples comercial

Números entre parênteses representam as cadeias.

Ressalta-se que no caso dos experimentos com progênies originárias de cruzamentos em cadeia, tomou-se o cuidado de não permitir que progênies constituintes de uma mesma cadeia fossem avaliadas em experimentos distintos.

A obtenção das 30 subpopulações de tamanho reduzido, com seleção, efetuou-se conforme os procedimentos descritos a seguir:

Adotando-se como critério de seleção a variável peso de espigas, foram escolhidas 10 progênies no experimento 5 e 10 no experimento 6, sendo cada grupo de 10 constituído das 5 progênies mais produtivas e das 5 menos produtivas. Para a seleção das 10 restantes, foram reunidos os dados dos experimentos de 1 a 4 e, em vez de progênies, calculou-se a média das cadeias, selecionando-se também as 5 mais produtivas e 5 menos produtivas de um total de 72 cadeias. 
Com as sementes remanescentes dessas progênies/cadeias, foi instalado em novembro de 2001, na área experimental da ESALQ, um lote para recombinação. Cada progênie ou cadeia ocupou uma linha de $6 \mathrm{~m}$, com 0,2 $\mathrm{m}$ entre plantas, perfazendo um total de 30 plantas. Ressalta-se que na constituição dos lotes de sementes para o plantio, em se tratando de cadeias, foram tomadas quantidades iguais de sementes de cada uma das três progênies que a constituiam.

À época do florescimento, efetuou-se artificialmente uma recombinação entre plantas da mesma linha e, na colheita, as espigas de cada linha foram colhidas em conjunto. Na seqüência desse trabalho, partes equivalentes de sementes dessas espigas foram misturadas para constituir um lote. Este procedimento ensejou a obtenção de 10 subpopulações com $\mathrm{N}=1$ (originárias de progênies de autofecundação), $10 \operatorname{com} \mathrm{N}=2$ (originárias de progênies de irmãos germanos) e 10 com $\mathrm{N}=3$ (originárias da recombinação de três progênies dentro de uma cadeia). As subpopulações de tamanhos efetivos (N) 1, 2 e 3 foram identificadas como $\mathrm{N}_{1}, \mathrm{~N}_{2}$ e $\mathrm{N}_{3}$ nesse estudo .

Estas 30 subpopulações foram avaliadas no experimento de número 7, cuja instalação ocorreu em jan/2003. O delineamento foi em blocos casualizados, com 9 repetições no Local 1 e 10 no Local 2. A unidade experimental obedeceu às mesmas dimensões dos experimentos anteriores. A testemunha, o híbrido simples comercial AG 5055, foi plantada no início e final de cada bloco e dentro do bloco, sempre após uma seqüência de 10 unidades com tratamentos.

Contíguos ao lote em que se obtiveram as subpopulações de tamanho reduzido, dois outros lotes foram instalados com as mesmas progênies/cadeias, as quais foram utilizadas em cruzamentos 'topcrosses' com uma população de base ampla, o composto GN-03, e uma de base estreita, o híbrido triplo P 34041. Cada progênie/cadeia ocupou uma linha de 3,0 m, com 0,2 m entre plantas, perfazendo um total de 15 plantas após o desbaste. As polinizações artificiais em cada lote eram sempre realizadas com a mistura de pólen de , no mínimo, 30 plantas dos respectivos testadores. Na colheita, as linhas foram colhidas separadamente e, no laboratório, efetuou-se a debulha das espigas e mistura das sementes. 
Ao término deste trabalho, foram obtidas 60 famílias 'topcrosses' que foram avaliadas no experimento de número 8, instalado em abril/2002 em dois locais: Piracicaba - SP e Maurilândia - GO. Entretanto, devido a problemas de má qualidade dos dados, optou-se pelo descarte do experimento instalado em Maurilândia. O delineamento e a unidade experimental seguiram os mesmos padrões dos anteriores. $\mathrm{O}$ número de repetições por local foi quatro. A testemunha utilizada foi o híbrido simples comercial Z - 8420.

Em jan/2002, essas mesmas progênies/cadeias, ainda com o uso de sementes remanescentes, foram plantadas na área experimental da ESALQ em três lotes distintos, de acordo com o tipo de material: $\mathrm{S}_{1}$, irmãos germanos e cadeia. Cada progênie ocupou uma linha de $6 \mathrm{~m}$, com 0,2 m entre plantas, perfazendo um total de 30 plantas, com exceção das progênies originárias de autofecundação, cujas linhas eram de apenas 3 $\mathrm{m}$ com 15 plantas. Na época do florescimento, cruzamentos dialélicos foram realizados entre as 5 progênies/cadeias mais produtivas e as 5 menos produtivas. Efetuou-se também uma recombinação entre plantas da mesma progênie para representar os pais.

A avaliação dos materiais obtidos iniciou-se em agosto/2002 com a instalação de 3 experimentos em Guaíra - SP e Piracicaba - SP, identificados pelos números 9, 10 e 11, os quais consistiam, respectivamente, de híbridos originários de cruzamentos entre cadeias, irmãos germanos e $\mathrm{S}_{1}$ 's. Todavia, devido a intempéries, os experimentos de Piracicaba foram perdidos. O delineamento estatístico e a unidade experimental também seguiram os mesmos padrões dos anteriores. Cada experimento foi constituído de 35 tratamentos (25 híbridos e 10 genitores), com quatro repetições.

Ressalta-se que a obtenção dos materiais 'topcrosses' e híbridos provenientes de cruzamentos dialélicos, não foi precedida de uma recombinação das progênies/cadeias, uma vez que o 'conjunto gênico' destas equivale ao das subpopulações que lhes correspondem.

Foram tomados os dados de sete caracteres, conforme descrição a seguir:

- Altura da planta (AP): avaliada em cinco plantas competitivas, escolhidas ao acaso em cada parcela; a medição foi efetuada em centímetros, da superfície do solo até à inserção da última folha. 
- Altura da espiga (AE): avaliada pelos mesmos critérios adotados para altura de planta; a medição efetuou-se da superfície do solo até à inserção basal da primeira espiga, sendo esta definida como aquela situada mais próxima ao ápice da planta.

- Peso de espigas (PE): efetuou-se a pesagem, em $\mathrm{kg}$, de todas as espigas despalhadas da parcela.

- Peso de grãos (PG): efetuou-se a pesagem, em kg, dos grãos da parcela.

- Diâmetro da espiga (DE): foram selecionadas cinco espigas ao acaso para avaliação deste caráter. A medição efetuou-se em centímetros, considerando-se o diâmetro total da porção mediana.

- Comprimento da espiga (CE): nas mesmas espigas selecionadas para avaliação do caráter diâmetro da espiga, efetuou-se a medição, em centímetros, do comprimento total das espigas.

- prolificidade (PR): obtida através da relação número de espigas/estande final.

Nos experimento 8 mensurou-se apenas o caráter PE, e nos experimentos 9, 10 e 11, PG.

Os caracteres peso de espigas e peso de grãos foram corrigidos para o estande inicial de 20 plantas, conforme metodologia apresentada por Vencovsky (1992), de acordo com a seguinte equação de regressão:

$\hat{Y}_{i j}=Y_{i j}-\hat{b}\left(X_{i j}-20\right)$, em que

$\hat{\mathrm{Y}}_{\mathrm{ij}}$ : peso corrigido de espigas do tratamento $\mathrm{i}$, na repetição $\mathrm{j}$;

$Y_{i j}$ : peso observado de espigas do tratamento i, na repetição j;

$\hat{\mathrm{b}}$ : coeficiente de regressão linear do peso de espigas, em relação à variável independente estande;

$\mathrm{X}_{\mathrm{ij}}$ : estande observado. 


\subsubsection{Análise da variância}

As análises individuais dos experimentos 1, 2, 3, 4, 5, 6 e 7, os quais foram avaliados em mais de um local, foram realizadas de acordo com o delineamento em blocos casualizados, a fim de que se verificasse a ordem de grandeza das variâncias residuais. Como em nenhum deles a relação entre a maior e a menor variância ultrapassou 7, a análise agrupada ou conjunta pode ser realizada sem maiores problemas ( Pimentel - Gomes \& Garcia, 2002).

\subsubsection{Progênies em cadeia}

A análise agrupada dos experimentos de 1 a 4, para um local, consistindo de progênies obtidas através de cruzamentos em cadeia, foram realizadas de acordo com o modelo matemático, a seguir:

$$
\mathrm{Y}_{\mathrm{ijkm}}=\mu+\mathrm{e}_{\mathrm{i}}+\mathrm{c}_{\mathrm{j} / \mathrm{i}}+\mathrm{p}_{\mathrm{k} / \mathrm{ij}}+\mathrm{b}_{\mathrm{m} / \mathrm{i}}+\varepsilon_{\mathrm{ijkm}} \text {, em que: }
$$

$\mathrm{Y}_{\mathrm{ijkm}}$ : é o valor observado da progênie $\mathrm{k}$, dentro da cadeia $\mathrm{j}$ e experimento $\mathrm{i}$, no bloco $\mathrm{m}$;

$\mu$ : média geral, fixa;

$\mathrm{e}_{\mathrm{i}}$ : é o efeito do experimento $\mathrm{i}(\mathrm{i}=1 \ldots . . \mathrm{I})$, aleatório;

$\mathrm{c}_{\mathrm{j} / \mathrm{i}}$ : é o efeito da cadeia $\mathrm{j}(\mathrm{j}=1 \ldots . . \mathrm{J})$, dentro do experimento $\mathrm{i}$, aleatório;

$\mathrm{p}_{\mathrm{k} / \mathrm{ij}}$ : é o efeito da progênie $\mathrm{k}(\mathrm{k}=1 \ldots . \mathrm{K})$, dentro da cadeia $\mathrm{j}$ e experimento i, aleatório;

$\mathrm{b}_{\mathrm{m} / \mathrm{i}}$ : é o efeito do bloco $\mathrm{m}(\mathrm{m}=1 \ldots . . \mathrm{M})$, dentro do experimento i, aleatóro;

$\varepsilon_{\mathrm{ijkm}}$ : é o erro experimental, aleatório, com $\varepsilon_{\mathrm{ijkm}} \sim \operatorname{NID}\left(0, \sigma^{2}\right)$.

A estrutura da análise da variância desses experimentos é apresentada na tabela seguinte: 
Tabela 5. Análise agrupada da variância para progênies de cruzamentos em cadeia, para um local, e para todos os caracteres, em nível de totais ou de médias de parcelas e esperança dos quadrados médios expressa em termos de componentes da variância e covariância

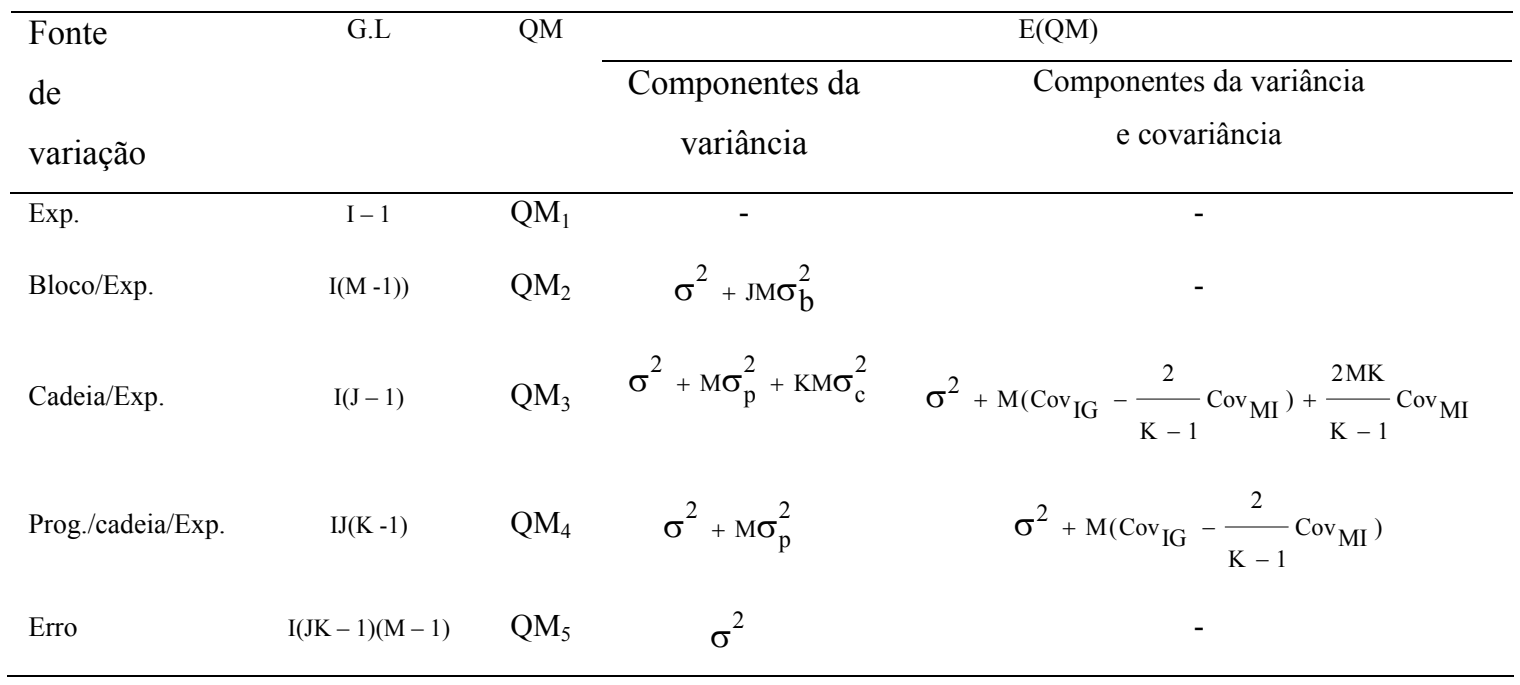

A estatística $\mathrm{F}$ correspondente às fontes de variação foi obtida de acordo com as seguintes expressões:

$$
\begin{aligned}
& \mathrm{QM}_{1} /\left(\mathrm{QM}_{2}+\mathrm{QM}_{3}-\mathrm{QM}_{5}\right) \\
& \mathrm{QM}_{2} / \mathrm{QM}_{5} \\
& \mathrm{QM}_{3} / \mathrm{QM}_{4}
\end{aligned}
$$$$
\text { QM4 / QM5. }
$$

Quando o denominador é expresso por uma combinação linear de quadrados médios, o número de graus de liberdade é obtido pela fórmula clássica de Satterthwait (Barbin, 1998). Esta observação estende-se às situações correlatas.

A análise envolvendo os dois locais, denominada de 'análise agrupada conjunta', foi realizada de acordo com o seguinte modelo matemático:

$$
\mathrm{Y}_{\mathrm{ijklm}}=\mu+\mathrm{e}_{\mathrm{i}}+\mathrm{l}_{1}+\mathrm{c}_{\mathrm{j} / \mathrm{i}}+\mathrm{p}_{\mathrm{k} / \mathrm{ij}}+\mathrm{b}_{\mathrm{m} / \mathrm{il}}+(\mathrm{el})_{\mathrm{il}}+(\mathrm{cl})_{\mathrm{jl} / \mathrm{i}}+(\mathrm{pl})_{\mathrm{kl} / \mathrm{ij}}+\varepsilon_{\mathrm{ijklm}},
$$

em que: 
$\mathrm{Y}_{\mathrm{ijklm}}$ : é o valor observado da progênie $\mathrm{k}$, dentro da cadeia j e experimento i, no bloco $\mathrm{m}$ dentro do Local 1;

$\mu$ : é a média geral, fixa;

$\mathrm{e}_{\mathrm{i}}$ : é o efeito do experimento i $(\mathrm{i}=1 \ldots . . . \mathrm{I})$, aleatório;

$1_{1}$ : é o efeito do Local $1(1=1 \ldots . . L)$, fixo;

$\mathrm{c}_{\mathrm{j} / \mathrm{i}}$ : é o efeito da cadeia $\mathrm{j}(\mathrm{j}=1 \ldots . . \mathrm{J})$, aleatório;

$\mathrm{p}_{\mathrm{k} / \mathrm{ij}}$ : é o efeito da progênie $\mathrm{k}(\mathrm{k}=1 \ldots . . \mathrm{K})$, dentro da cadeia $\mathrm{j}$ e do experimento $\mathrm{i}$, aleatório;

$\mathrm{b}_{\mathrm{m} / \mathrm{il}}$ : é o efeito do bloco $\mathrm{m}(\mathrm{m}=1 \ldots . . \mathrm{M})$, dentro do Local 1 e experimento $\mathrm{i}$;

$(\mathrm{el})_{\mathrm{il}}$ : é o efeito da interação do experimento i, com o Local l;

(cl) $)_{\mathrm{jl} / \mathrm{i}}$ : é o efeito da interação da cadeia $\mathrm{j}$, com o Local 1 , dentro do experimento i;

$(\mathrm{pl})_{\mathrm{kl} / \mathrm{ij}}$ : é o efeito da interação da progênie $\mathrm{k}$, com o Local 1 , dentro da cadeia $\mathrm{j}$ e do experimento i;

$\varepsilon_{\mathrm{ijklm}}$ : é o erro experimental, aleatório, com $\varepsilon_{\mathrm{ijklm}} \sim \operatorname{NID}\left(0, \sigma^{2}\right)$.

A estrutura da análise da variância com as fontes de variação e suas respectivas esperanças dos quadrados médios está apresentada na Tabela 6. 
Tabela 6. Análise agrupada conjunta da variância, para progênies de cruzamentos em cadeia, para todos os caracteres, em nível de totais ou de médias de parcelas e esperança dos quadrados médios, expressa em termos de componentes da variância e covariância, correspondentes às fontes de variação de maior interesse

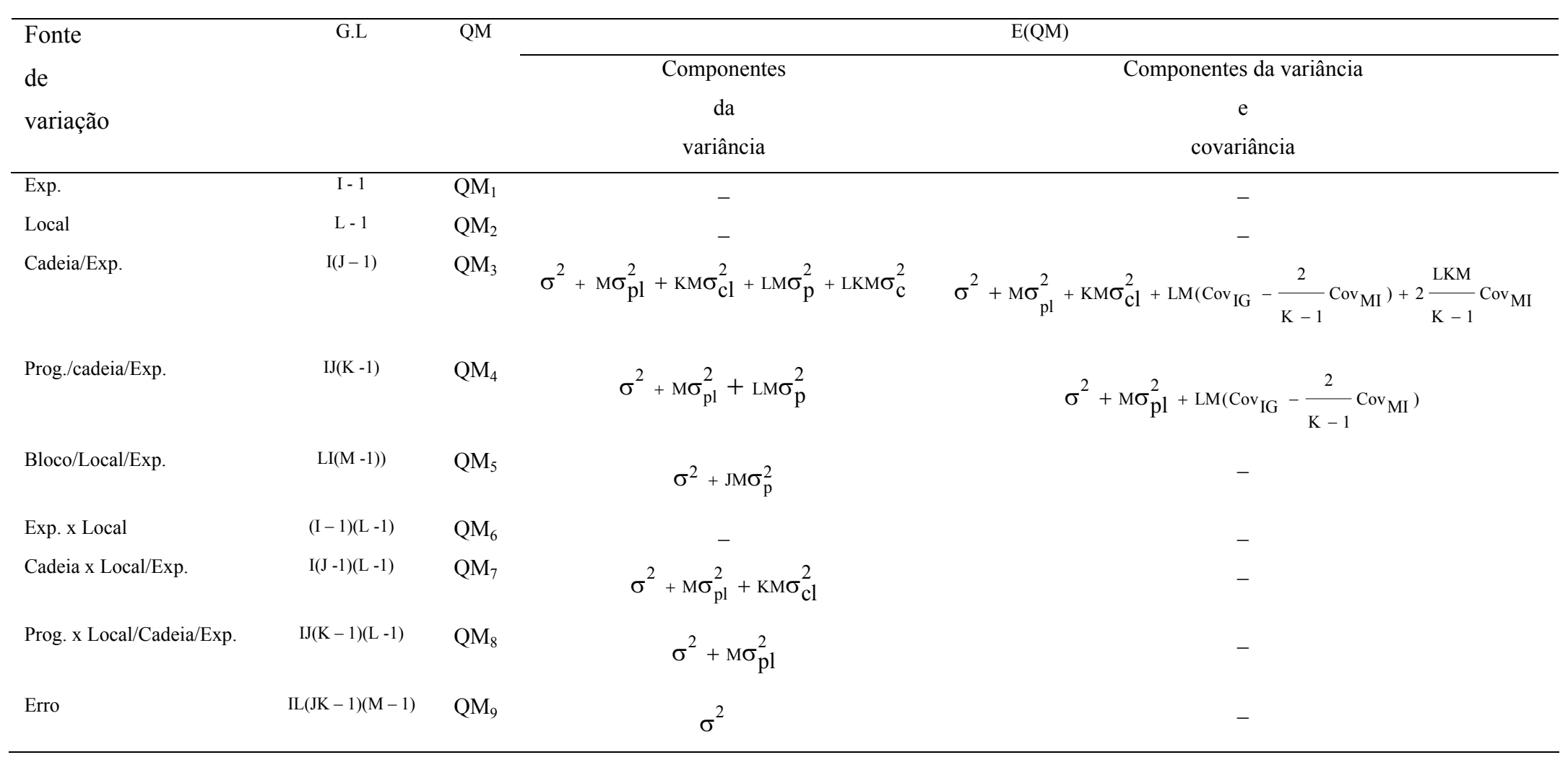


A estatística $\mathrm{F}$ correspondente às fontes de variação foi obtida de acordo com as seguintes expressões:

$$
\begin{aligned}
& \mathrm{QM}_{1} /\left(\mathrm{QM}_{3}+\mathrm{QM}_{6}-\mathrm{QM}_{7}\right) \\
& \mathrm{QM}_{2} /\left(\mathrm{QM}_{7}+\mathrm{QM}_{6}\right) ; \\
& \mathrm{QM}_{3} /\left(\mathrm{QM}_{4}+\mathrm{QM}_{7}-\mathrm{QM}_{8}\right) \\
& \mathrm{QM}_{4} / \mathrm{QM}_{8} ; \\
& \mathrm{QM}_{5} / \mathrm{QM}_{9} ; \\
& \mathrm{QM}_{6} /\left(\mathrm{QM}_{5}+\mathrm{QM}_{7}-\mathrm{QM}_{9}\right) ; \\
& \mathrm{QM}_{7} / \mathrm{QM}_{8} ; \\
& \mathrm{QM}_{8} / \mathrm{QM}_{9} .
\end{aligned}
$$

\subsubsection{Progênies de irmãos germanos e $S_{1}$}

Os experimentos 5 e 6, que consistem de progênies de irmãos germanos e de autofecundação, foram analisados de acordo com o seguinte modelo matemático:

$$
\mathrm{Y}_{\mathrm{klm}}=\mu+\mathrm{p}_{\mathrm{k}}+\mathrm{l}_{1}+(\mathrm{pl})_{\mathrm{kl}}+\mathrm{b}_{\mathrm{m} / 1}+\varepsilon_{\mathrm{klm}}, \text { em que: }
$$

$\mathrm{Y}_{\mathrm{klm}}$ : valor observado da progênie $\mathrm{k}$, no bloco m e Local 1;

$\mu$ : é a média geral, fixo;

$\mathrm{p}_{\mathrm{k}}$ : é o efeito da progênie $\mathrm{k}(\mathrm{k}=1 \ldots . . \mathrm{K})$, aleatório;

$1_{1}$ : é o efeito do Local $1(1=1 \ldots . . \mathrm{L})$, aleatório;

$(\mathrm{pl})_{\mathrm{kl}}$ : é o efeito da interação da progênie k com o Local 1, aleatório;

$\mathrm{b}_{\mathrm{m} / \mathrm{l}}$ : é o efeito do bloco $\mathrm{m}(\mathrm{m}=1 \ldots . . \mathrm{M})$, aleatório;

$\varepsilon_{\mathrm{klm}}$ : é o erro experimental, aleatório, com $\varepsilon_{\mathrm{klm}} \sim \operatorname{NID}\left(0, \sigma^{2}\right)$.

A estrutura da análise da variância dos experimentos 5 e 6 é dada na tabela seguinte: 
Tabela 7. Estrutura da análise conjunta da variância dos experimentos 5 e 6, para todos os caracteres, em nível de totais ou de médias de parcelas, com os quadrados médios e suas respectivas esperanças

\begin{tabular}{|c|c|c|c|c|c|}
\hline Fonte de & & GL & QM & $\mathrm{F}$ & $\mathrm{E}(\mathrm{QM})$ \\
\hline \multicolumn{6}{|l|}{ Variação } \\
\hline Local & & $\mathrm{L}-1$ & $\mathrm{QM}_{1}$ & $\mathrm{QM}_{1} /\left(\mathrm{QM}_{4}+\mathrm{QM}_{2}-\mathrm{QM}_{5}\right)$ & $\sigma^{2}+\mathrm{M} \sigma_{\mathrm{pl}}^{2}+\mathrm{K} \sigma_{\mathrm{b}}^{2}+\mathrm{KM} \phi_{1}$ \\
\hline Bloco/Local & & $\mathrm{L}(\mathrm{M}-1)$ & $\mathrm{QM}_{2}$ & $\mathrm{QM}_{2} / \mathrm{QM}_{5}$ & $\sigma^{2}+K \sigma_{b}^{2}$ \\
\hline Progênies & & $\mathrm{K}-1$ & $\mathrm{QM}_{3}$ & $\mathrm{QM}_{3} / \mathrm{QM}_{5}$ & $\sigma^{2}+1 M \sigma_{p}^{2}$ \\
\hline Progênies & $\mathrm{x}$ & $(\mathrm{L}-1)(\mathrm{K}-1)$ & $\mathrm{QM}_{4}$ & $\mathrm{QM}_{4} / \mathrm{QM}_{5}$ & $\sigma^{2}+1 \mathrm{M} \sigma_{\mathrm{pl}}^{2}$ \\
\hline \multicolumn{6}{|l|}{ Local } \\
\hline Resíduo & & $\mathrm{L}(\mathrm{K}-1)(\mathrm{M}-1)$ & $\mathrm{QM}_{5}$ & - & $\sigma^{2}$ \\
\hline
\end{tabular}

\subsubsection{Subpopulações de tamanho reduzido}

A abordagem do processo dispersivo neste trabalho concentrou-se, basicamente, nos resultados do experimento 7 , cujo modelo matemático para um local apresenta-se a seguir:

$$
\mathrm{Y}_{\mathrm{ijkm}}=\mu+\mathrm{b}_{\mathrm{m}}+\mathrm{n}_{\mathrm{i}}+\mathrm{s}_{\mathrm{j}}+(\mathrm{ns})_{\mathrm{ij}}+\mathrm{f}_{\mathrm{k} / \mathrm{ij}}+\varepsilon_{\mathrm{ijkm}} \text {, em que: }
$$

$\mathrm{Y}_{\mathrm{ijkm}}$ : valor observado da subpopulação $\mathrm{k}$, dentro do tamanho efetivo i e seleção j, no bloco m;

$\mu$ : é a média geral, fixo;

$\mathrm{b}_{\mathrm{m}}$ : é o efeito do bloco $\mathrm{m}(\mathrm{m}=1 \ldots . . \mathrm{M})$, aleatório;

$\mathrm{n}_{\mathrm{i}}$ : é o efeito do tamanho efetivo $\mathrm{i}(\mathrm{i}=1 \ldots . \mathrm{I})$, fixo; 
$s_{j}$ : é o efeito da seleção $j(j=1 \ldots . . J)$, fixo;

$(n s)_{\mathrm{ij}}$ : é o efeito da interação entre tamanho efetivo i com a seleção j, fixo;

$\mathrm{f}_{\mathrm{k} / \mathrm{ij}}$ : é o efeito da subpopulação $\mathrm{k}(\mathrm{k}=1 \ldots . .5)$, aleatório;

$\varepsilon_{\mathrm{ijkm}}$ : é o erro experimental, aleatório, com $\varepsilon_{\mathrm{ijkm}} \sim \operatorname{NID}\left(0, \sigma^{2}\right)$.

Na tabela seguinte apresenta-se a estrutura da análise da variância do experimento 7 para um local:

Tabela 8. Estrutura da análise da variância do experimento 7, consistindo de subpopulações de tamanho reduzido, para todas os caracteres, em nível de total ou média de parcela

\begin{tabular}{lccc}
\hline Fonte de variação & GL & QM & F \\
\hline Bloco & $\mathrm{M}-1$ & $\mathrm{QM}_{1}$ & $\mathrm{QM}_{1} / \mathrm{QM}_{6}$ \\
Tamanho efetivo & $\mathrm{I}-1$ & $\mathrm{QM}_{2}$ & $\mathrm{QM}_{2} / \mathrm{QM}_{5}$ \\
Seleção & $\mathrm{J}-1$ & $\mathrm{QM}_{3}$ & $\mathrm{QM}_{3} / \mathrm{QM}_{5}$ \\
Tamanho efetivo x Seleção & $(\mathrm{I}-1)(\mathrm{J}-1)$ & $\mathrm{QM}_{4}$ & $\mathrm{QM}_{4} / \mathrm{QM}_{5}$ \\
Subpopulações/Tamanho efetivo x Seleção & $\mathrm{IJ}(\mathrm{K}-1)$ & $\mathrm{QM}_{5}$ & $\mathrm{QM}_{5} / \mathrm{QM}_{6}$ \\
Erro & $(\mathrm{IJK}-1)(\mathrm{M}-1)$ & $\mathrm{QM}_{6}$ & - \\
\hline
\end{tabular}

O modelo matemático utilizado na análise conjunta desse experimento apresenta-se a seguir:

$\mathrm{Y}_{\mathrm{ijklm}}=\mu+\mathrm{b}_{\mathrm{m}}+\mathrm{n}_{\mathrm{i}}+\mathrm{s}_{\mathrm{j}}+(\mathrm{ns})_{\mathrm{ij}}+\mathrm{f}_{\mathrm{k} / \mathrm{ij}}+\mathrm{l}_{1}+(\mathrm{ns})_{\mathrm{ij}}+(\mathrm{sl})_{\mathrm{jl}}+(\mathrm{fl})_{\mathrm{kl} / \mathrm{ij}}+(\mathrm{nsl})_{\mathrm{ijl}}+\varepsilon_{\mathrm{ijklm}}, \quad \mathrm{em}$ que:

$Y_{\text {ijklm }}$ : é o efeito observado da subpopulação k, dentro do tamanho efetivo i e seleção j, no bloco m dentro do Local 1;

$\mu$ : é a média geral, fixo; 
$\mathrm{b}_{\mathrm{m}}$ : é o efeito do bloco $\mathrm{m}(\mathrm{m}=1 \ldots . . \mathrm{M})$, aleatório;

$\mathrm{n}_{\mathrm{i}}$ : é o efeito do tamanho efetivo $\mathrm{i}(\mathrm{i}=1 \ldots . \mathrm{I})$, fixo;

$s_{j}$ : é o efeito da seleção $j(j=1 \ldots . . . J)$, fixo;

$(n s)_{i j}$ : é o efeito da interação entre o tamanho efetivo i com a seleção j, fixo;

$\mathrm{f}_{\mathrm{k} / \mathrm{ij}}$ : é o efeito da subpopulação $\mathrm{k}(\mathrm{k}=1 \ldots . \mathrm{K})$, dentro do efeito tamanho efetivo $\mathrm{x}$ seleção ij, aleatório;

$1_{1}$ : é o efeito do Local $1(1=1 \ldots . . \mathrm{L})$, fixo;

$(\text { ns })_{\mathrm{ij}}$ : é o efeito da interação do tamanho efetivo i com a seleção j, fixo;

$(\mathrm{sl})_{\mathrm{j} 1}$ : é o efeito da interação da seleção j com o Local 1, fixo;

$(\mathrm{fl})_{\mathrm{kl} / \mathrm{ij}}$ : é o efeito da interação da subpopulação $\mathrm{k}$ com o Local 1, dentro do efeito tamanho efetivo x seleção ij, aleatório;

$(\text { nsl })_{\mathrm{ijl}}$ : é o efeito da interação do tamanho efetivo i com a seleção j e Local 1, fixo;

$\varepsilon_{\mathrm{ijklm}}$ : é o erro experimental, aleatório, com $\varepsilon_{\mathrm{ijklm}} \sim \operatorname{NID}\left(0, \sigma^{2}\right)$.

$\mathrm{Na}$ tabela seguinte apresenta-se a estrutura da análise de variância desse experimento: 
Tabela 9. Estrutura da análise da variância conjunta do experimento 7, para todas as variáveis, em nível de total ou média de parcela

\begin{tabular}{lccc}
\hline Fonte de variação & $\mathrm{G} . \mathrm{L}$ & $\mathrm{QM}$ & $\mathrm{F}$ \\
\hline Bloco/Local & $\mathrm{L}(\mathrm{M}-1)$ & $\mathrm{QM}_{1}$ & $\mathrm{QM}_{1} / \mathrm{QM}_{2}$ \\
Local & $\mathrm{L}-1$ & $\mathrm{QM}_{2}$ & $\mathrm{QM}_{2} /\left(\mathrm{QM}_{1}+\mathrm{QM}_{7}\right)$ \\
Tamanho efetivo & $\mathrm{I}-1$ & $\mathrm{QM}_{3}$ & $\mathrm{QM}_{3} / \mathrm{QM}_{6}$ \\
Seleção & $\mathrm{J}-1$ & $\mathrm{QM}_{4}$ & $\mathrm{QM}_{4} / \mathrm{QM}_{6}$ \\
Tamanho efetivo x Seleção & $(\mathrm{I}-1)(\mathrm{J}-1)$ & $\mathrm{QM}_{5}$ & $\mathrm{QM}_{5} / \mathrm{QM}_{6}$ \\
Subpopulação/Tamanho efetivo x Seleção & $\mathrm{IJ}(\mathrm{K}-1)$ & $\mathrm{QM}_{6}$ & $\mathrm{QM}_{6} / \mathrm{QM}_{7}$ \\
Subpopulação x Local/Tamanho efetivo x Seleção & $\mathrm{IJ}(\mathrm{K}-1)(\mathrm{L}-1)$ & $\mathrm{QM}_{7}$ & $\mathrm{QM}_{7} / \mathrm{QM}_{11}$ \\
Tamanho efetivo x Local & $(\mathrm{I}-1)(\mathrm{L}-1)$ & $\mathrm{QM}_{8}$ & $\mathrm{QM}_{8} / \mathrm{QM}_{7}$ \\
Seleção x Local & $(\mathrm{J}-1)(\mathrm{L}-1)$ & $\mathrm{QM}_{9}$ & $\mathrm{QM}_{9} / \mathrm{QM}_{7}$ \\
Tamanho efetivo x Seleção x Local & $(\mathrm{I}-1)(\mathrm{J}-1)(\mathrm{L}-1)$ & $\mathrm{QM}_{10}$ & $\mathrm{QM}_{10} / \mathrm{QM}_{7}$ \\
Erro & $\mathrm{L}[(\mathrm{IJK}-1)(\mathrm{M}-1)]$ & $\mathrm{QM}_{11}$ & - \\
\hline
\end{tabular}

\subsubsection{Progênies 'topcrosses'}

De acordo com Vencovsky \& Barriga (1992), o esquema de cruzamento 'topcross' pode ser considerado como um dialelo parcial, ou com mais propriedade, como um delineamento genético fatorial, quando se utilizam dois ou mais testadores.

No presente trabalho os materiais 'topcrosses' foram analisados de acordo com esta última opção, cujo modelo matemático apresenta-se a seguir:

$$
\mathrm{Y}_{\mathrm{kjm}}=\mu+\mathrm{f}_{\mathrm{j}}+\mathrm{t}_{\mathrm{k}}+(\mathrm{ft})_{\mathrm{jk}}+\mathrm{b}_{\mathrm{m}}+\varepsilon_{\mathrm{kjm}} \text {, em que: }
$$

$\mathrm{Y}_{\mathrm{kjm}}$ : valor observado da subpopulação j com o testador k, no bloco m;

$\mu$ : é a média geral, fixo;

$\mathrm{f}_{\mathrm{j}}$ : é o efeito da progênie 'topcross' $\mathrm{j}(\mathrm{j}=1 \ldots . . \mathrm{J})$, aleatório;

$\mathrm{t}_{\mathrm{k}}$ : é o efeito do testador $\mathrm{k}(\mathrm{k}=1 \ldots . . \mathrm{K})$, fixo; 
$(\mathrm{ft})_{\mathrm{jk}}$ : é o efeito da interação da progênie 'topcross' j com o testador k, aleatório;

$\mathrm{b}_{\mathrm{m}}$ : é o efeito do bloco $\mathrm{m}(\mathrm{m}=1 \ldots . . \mathrm{M})$, aleatório;

$\varepsilon_{\mathrm{klm}}$ : é o erro experimental, aleatório, com $\varepsilon_{\mathrm{klm}} \sim \operatorname{NID}\left(0, \sigma^{2}\right)$.

$\mathrm{Na}$ tabela seguinte apresenta-se a estrutura da análise da variância desse experimento:

Tabela 10. Estrutura da análise da variância do experimento 8 para o caráter peso de espigas, em nível de total de parcela

\begin{tabular}{lccc}
\hline Fonte de variação & $\mathrm{GL}$ & $\mathrm{QM}$ & $\mathrm{F}$ \\
\hline Bloco & $(\mathrm{M}-1)$ & $\mathrm{QM}_{1}$ & $\mathrm{QM}_{1} / \mathrm{QM}_{5}$ \\
Progênie 'topcross' & $\mathrm{J}-1$ & $\mathrm{QM}_{2}$ & $\mathrm{QM}_{2} / \mathrm{QM}_{4}$ \\
Testador & $\mathrm{K}-1$ & $\mathrm{QM}_{3}$ & $\mathrm{QM}_{3} / \mathrm{QM}_{4}$ \\
Testador x Progênie 'topcross' & $(\mathrm{J}-1)(\mathrm{K}-1)$ & $\mathrm{QM}_{4}$ & $\mathrm{QM}_{4} / \mathrm{QM}_{5}$ \\
Resíduo & $(\mathrm{JK}-1)(\mathrm{M}-1)$ & $\mathrm{QM}_{5}$ & - \\
\hline
\end{tabular}

A capacidade geral e específica de combinação das subpopulações foram calculadas através das expressões apresentadas por Vencovsky \& Barriga (1992):

$$
\begin{aligned}
& \operatorname{cgc}=\bar{y}_{. j .} \cdot \bar{y}_{\ldots} ; \\
& \operatorname{cec}=\bar{y}_{j k .}+\bar{y}_{\ldots . .} \cdot \bar{y}_{j . .} \cdot \bar{y}_{. k .} \cdot \\
& \text { Para avaliar se os dois testadores estavam ordenando igualmente as }
\end{aligned}
$$
subpopulações, aplicou-se o coeficiente de correlação de Spearman $(\rho)$.

\subsubsection{Cruzamento dialélico parcial}

Inicialmente, foram realizadas análises individuais dos experimentos 9 , 10 e 11, segundo o delineamento em blocos casualizados, tendo em vista a obtenção dos 
quadrados médios residuais. A análise com os valores médios, bem como a estimativa de parâmetros pertinentes, foi realizada de acordo com a metodologia de análise de cruzamentos dialélicos parciais proposta por Miranda Filho e Geraldi (1984), que consiste na adaptação do modelo de Gardner e Eberhart (1966), para representar a média do cruzamento entre a variedade ou linhagem $\mathrm{i}$ do grupo 1 , e a variedade ou linhagem $\mathrm{j}$ do grupo 2. Todos os efeitos são considerados como fixos. Nos experimentos anteriormente referidos, o efeito de subpopulações, antes considerado aleatório, foi considerado aqui como fixo, uma vez que houve um interesse evidente na realização de tais cruzamentos com essas subpopulações.

O modelo adaptado exposto pelos autores é o que segue:

$Y_{i j}=\mu+\alpha d+\frac{1}{2}\left(v_{i}+v_{j}\right)+\theta\left(\bar{h}+h_{i}+h_{j}+s_{i j}\right)+\bar{e}_{i j}$, em que:

$\mathrm{Y}_{\mathrm{ij}}$ : média do cruzamento entre a subpopulação $\mathrm{i}$ do grupo 1 (cinco progênies mais produtivas) e a subpopulação $\mathrm{j}$ do grupo 2 (cinco progênies menos produtivas); $\theta=1$ e $\alpha=0$ para os híbridos. Para representar as subpopulações paternais, $\mathrm{y}_{\mathrm{ij}}$ é substituído por $\mathrm{y}_{\mathrm{ii}}$ ou $\mathrm{y}_{\mathrm{jj}}$, para as subpopulações dos grupos 1 e 2, respectivamente;

$\mu$ : é a média dos valores médios das subpopulações paternais dos dois grupos;

d : é a medida da diferença entre as médias dos dois grupos de subpopulações;

$v_{i}$ e $v_{j}$ : são os efeitos de subpopulações relativos aos grupos 1 e 2, respectivamente;

$\overline{\mathrm{h}}$ : é o efeito da heterose média de todos os cruzamentos;

$h_{i}$ e $h_{j}$ : são os efeitos de heterose das subpopulações relativos aos grupos 1 e 2 , respectivamente; 
$\mathrm{s}_{\mathrm{ij}}$ : é o efeito da heterose específica do cruzamento entre as subpopulações i e j;

$\overline{\mathrm{e}}_{\mathrm{ij}}$ : é o erro experimental, com $\overline{\mathrm{e}}_{\mathrm{ij}} \sim \operatorname{NID}\left(0, \sigma^{2}\right)$.

A análise da variância para o esquema de cruzamentos em dialelo parcial é apresentada a seguir:

Tabela 11. Estrutura da análise individual da variância dos experimentos 9, 10 e 11, baseado em um dialelo parcial, de acordo com o modelo sugerido por Miranda Filho \& Geraldi (1984)

\begin{tabular}{lccc}
\hline Fontes de variação & GL & QM & F \\
\hline Tratamentos & $\mathrm{N}-1$ & $\mathrm{QM}_{1}$ & $\mathrm{QM} / \mathrm{QM}_{10}$ \\
Subpopulações (Grupo 1) & $\mathrm{I}-1$ & $\mathrm{QM}_{2}$ & $\mathrm{QM} / \mathrm{QM}_{10}$ \\
Subpopulações (Grupo 2) & $\mathrm{J}-1$ & $\mathrm{QM}_{3}$ & $\mathrm{QM} / \mathrm{QM}_{10}$ \\
Grupo 1 x Grupo 2 & 1 & $\mathrm{QM}_{4}$ & $\mathrm{QM} / \mathrm{QM}_{10}$ \\
Heterose (H) & $\mathrm{IJ}$ & $\mathrm{QM}_{5}$ & $\mathrm{QM} 5 / \mathrm{QM}_{10}$ \\
H. Média & 1 & $\mathrm{QM}_{6}$ & $\mathrm{QM} 6 / \mathrm{QM}_{10}$ \\
H. Grupo 1 & $\mathrm{I}-1$ & $\mathrm{QM}_{7}$ & $\mathrm{QM} 7 / \mathrm{QM}_{10}$ \\
H. Grupo 2 & $\mathrm{J}-1$ & $\mathrm{QM}_{8}$ & $\mathrm{QM} 8 / \mathrm{QM}_{10}$ \\
H. Específica & $(\mathrm{I}-1)(\mathrm{J}-1)$ & $\mathrm{QM}_{9}$ & $\mathrm{QM} 9 / \mathrm{QM}_{10}$ \\
Resíduo & - & $\mathrm{QM}_{10}$ & - \\
\hline
\end{tabular}

Ressalta-se que as testemunhas incluídas nos experimentos não foram consideradas como um tratamento adicional, sendo retiradas, portanto, da análise estatística. Todas as análises foram realizadas através dos procedimentos 'GLM' e 'Mixed' do software SAS v. 8.12, excetuando-se as referentes aos experimentos 9, $10 \mathrm{e}$ 11, que foram realizadas com o programa 'Genes'. 


\subsubsection{Estimativas de componentes da variância}

\subsubsection{Experimentos com progênies obtidas através de cruzamentos em cadeia}

A expressão que permite estimar a variância genética, para um local, foi deduzida da Tabela 4, sendo apresentada tanto em termos de variâncias quanto de covariâncias. Expressões para estimar a covariância de meios irmãos e irmãos germanos também foram deduzidas, para facilitar o entendimento das expressões que permitem estimar os componentes da variância genética:

$$
\hat{\sigma}_{\mathrm{gc}}^{2}=\frac{\mathrm{QM}_{4}-\mathrm{QM}_{5}}{\mathrm{M}} \text {, em que } \hat{\sigma}_{\mathrm{gc}}^{2} \text { é a estimativa da variância genética }
$$

entre progênies de cruzamentos em cadeia;

$$
\hat{\sigma}_{\mathrm{gc}}^{2}=\hat{\operatorname{Cov}}_{\mathrm{ig}}-\frac{2}{\mathrm{~K}-1} \hat{\operatorname{Cov}}_{\mathrm{mi}} \text {, em que } \hat{\operatorname{Cov}}_{\mathrm{ig}} \text { é a covariância entre }
$$

progênies de irmãos germanos e $\hat{\operatorname{Cov}}_{\mathrm{mi}}$ é a covariância entre progênies de meios irmãos;

$$
\begin{aligned}
& \hat{\operatorname{Cov}}_{\mathrm{mi}}=\frac{(\mathrm{K}-1)\left(\mathrm{QM}_{3}-\mathrm{QM}_{4}\right)}{2 \mathrm{MK}} ; \\
& \hat{\operatorname{Cov}}_{\mathrm{ig}}=\frac{\mathrm{QM}_{3}+(\mathrm{K}-1) \mathrm{QM}_{4}-\mathrm{KQM}_{5}}{\mathrm{MK}} ; \\
& \hat{\sigma}_{\mathrm{A}}^{2}=4 \times \hat{\operatorname{Cov}}_{\mathrm{MI}} ; \\
& \hat{\sigma}_{\mathrm{D}}^{2}=4 \times\left(\hat{\operatorname{Cov}}_{\mathrm{ig}}-2 \times \hat{\operatorname{Cov}}_{\mathrm{MI}}\right) .
\end{aligned}
$$

As variâncias dessas estimativas de variâncias foram obtidas através das seguintes expressões:

$$
\hat{\mathrm{V}}\left(\hat{\sigma}_{\mathrm{A}}^{2}\right)=2\left[\frac{2(\mathrm{~K}-1)}{\mathrm{MK}}\right]^{2}\left[\frac{\mathrm{QM}_{3}^{2}}{\mathrm{I}(\mathrm{J}-1)+2}+\frac{\mathrm{QM}_{4}^{2}}{\mathrm{IJ}(\mathrm{K}-1)+2}\right]
$$




$$
\hat{\mathrm{V}}\left(\hat{\mathrm{\sigma}}_{\mathrm{D}}^{2}\right)=\left\{2\left(\frac{4}{\mathrm{MK}}\right)^{2}\left[\frac{(2-\mathrm{K})^{2} \mathrm{QM}_{3}^{2}}{\mathrm{I}(\mathrm{J}-1)+2}+\frac{(2 \mathrm{~K}-2)^{2} \mathrm{QM}_{4}^{2}}{\mathrm{IJ}(\mathrm{K}-1)+2}+\frac{\mathrm{K}^{2} \mathrm{QM}_{5}^{2}}{\mathrm{I}(\mathrm{JK}-1)(\mathrm{M}-1)+2}\right]\right\}
$$

As expressões referentes à análise conjunta da variância foram deduzidas da Tabela 5 e apresentam-se a seguir:

$$
\begin{aligned}
& \hat{\sigma}_{\mathrm{gc}}^{2}=\frac{\mathrm{QM}_{4}-\mathrm{QM}_{8}}{\mathrm{LM}} ; \\
& \hat{\sigma}_{\mathrm{gc}}^{2}=\hat{\operatorname{Cov}}_{\mathrm{ig}}-\frac{2 \hat{\mathrm{Cov}}_{\mathrm{mi}}}{(\mathrm{K}-1)} ; \\
& \hat{\mathrm{Cov}}_{\mathrm{mi}}=\left(\frac{\mathrm{K}-1}{2 \mathrm{LKM}}\right)\left[\mathrm{QM}_{3}+\mathrm{QM}_{8}-\left(\mathrm{QM}_{4}+\mathrm{QM}_{7}\right] ;\right. \\
& \hat{\mathrm{Cov}}_{\mathrm{ig}}=\left[\frac{\mathrm{QM}_{3}+(\mathrm{K}-1) \mathrm{QM}_{4}+(1-\mathrm{K}) \mathrm{QM}_{8}-\mathrm{QM}_{7}}{\mathrm{LKM}}\right] ;
\end{aligned}
$$

As expressões das estimativas dos componentes da variância genética são equivalentes àquelas apresentadas para um Local. As variâncias associadas às estimativas dos componentes de variância foram obtidas de acordo com as seguintes expressões:

$$
\begin{aligned}
& \hat{\mathrm{V}}\left(\hat{\sigma}_{\mathrm{A}}^{2}\right)=2\left[\frac{2(\mathrm{k}-1)}{\mathrm{LKM}}\right]^{2}\left[\frac{\mathrm{QM}_{3}^{2}}{\mathrm{I}(\mathrm{J}-1)+2}+\frac{\mathrm{QM}_{4}^{2}}{\mathrm{IJ}(\mathrm{K}-1)+2}+\frac{\mathrm{QM}_{7}^{2}}{\mathrm{I}(\mathrm{J}-1)(\mathrm{L}-1)+2}+\frac{\mathrm{QM}_{8}^{2}}{\mathrm{IJ}(\mathrm{K}-1)(\mathrm{L}-1)+2}\right] \\
& \hat{\mathrm{V}}\left(\hat{\sigma}_{\mathrm{D}}^{2}\right)=2\left[\frac{4}{\mathrm{LKM}}\right]^{2}\left[\frac{(2-\mathrm{K})^{2} \mathrm{QM}_{3}^{2}}{\mathrm{I}(\mathrm{J}-1)+2}+\frac{(2 \mathrm{~K}-2)^{2} \mathrm{QM}_{4}^{2}}{\mathrm{IJ}(\mathrm{K}-1)+2}+\frac{(\mathrm{K}-2)^{2} \mathrm{QM}_{7}{ }^{2}}{\mathrm{I}(\mathrm{J}-1)(\mathrm{L}-1)+2}+\frac{(2-2 \mathrm{~K})^{2} \mathrm{QM}_{8}^{2}}{\mathrm{IJ}(\mathrm{K}-1)(\mathrm{L}-1)+2}\right] .
\end{aligned}
$$

\subsubsection{Progênies de irmãos germanos e $S_{1}$}

As expressões das estimativas da variância genética foram deduzidas da Tabela 7 e apresentam-se a seguir: 


$$
\hat{\sigma}_{\text {ig }}^{2}=\frac{\mathrm{QM}_{3}-\mathrm{QM}_{4}}{\mathrm{LM}} \text {, em que } \hat{\sigma}_{\mathrm{ig}}^{2} \text { é a estimativa da variância genética entre }
$$

progênies de irmãos germanos;

$$
\hat{\sigma}_{\mathrm{S} 1}^{2}=\frac{\mathrm{QM}_{3}-\mathrm{QM}_{4}}{\mathrm{LM}} \text {, em que } \hat{\sigma}_{\mathrm{S} 1}^{2} \text { é estimativa da variância genética entre }
$$

progênies $\mathrm{S}_{1}$.

Em nível intrapopulacional, a $\sigma_{\text {ig }}^{2}$ contém $\frac{1}{2} \sigma_{\mathrm{A}}^{2}+\frac{1}{4} \sigma_{\mathrm{D}}^{2}$, ao passo que a $\sigma_{\mathrm{S} 1}^{2}$ contém $\sigma_{\mathrm{A}}^{2}+\frac{1}{4} \sigma_{\mathrm{D}}^{2}+\mathrm{D}_{1}+\frac{1}{8} \mathrm{D}_{2}$, em que:

$\mathrm{D}_{1}$ : covariância entre os efeitos aditivos e dominantes nos homozigotos;

$\mathrm{D}_{2}$ : variância dos efeitos de dominância nos homozigotos.

Com progênies de irmãos germanos e $\mathrm{S}_{1 \text { 's }}$ é impossível isolar os componentes da variância genética, a não ser que algumas hipóteses sejam definidas previamente. $\mathrm{O}$ que se expõe a seguir foi baseado na metodologia adotada por Nass (1992).

$\mathrm{Na}$ estimação da variância genética aditiva, para as variáveis com baixa dominância (CE, DE, PR, AP e AE), assumiu-se que $\sigma_{\mathrm{D}}^{2}=0$. Assim, para as progênies de irmãos germanos tem-se $\sigma_{\mathrm{A}}^{2}=2 \sigma_{\mathrm{IG}}^{2}$; enquanto que para as progênies $\mathrm{S}_{1}$ tem-se $\sigma_{\mathrm{A}}^{2}=\sigma_{\mathrm{S}_{1}}^{2}$.

Para a variável $\mathrm{PE}$, em que os efeitos de dominância gênica são importantes, assumiu-se que $\sigma_{\mathrm{A}}^{2}=\sigma_{\mathrm{D}}^{2}$. Logo, para as progênies de irmãos germanos, $\hat{\sigma}_{\mathrm{A}}^{2}=\frac{4}{3} \hat{\sigma}_{\mathrm{ig}}^{2}$, e para progênies $\mathrm{S}_{1^{\prime} \mathrm{s}}, \hat{\sigma}_{\mathrm{A}}^{2}=\frac{4}{5} \hat{\sigma}_{\mathrm{S} 1}^{2}-\frac{4}{5} \hat{\mathrm{D}}$, sendo $\mathrm{D}=\mathrm{D}_{1}+\frac{1}{8} \mathrm{D}_{2} \cdot \mathrm{A}$ expressão que estima $\mathrm{D}$ pode ser encontrada efetuando-se algumas operações algébricas naquela que estima a variância genética aditiva com progênies $S_{1^{\prime} \mathrm{s}}$ e, dado que $\hat{\sigma}_{i \mathrm{~g}}^{2}=\frac{3}{4} \hat{\sigma}_{\mathrm{A}}^{2}$, 
obtém-se o estimador de D em termos das variâncias genéticas com progênies de irmãos germanos e $\mathrm{S}_{1^{\prime} \mathrm{s} .}: \hat{\mathrm{D}}=\hat{\sigma}_{\mathrm{S} 1}^{2}-\frac{5}{3} \hat{\sigma}_{\text {ig }}^{2}$.

\subsubsection{Depressão por endogamia (I)}

Este parâmetro foi estimado para as subpopulações de tamanho reduzido per se, bem como para as subpopulações agrupadas em função do tamanho efetivo e seleção, em \%, de acordo com a seguinte expressão:

$$
\mathrm{I} \%=\left(\frac{\mathrm{M}_{0}-\mathrm{M}_{\mathrm{Sk}}}{\mathrm{M}_{0}}\right) \times 100, \text { em que: }
$$

$\mathrm{M}_{0}$ : média da população original;

$\mathrm{M}_{\mathrm{Sk}}$ : média da k-ésima subpopulação ou grupo de subpopulação.

Uma vez que a população original não foi incluída como um tratamento no experimento $7, \mathrm{M}_{0}$ foi estimado pelo método dos mínimos quadrados, resolvendo-se a seguinte equação matricial:

$$
\begin{aligned}
& \begin{array}{lll}
\hat{y} & \mathrm{\beta}
\end{array} \\
& \left(\begin{array}{l}
m_{1} \\
m_{2} \\
m_{3}
\end{array}\right)=\left(\begin{array}{ll}
1 & 1 / 2 \\
1 & 1 / 4 \\
1 & 1 / 6
\end{array}\right)\left(\begin{array}{l}
M_{0} \\
d
\end{array}\right) \text {, em que: }
\end{aligned}
$$

$\mathrm{m}_{1}$ : é a média das subpopulações de tamanho efetivo 1;

$\mathrm{m}_{2}$ : é a média das subpopulações de tamanho efetivo 2;

$\mathrm{m}_{3}$ : é a média das subpopulações de tamanho efetivo 3;

d : é a contribuição dos locos heterozigotos.

A segunda coluna da matriz $x$ refere-se aos coeficientes de endogamia das subpopulações de tamanho efetivo 1, 2 e 3, respectivamente. 


\section{RESULTADOS E DISCUSSÃO}

\subsection{Processo dispersivo}

Há duas maneiras distintas de tratar o processo dispersivo e de deduzir suas conseqüências: uma é considerá-lo como processo amostral e descrevê-lo em termos de variância de amostragem. A outra é considerá-lo como um processo de endogamia, e descrevê-lo em termos de mudanças genotípicas, resultantes de acasalamento entre indivíduos aparentados. Desses, a primeira abordagem é provavelmente a mais simples para uma descrição de como opera o processo, mas a segunda proporciona maneira mais conveniente de expressar suas conseqüências (Falconer \& Mackay, 1996).

No presente estudo as conseqüências do processo dispersivo foram aferidas basicamente pelo desempenho per se das subpopulações, o qual é um indicativo de divergência alélica, depressão por endogamia e pela variabilidade supostamente existente entre essas subpopulações, a qual também pode ser um indicativo de diferenciação genética entre as mesmas devido ao efeito da deriva.

Outro aspecto relevante que deve ser ressaltado é que em estudos do processo dispersivo ou deriva genética a seleção normalmente é excluída. Há casos porém em que a deriva é investigada no transcorrer de um programa de seleção recorrente. Neste trabalho, a inclusão da seleção teve por finalidade: mensurar o efeito da mesma, verificando o seu efeito entre e dentro dos diferentes níveis de tamanhos efetivos $\left(\mathrm{N}_{\mathrm{s}}\right)$ das subpopulações e, principalmente, se a seleção, da forma como realizada (seleção divergente), poderia gerar divergência genética suficiente para expressão da heterose entre cruzamentos das subpopulações. 


\subsubsection{Análise da variância}

Os resultados da análise conjunta da variância do experimento 7 são apresentados na Tabela 12 para as variáveis PE, CE, DE e PR e Tabela 13 para os caracteres AP e AE. A precisão experimental pode ser considerada satisfatória para todas as variáveis. Os maiores coeficientes de variação foram encontrados para as variáveis PE e PR: 16,6 e 15,5\%, respectivamente, inserindo-se na classificação média de acordo com Scapim et al. (1995).

Para todas os caracteres o teste $\mathrm{F}$ mostrou diferenças estatísticas significativas $(\mathrm{p} \leq 0,05)$ para as médias de subpopulações, o que já era esperado devido à ação da deriva combinada com a da seleção. A decomposição do efeito de subpopulações permitiu aferir a variabilidade dentro dos níveis de tamanho efetivo e seleção. Também nesse caso observou-se pelo teste $\mathrm{F}$ diferenças estatísticas significativas para a maioria das subpopulações inseridas dentro das seis combinações possíveis. Obviamente, as diferenças detectadas entre as subpopulações, dentro de uma determinada combinação do efeito tamanho efetivo x seleção, devem ser creditadas em parte à deriva.

Em termos teóricos, seria esperado que as variâncias apresentassem um padrão de crescimento inversamente proporcional ao tamanho efetivo. Em geral, isto não foi observado para nenhum dos caracteres, que apresentaram um comportamento um tanto quanto errático dessas variâncias. Entretanto, verificou-se que $\mathrm{CE}$ e $\mathrm{AP}$ com seleção negativa, e AP com seleção positiva apresentaram um comportamento de acordo com as expectativas teóricas. Esse comportamento imprevisível das variâncias pode estar associado ao pequeno tamanho amostral.

Com relação ao tamanho efetivo, foram observadas diferenças estatísticas significativas para PE, CE, PR e AP, o que demonstra a importância de se trabalhar com tamanhos adequados de populações em programas de seleção, visto que caracteres importantes para a produção podem ser afetados quando o tamanho efetivo é muito reduzido. Os caracteres $\mathrm{DE}$ e $\mathrm{AE}$, por sua vez, não apresentaram diferenças pelo teste empregado. 
Quanto ao efeito da seleção, este não foi eficaz para AP e AE. Para os outros caracteres foram observadas diferenças estatísticas significativas. Ressalta-se que o critério de seleção das subpopulações restringiu-se ao caráter PE. O fato de a seleção ter sido eficiente para os caracteres $\mathrm{CE}, \mathrm{DE}$ e $\mathrm{PR}$, provavelmente deve-se à existência de uma maior correlação genética dos mesmos com o PE.

O efeito da interação tamanho efetivo x seleção foi significativo para os caracteres PE e PR. Não se verificaram diferenças estatísticas significativas para as interações entre os efeitos tamanho efetivo e seleção com locais, mas o efeito significativo da interação de subpopulações com locais no tocante aos caracteres PE, $\mathrm{CE}$, AP e AE demonstra que houve um comportamento diferenciado das mesmas em termos de resposta às variações ambientais. Quanto ao efeito de locais, mesmo em se tratando de ambientes bem contrastantes, não se verificaram diferenças para PE e DE.

As análises da variância para o Local 1 (ESALQ/Genética) e Local 2 (Anhembi), são apresentadas nas Tabelas 14 e 15. A precisão experimental nos dois locais, para todas os caracteres, é aceitável, apresentando valores bem próximos àqueles já descritos nas Tabelas 12 e 13. Os maiores valores novamente foram observados para PE e PR, mas mesmo estes não podem ser considerados como excessivos, segundo resultados da literatura.

Quanto à significância estatística dos efeitos do modelo, em ambos os locais, observou-se que, de uma maneira geral, há uma grande consistência com os resultados já comentados na análise conjunta da variância.

Detectou-se diferença estatística significativa para o efeito de subpopulações, pelo teste F, para todos os caracteres, tanto no Local 1 quanto no Local 2. A decomposição desse efeito dentro das combinações de níveis de tamanho efetivo e seleção também revela uma grande variabilidade entre as subpopulações. Entretanto, em alguns casos, a resposta das subpopulações foram diferentes de um local para o outro, o que já era esperado, tendo em vista a detecção de significância estatística para o efeito de Local x subpopulação na análise conjunta. O exemplo mais apropriado para essa diferenciação na resposta entre locais são as subpopulações de tamanho efetivo 3 , com seleção negativa $\left(\mathrm{N}_{3}^{-}\right)$. Constatou-se que no Local 1 (Tabelas 14 e 16), estas 
apresentaram diferença estatística significativa somente para as variáveis $D E$ e PR, enquanto que no Local 2 (Tabelas 15 e 16), com exceção de DE, significância estatística foi observada em todas as outras variáveis.

Os dados concernentes ao efeito do tamanho efetivo demonstraram que, no Local 1, diferenças estatísticas significativas foram detectadas para todos os caracteres, fora $\mathrm{AE}$, ao passo que, no Local 2, apenas PE, CE e AP diferiram estatisticamente. Ressalta-se que as diferenças observadas com relação ao tamanho efetivo podem ser atribuídas em parte ao efeito da deriva genética, uma vez que, conforme a teoria, a redução drástica do tamanho da população pode levar à perda de alelos, favoráveis ou desfavoráveis, de maneira aleatória (Falconer \& Mackay, 1996).

No que concerne ao efeito da seleção, verificou-se que no Local 1 somente AP e AE não apresentaram significância estatística; este mesmo resultado foi encontrado no Local 2 e, volta-se a repetir, também na análise conjunta, em que se agregou a provável causa.

$\mathrm{Na}$ análise da variância por local a única interação existente é a do efeito tamanho efetivo com o de seleção. No Local 1, a interação foi significativa somente para PR, mas, no Local 2, além desta, a interação para PE também foi significativa, o que fez com que na análise conjunta esta interação também mostrasse significância.

\subsubsection{Valores médios em função do tamanho efetivo e seleção}

As Tabelas 17 a 22 permitem que se faça uma avaliação do efeito da redução do tamanho efetivo e, por conseqüência, da taxa de endogamia, nos caracteres mensurados, bem como uma avaliação desse efeito com seleção positiva e negativa. Os tamanhos efetivos 1, 2 e 3 das subpopulações correspondem a uma taxa média de endogamia de $50 \%, 25 \%$ e 17\%, conforme expressão dada por Falconer \& Mackay (1997): $V F=1 / 2 N$. A abordagem será realizada apenas com os dados médios dos dois locais.

Na Tabela 17 são apresentados os valores médios do caráter PE de acordo com a combinação fatorial de níveis dos tratamentos tamanho efetivo e seleção. 
Ressalta-se que os dados referentes a esse caráter revestem-se como um dos mais importantes deste trabalho, uma vez que a seleção foi efetuada em função unicamente dessa variável. A comparação entre as médias das subpopulações de $\mathrm{N}_{3}$ e $\mathrm{N}_{1}$, ou seja, com taxas de endogamia de $17 \%$ e $50 \%$, revelou que houve um decréscimo de aproximadamente $31 \%$. Entre o $\mathrm{N}_{3}$ e $\mathrm{N}_{2}$, e $\mathrm{N}_{2}$ e $\mathrm{N}_{1}$, os decréscimos foram $12 \%$ e $22 \%$, respectivamente. Estes resultados estão de acordo com o que se esperava, visto que a variável PE, dentre aquelas de importância para o milho, é umas das mais afetadas negativamente com o aumento da taxa de homozigose. Como a hipótese subjacente é que os valores médios decresçam com o aumento da endogamia, o cálculo desses porcentuais entre médias de $\mathrm{N}_{\mathrm{s}}$ foi sempre realizado comparando-se o menor $\mathrm{N}$ com o maior. Esta observação é válida para todos os outros caracteres.

A comparação das médias, efetuada através do teste de Tukey, demonstrou que o $\mathrm{N}_{3}$ e $\mathrm{N}_{2}$ não apresentaram diferença estatística significativa, mas diferiram quando comparados com o $\mathrm{N}_{1}$.

A tendência das médias dos $\mathrm{N}_{\text {'s, }}$, dentro dos níveis de seleção, positiva ou negativa, apresenta o mesmo padrão de comportamento das médias marginais, ou seja, há uma tendência de decréscimo de $\mathrm{N}_{\mathrm{s}}$ maiores para os menores. Esta tendência é bem mais acentuada quando se observa o nível de seleção negativa: em termos porcentuais, o decréscimo entre o $\mathrm{N}_{3}$ e $\mathrm{N}_{2}, \quad \mathrm{~N}_{3}$ e $\mathrm{N}_{1}$ e $\mathrm{N}_{2}$ e $\mathrm{N}_{1}$ foi de $19 \%, 47 \%$ e $35 \%$, respectivamente, ao passo que no nível com seleção positiva, na mesma ordem citada, o decréscimo foi de 5\%,17\% e 12\%. Verificou-se, portanto, que a seleção positiva não foi suficiente para compensar os efeitos depressivos da endogamia.

A diferença entre a seleção positiva e negativa entre os diferentes $\mathrm{N}_{\mathrm{s}}$, também atende às expectativas teóricas, porquanto a endogamia tende a aumentar a efetividade da seleção (Hallauer \& Miranda Filho, 1995).

Quanto ao caráter CE, cujos dados apresentam-se na Tabela 18, constatou-se que as médias referentes aos $\mathrm{N}_{\text {s }}$ seguem um padrão de decréscimo semelhante ao já descrito para PE, mas em intensidade bem menor. Expressando-o em termos porcentuais, obteve-se $1 \%, 9 \%$ e $1 \%$ para as comparações entre o $\mathrm{N}_{3}$ e $\mathrm{N}_{2}, \mathrm{~N}_{3}$ e $\mathrm{N}_{1}$, e $\mathrm{N}_{2}$ e $\mathrm{N}_{1}$, respectivamente. 
Todavia, os valores médios dos $\mathrm{N}_{\mathrm{s}}$, dentro do nível de seleção positiva, já não se apresentam de acordo com o padrão até agora observado: verificou-se que houve um leve aumento, de aproximadamente $2 \%$, do $\mathrm{N}_{3}$ para o $\mathrm{N}_{2}$. Isto significa que, nesse caso, a seleção positiva compensou o efeito depressivo da endogamia. Com seleção negativa, manteve-se o padrão de decrescimento do $\mathrm{N}_{3}$ ao $\mathrm{N}_{1}$. As diferenças entre seleção positiva e negativa estão dentro das expectativas teóricas como já mencionado.

Vale ressaltar que CE, bem como DE, PR, AP e AE, foram selecionadas indiretamente através de PE. Logo, o fato de apresentarem um comportamento semelhante ou não ao $\mathrm{PE}$, no que concerne especificamente às diferenças entre seleção positiva e negativa, relaciona-se diretamente à existência de correlações genéticas maiores ou menores entre aquelas variáveis e PE.

Os dados referentes ao caráter DE são apresentados na Tabela 19. Verificou-se que praticamente não houve diferença entre as médias dos $\mathrm{N}_{\mathrm{s}}$, em valores absolutos, apesar de permanecer uma leve tendência de decréscimo, em torno de 4\%, do $\mathrm{N}_{3}$ e $\mathrm{N}_{2}$ em relação ao $\mathrm{N}_{1}$, mas não o suficiente para acusar significância estatística pelo teste de Tukey. Resultados experimentais já demonstraram que a variável DE não decresce tão rapidamente com o incremento da homozigosidade, como o caráter PE, por exemplo, o que pode ser uma explicação para os resultados aqui obtidos.

Observando-se os $\mathrm{N}_{\text {s }}$ dentro dos níveis de seleção, verificou-se que com seleção positiva os valores são muito próximos, uma vez que a maior diferença entre eles, $\mathrm{N}_{3} \operatorname{com} \mathrm{N}_{1}$, não superou os $3 \%$. Com seleção negativa, a média do $\mathrm{N}_{2}$ foi um pouco superior ao $\mathrm{N}_{3}$, mas houve um decréscimo em torno de 5\% quando se compara a média do $\mathrm{N}_{1}$ com o $\mathrm{N}_{3}$.

A diferença entre seleção positiva e negativa foi maior com subpopulações $\mathrm{N}_{1}$; uma explicação para a maior efetividade da seleção em subpopulações com $\mathrm{N}_{1}$, é que ao se realizar a seleção para PE antes da geração das subpopulações, as progênies $\mathrm{S}_{1}$, evidentemente, já eram endogâmicas, mas as outras, não. Logo, uma maior eficiência da seleção já era esperada nessa fase, refletindo-se também nas subpopulações. 
Os resultados referentes ao caráter PR são apresentados na Tabela 20 . Constatou-se que as médias dos $\mathrm{N}_{\mathrm{s}}$ apresentaram um padrão decrescente do maior $\mathrm{N}$ para o menor, ou, em termos de endogamia, das subpopulações menos endogâmicas para as mais endogâmicas, como era de se esperar. Vale ressaltar que o decréscimo do $\mathrm{N}_{3}$ para o $\mathrm{N}_{2}$ foi mais acentuado do que do $\mathrm{N}_{2}$ para o $\mathrm{N}_{1}: 10 \%$ e $2 \%$, respectivamente. Isto ocorreu porque, com seleção positiva, a média das subpopulações com $\mathrm{N}_{1}$ foi superior em aproximadamente $7 \%$ e $3 \%$ à média das subpopulações com $\mathrm{N}_{2}$ e $\mathrm{N}_{3}$, respectivamente, o que contribuiu para arrefecer a tendência de decréscimo.

Em uma primeira análise, pode parecer que esses dados sejam contraditórios, mas é possível que na seleção inicial efetuada com progênies $\mathrm{S}_{1}$ para $\mathrm{PE}$, um dos componentes da produção que mais tenha contribuído seja justamente a prolificidade.

A diferença entre a seleção positiva e negativa coaduna-se com o que preconiza a teoria, qual seja, de que a seleção apresenta maior efetividade com materiais mais endogâmicos. Ademais, vale destacar que a seleção foi ineficaz com subpopulações apresentando a menor taxa de endogamia (17\%).

Os valores médios do caráter AP são apresentados na Tabela 21. Com relação às médias dos $\mathrm{N}_{\text {s }}$, constatou-se um padrão decrescente das mesmas à medida que havia um aumento da taxa de endogamia, fato este que também se repetiu com os caracteres PE, CE e PR. O decréscimo observado entre o $\mathrm{N}_{2}$ e $\mathrm{N}_{3}$ e $\mathrm{N}_{1}$ e $\mathrm{N}_{2}$, com seleção positiva, foi de aproximadamente $2 \%$ em ambas as comparações e, com seleção negativa, $3 \%$ e $5 \%$, respectivamente. Em vista desses resultados, pode-se dizer que este caráter tende a decrescer mais lentamente à medida que ocorre um incremento da endogamia. Vale assinalar também que nos níveis 2 e 3 do fator tamanho efetivo, o efeito da seleção, mensurado pela diferença entre a seleção positiva e negativa, foi praticamente nulo; no nível 1, entretanto, nota-se um efeito mais acentuado da seleção, como também já vem ocorrendo para os demais caracteres.

$\mathrm{Na}$ Tabela 22 apresentam-se os valores médios referentes ao caráter AE. Houve um decréscimo de aproximadamente $6 \%$ entre os níveis 2 e 3 de $\mathrm{N}$, mas as médias dos níveis 1 e 2 não diferiram. Este resultado foi possível porque, com seleção 
positiva, os valores médios com $\mathrm{N}_{1}$ e $\mathrm{N}_{2}$ foram praticamente iguais e mesmo com seleção negativa o decréscimo foi de somente 1\%. Hallauer \& Miranda Filho (1995) demonstraram com base numa ampla revisão que, excetuando-se rendimento, alguns caracteres, dentre os quais AP e AE, decrescem mais fortemente nas primeiras gerações de endogamia e, nas seguintes, tendem a diminuir a tendência de queda; em alguns trabalhos, até um leve crescimento do valor médio em gerações mais avançadas foi relatado. Uma das explicações possível para este fato é a de que o decréscimo do valor fenotípico médio de alguns caracteres nem sempre ocorre de forma linear em função do incremento da endogamia.

Deve-se ressaltar também que não houve efeito da seleção nas subpopulações com $\mathrm{N}_{1}$; aliás, neste nível de $\mathrm{N}$, tem-se o único caso em que se observou até uma leve superioridade do valor médio com seleção negativa, entre todos os caracteres avaliados.

A diferença entre a seleção positiva e negativa, nos três níveis de $\mathrm{N}$, demonstrou a maior eficiência da seleção com subpopulações mais endogâmicas, o que também já havia ocorrido com os demais caracteres.

Os valores médios marginais da seleção demonstram, para todos os caracteres, superioridade da seleção positiva em relação à negativa, como era de se esperar, principalmente em se tratando do caráter PE. Estas médias também apresentaram significância estatística pelo teste de Tukey $(p \leq 0,05)$, com exceção dos caracteres AP e AE.

As Figuras 2 a 7, para os caracteres PE, CE, DE, PR, AP e AE, respectivamente, corroboram o que já foi discutido anteriormente para o efeito da seleção em subpopulações com diferentes tamanhos efetivos (Tabelas 17 a 22). Quanto à dispersão desses valores, esperava-se que subpopulações com maior taxa de endogamia mostrassem uma maior dispersão, como de fato ocorreu com os caracteres PE e PR. Para os demais, isto não se confirmou totalmente. 


\subsubsection{Valores médios das subpopulações, depressão por endogamia e desempenho em relação à testemunha}

Para todos os caracteres avaliados, apresentam-se nas Tabelas 23 a 26, por local, os valores médios com base na parcela, depressão por endogamia e uma comparação das médias das subpopulações com a testemunha, o híbrido simples A 5055. Nas Tabelas 27 e 28, estas mesmas estimativas são apresentadas tomando-se por base a média dos dois locais.

Convém lembrar que a população original, composto GN-04, não foi incluída no mesmo experimento em que se avaliaram as subpopulações de tamanho reduzido. Por conseguinte, a média da população original $\left(m_{0}\right)$ teve que ser estimada conforme já exposto anteriormente.

No Local 1, as médias estimadas foram 2,89 $\left(\mathrm{kg} / 4 \mathrm{~m}^{2}\right), 15,79$ (cm/esp.), 4,14 (cm/esp.), 1,59 (esp./pl.), 224,96 (cm/pl.) e 129,05 (cm/pl.) para PE, CE, DE, PR, AP e AE, respectivamente. No Local 2, na mesma ordem citada e respectivas unidades, as estimativas encontradas foram: 2,69, 16,37, 4,16, 1,30, 207,19 e 99,05. Para os dois locais, ainda nessa mesma ordem, as estimativas encontradas foram: 2,79, 16,07, 4,15, 1,45, 216,08 e 114,05. Abstraindo-se dos experimentos de 1 a 4 (cruzamentos em cadeia) o efeito ambiental de anos, fornecem-se os valores médios aí encontrados, na mesma ordem das estimativas anteriores, para que se possa ter uma base de comparação, uma vez que estes também estimam $\mathrm{m}_{0}: 2,72,16,66,4,44,1,25,220,81$ e 127,09.

Em geral, nos locais 1 e 2, verificou-se uma considerável variabilidade, para todos os caracteres, quanto ao desempenho per se das subpopulações, o que já havia sido demonstrado pela significância estatística do teste F na análise da variância, quando se efetuou a decomposição do efeito de subpopulações dentro dos níveis de $\mathrm{Ne}$ seleção (Tabelas 14, 15 e 16).

Em virtude da grande variabilidade das estimativas da depressão por endogamia entre subpopulações, torna-se menos visível um padrão de comportamento dessas estimativas em função do tamanho efetivo. Contudo, pode-se observar que houve tendência de decréscimo à medida que os $\mathrm{N}_{\mathrm{s}}$ aumentam, principalmente para $\mathrm{PE}$, tanto 
no Local 1 quanto no Local 2. Para os outros caracteres essa tendência fica mais evidente apenas quando se comparam as subpopulações com $\mathrm{N}_{1}$ e $\mathrm{N}_{3}$.

Dentro de um mesmo nível de endogamia e seleção, constatou-se uma variação considerável na depressão apresentada pelas subpopulações, aparentemente sem nenhum padrão, o que, em parte, pode ser atribuído às mudanças das freqüências gênicas causadas pela deriva (Falconer \& Mackay, 1995). Isto explica também os valores negativos observados em algumas subpopulações, os quais, neste caso, correspondem àquelas subpopulações que apresentaram um valor médio superior à média estimada da população original.

A comparação do valor médio com a testemunha demonstra que esta foi inferior à maioria das subpopulações apenas quanto aos caracteres PR, AP e AE, como já era previsto, uma vez que o híbrido utilizado, A 5055, não é prolífico e apresenta um porte relativamente baixo.

O desempenho das subpopulações per se, a depressão por endogamia e o desempenho em relação à testemunha, com base na média dos dois locais, constantes das Tabelas 27 e 28, não apresentam aspectos relevantes que possam vir a alterar o que já foi constatado por local, portanto, comentários adicionais não serão efetuados.

Estas mesmas estimativas são apresentadas nas Tabelas 29 a 32, por local. A diferença é que, em vez de dados médios por subpopulação, neste caso apresentam-se as médias de cinco subpopulações hierarquizadas segundo os níveis dos fatores tamanho efetivo e seleção. A apresentação dos dados dessa maneira é bem mais apropriada, pois facilita o discernimento de tendências, além do que a depressão por endogamia fica bem melhor estimada.

Quanto ao caráter PE, os valores médios do Local 1 mostraram-se ligeiramente superiores aos do Local 2, com exceção das subpopulações com $\mathrm{N}_{1}$ e seleção positiva. A divergência entre a seleção positiva e negativa é bem mais acentuada do que nos outros caracteres, como era de se esperar, e tende a aumentar à medida que também aumenta a endogamia das subpopulações, o que está de acordo com a teoria da seleção com populações endogâmicas. 
A depressão por endogamia, em ambos os locais, exibiu um padrão consistente de decréscimo enquanto diminui a taxa de endogamia das subpopulações. Admitindo-se que a seleção não interage com os níveis de $\mathrm{N}$, pode-se tomar a média dos valores encontrados com seleção negativa e positiva e compará-la com estimativas encontradas na literatura, cujas populações apresentem endogamia equivalente. Para as subpopulações com $\mathrm{N}_{1}$, a estimativa média da depressão foi de $41 \%$ no Local 1 e $38 \%$ no Local 2. Estes valores estão coerentes com os encontrados por Vianna et al. (1982), Lima et al. (1984) e Gama et al. (1985). Para as subpopulações com $\mathrm{N}_{2}$, estas estimativas foram $22 \%$ e $23 \%$, e com $\mathrm{N}_{3}, 13 \%$ e $11 \%$, nos locais 1 e 2 , respectivamente. Estes valores são bastante superiores aos relatados por Corrales Blandon (1996) e Astete Maldonado (2001), que analisaram subpopulações, sem seleção, com taxa de endogamia de $19 \%$ e $23 \%$, respectivamente.

Observou-se também que a seleção positiva atenuou os efeitos da depressão, quando se comparou com os níveis alcançados com seleção negativa. Em relação aos outros caracteres, PE apresentou valores bem mais elevados de depressão, o que evidencia a importância de genes com efeito dominante no controle do caráter.

A testemunha, em ambos os locais, superou as subpopulações, sendo que o melhor desempenho destas foi verificado com $\mathrm{N}_{3}$ e seleção positiva no Local 2. Esta relação também expressou nitidamente os efeitos da depressão por endogamia, como pôde ser observado pela tendência de decréscimo do $\mathrm{N}_{3}$ ao $\mathrm{N}_{1}$, tanto com seleção positiva quanto com negativa.

Os outros caracteres não apresentaram, como se observou para PE, uma clara distinção entre os níveis de seleção e tamanho efetivo. No tocante ao caráter CE, verificou-se que os valores médios são muito próximos, em ambos os locais. O valor médio mais discrepante foi observado nas subpopulações com $\mathrm{N}_{1}$ e seleção negativa. Nos dois locais, subpopulações com $\mathrm{N}_{2}$ e seleção positiva foram, em média, ligeiramente superiores àquelas com $\mathrm{N}_{3}$. Por conseguinte, as estimativas da depressão por endogamia refletiram esse comportamento dos valores médios. Com seleção negativa, a tendência de aumento dessas estimativas à medida que aumenta a taxa de endogamia das subpopulações ficou mais evidente. Já com seleção positiva, verificou-se que, pelo 
menos em parte, esta compensou o efeito da endogamia, visto que subpopulações com $\mathrm{N}_{2}$ foram menos sensíveis a este efeito do que as subpopulações com $\mathrm{N}_{3}$. Hallauer \& Miranda Filho (1995) relataram para populações com endogamia de 50\% uma estimativa de depressão de $8 \%$, valor este bem próximo ao encontrado neste trabalho, no mesmo nível de endogamia e seleção positiva. Corrales Blandon (1996) e Astete Maldonado (2001), reportam estimativas no valor de $3,81 \%$ e $4,30 \%$, as quais estão conformes com as estimativas encontradas para subpopulações com $\mathrm{N}_{3}$ e seleção positiva. Os valores relativamente baixos das estimativas de depressão por endogamia para esse caráter, provavelmente refletem uma contribuição mais importante de genes com efeito aditivo.

Com relação ao caráter $\mathrm{DE}$, algumas similaridades podem ser encontradas com o que já foi discutido para CE. Os valores médios das subpopulações com $\mathrm{N}_{\mathrm{s}}$ distintos, em ambos os locais, também são muito próximos, tanto com seleção positiva quanto negativa, principalmente em se tratando das subpopulações com $\mathrm{N}_{1}$ e $\mathrm{N}_{2}$. A comparação com a testemunha também reflete o comportamento similar dessas médias em ambos os locais.

Pode-se dizer também que a seleção positiva atenuou o efeito da endogamia, notadamente com as subpopulações de $\mathrm{N}_{1}$ e $\mathrm{N}_{2}$. Ainda neste nível de seleção, o efeito depressivo da endogamia é mais evidente apenas nas subpopulações com $\mathrm{N}_{1}$. Com seleção negativa, há uma inversão dos valores esperados entre as subpopulações de $\mathrm{N}_{3}$ e $\mathrm{N}_{2}$, com as últimas apresentando estimativas inferiores. No Local 2, as subpopulações com $\mathrm{N}_{3}$ e seleção positiva não foram afetadas pela endogamia.

Hallauer \& Miranda Filho (1995), com base em nove estimativas reportadas na literatura, estimaram a mudança no valor médio fenotípico do caráter $\mathrm{DE}$, devido ao incremento de $1 \%$ no coeficiente de endogamia, em -0,0926 mm. Astete Maldonado (2001), com base apenas em um resultado, estimou-a em -0,04 mm. Covertendo-se estes índices aos níveis de endogamia das subpopulações analisadas neste trabalho, e considerando apenas a seleção positiva, constatou-se que, no Local 1, há uma maior coerência com as estimativas apresentadas pelo último autor, mas bem inferiores às dos primeiros. No Local 2 , contudo, não se verificou depressão no nível de $17 \%$ de 
endogamia das subpopulações, mas, em nível de 50\%, foi 2 e 5 vezes superior à estimada por Hallauer \& Miranda Filho (1995) e Astete Maldonado (2001), respectivamente. Em nível de 25\%, há mais coerência com as estimativas apresentadas pelo último autor.

Em relação ao caráter PR, evidenciou-se claramente o efeito de locais, com superioridade dos valores médios observados no Local 1. Em termos de tendência, com seleção positiva, é possível observar em ambos os locais um pequeno decréscimo entre as médias das subpopulações com $\mathrm{N}_{3}$ e $\mathrm{N}_{2}$, mas a média correspondente ao $\mathrm{N}_{1}$ é superior às demais. Por causa disso, verificou-se um crescimento não muito acentuado da depressão por endogamia somente entre as subpopulações com $\mathrm{N}_{3}$ e $\mathrm{N}_{2}$. Com seleção negativa, houve um crescimento consistente da depressão à medida que se aumentou a endogamia das subpopulações. Quanto ao desempenho das subpopulações em relação à testemunha, demonstrou-se que, em geral, esta foi menos prolífica.

Concernente ao caráter AP, em ambos os locais, verificou-se que as subpopulações mais endogâmicas apresentaram uma tendência de redução da média, a qual foi um pouco mais acentuada com seleção negativa. Ressalta-se que, no Local 1, com subpopulações de $\mathrm{N}_{3}$, e no Local 2, com subpopulações de $\mathrm{N}_{2}$, a seleção não foi eficiente; aliás, as médias com seleção negativa foram até ligeiramente superiores às observadas com seleção positiva, o que demonstra que nesses dois casos não houve correlação entre AP e PE. Stojsin \& Kannenberg (1994) também não encontraram nenhuma tendência geral de resposta à seleção, ao selecionar indiretamente AP através de um índice que incluía produção de grãos.

As estimativas da depressão por endogamia foram um pouco maiores no Local 1; a maior diferença foi observada com subpopulações de $\mathrm{N}_{1}$ e seleção negativa. Astete Maldonado (2001), analisando subpopulações com 23\% de endogamia, estimou em 4,6\% a depressão para AP, a qual está bem próxima da encontrada nesse estudo, para subpopulações com $25 \%$ de endogamia. Refletindo a tendência já verificada para a média, em ambos os locais, constatou-se um maior efeito da depressão nas subpopulações mais endogâmicas. 
Quanto à comparação com a testemunha, verificou-se superioridade das subpopulações em todos os níveis de $\mathrm{N}$ e seleção. É possível constatar também, através desta relação, a tendência de decréscimo do caráter em questão com o aumento dos níveis de endogamia.

No que concerne ao caráter $\mathrm{AE}$, as médias obtidas tanto no Local 1 quanto no Local 2 não apresentaram uma tendência geral que pudesse ser estabelecida em função dos $\mathrm{N}_{\mathrm{s}}$, quando se analisam os valores obtidos com seleção positiva no Local 1 e positiva ou negativa no Local 2.

Observou-se que a média das subpopulações com endogamia de $50 \%$ e seleção positiva, praticamente não diferiu em relação àquelas com endogamia de $25 \%$, em ambos os locais. Com seleção negativa, a diferença observada entre a média dessas subpopulações também foi insignificante. Entretanto, resultados como estes, sem o fator seleção envolvido, não são incomuns na literatura, como demonstraram Hallauer \& Miranda Filho (1995). A seleção, por sua vez, foi ineficaz com subpopulações de $\mathrm{N}_{3}$, uma vez que a média com seleção positiva foi praticamente idêntica à obtida com seleção negativa, inclusive com uma leve superioridade desta última.

As estimativas da depressão por endogamia, nos dois locais, com seleção positiva, foram inferiores à obtida por Corrales Blandon (1996) e Astete Maldonado (2001), sem seleção, que foi de $12,2 \%$ e 8,5\%, respectivamente, respeitando-se, é claro, os níveis de endogamia em que as estimativas são comparáveis. Não se verificou, em termos médios, depressão em subpopulações com $\mathrm{N}_{3}$ e seleção negativa, resultado este que não tem uma explicação tão evidente. Mesmo entre o $\mathrm{N}_{1}$ e $\mathrm{N}_{2}$, ainda com seleção negativa, o efeito da depressão foi pouco expressivo, principalmente no Local 2.

A comparação com a testemunha revelou uma superioridade das subpopulações em todos os níveis de $\mathrm{N}$ e seleção, nos dois locais. A falta de um padrão consistente na variação das médias também fica bem nítida nesta relação.

Nas Tabelas 33 e 34 apresentam-se as mesmas estimativas para todos os caracteres, com base agora na média dos dois locais. O foco principal na discussão dos resultados constantes dessas tabelas recai sobre a depressão por endogamia, uma vez que as estimativas das médias das subpopulações coincidem com o que já foi exposto e 
discutido nas Tabelas 17 a 22, diferindo apenas na forma de apresentá-las. A razão para inseri-las novamente nas Tabelas 33 e 34 visa o estabelecimento de uma conexão entre os valores absolutos das subpopulações e o efeito da depressão por endogamia correspondente, expresso em porcentagem.

Quanto ao caráter $\mathrm{PE}$, as estimativas da depressão por endogamia apresentaram a mesma tendência já identificada por local, ou seja, subpopulações com taxas de endogamia mais elevadas, associadas a estimativas mais altas de depressão, notadamente naquelas com $\mathrm{N}_{1}$ e em todas as outras com seleção negativa. De acordo com a literatura, o caráter rendimento, expresso como produção de grãos ou peso de espigas, sempre tende a cair quando a endogamia é incrementada (Hallauer \& Miranda Filho, 1995).

Para os demais caracteres, esta tendência, identificada para PE, somente se configura quando se observa o nível com seleção negativa, enquanto que com seleção positiva não é possível estabelecer uma tendência que se aplique a todos eles. Uma explicação para este fato relaciona-se, provavelmente, à sensibilidade diferenciada desses caracteres ao incremento da homozigozidade, ao efeito atenuante da seleção positiva sobre a depressão, ao tamanho reduzido da amostra e à diferença não muito alta entre as taxas de endogamia de dois grupos de subpopulações analisadas: $17 \%\left(\mathrm{~N}_{3}\right)$ e $25 \%\left(\mathrm{~N}_{2}\right)$.

Quando se comparam as estimativas da depressão, com seleção positiva, entre as subpopulações com $\mathrm{N}_{3}$ e $\mathrm{N}_{1}$, constatou-se, para todos os caracteres, uma tendência de aumento das mesmas, com exceção de PR, cuja média superou a da população original, como se pôde observar pelo valor negativo associado à estimativa da depressão. Hallauer \& Miranda Filho (1995) também reportam, não para o caráter PR, mas para número de espigas na população BSSS, um aumento de $20 \%$ entre a geração $\mathrm{S}_{0}$ e $S_{1}$.

Comparando-se as subpopulações com $\mathrm{N}_{3}$ e $\mathrm{N}_{2}$, também com seleção positiva, verificou-se que somente o caráter $\mathrm{CE}$ divergiu em relação aos demais, os quais apresentaram um acréscimo nas estimativas de depressão, ou praticamente não diferiram, como é o caso do caráter DE. Entre as subpopulações com $\mathrm{N}_{2}$ e $\mathrm{N}_{1}$, que 
significa uma diferença na taxa de endogamia de $25 \%$, houve uma diminuição do efeito da depressão para os caracteres PR e AE. A comparação dos valores médios com a testemunha não apresentou mudanças significativas em relação ao que já fora comentado por local.

As Figuras 8 e 9 demonstraram que, para a maioria dos caracteres avaliados, com exceção de $\mathrm{AE}$, existe uma relação linear entre os valores médios e o coeficiente de endogamia.

\subsection{Avaliação da capacidade de combinação das subpopulações em esquema 'topcross'}

A realização de 'topcrosses' das subpopulações com um testador de base ampla, o composto GN-03, e um de base estreita, o híbrido triplo P 3041, teve como objetivo avaliar se a dispersão entre subpopulações, sob diferentes tamanhos efetivos, reflete-se também na dispersão dos efeitos de capacidade de combinação.

Os resultados da análise da variância do experimento 8 com progênies 'topcrosses', apenas para o caráter PE, apresentam-se na Tabela 35. O coeficiente de variação experimental foi de $13,8 \%$, que se insere dentro da classificação média definida por Scapim et al. (1995).

As fontes de variação mais importantes, tais como, testador, progênies 'topcrosses' e a interação entre as mesmas não apresentaram diferenças estatisticamente significativas. Algumas ilações podem ser extraídas desses resultados: os testadores não diferiram em suas estimativas para capacidade geral de combinação, o que é corroborado pelas médias obtidas muito próximas, conforme se pode verificar na Tabela 36. Entretanto, não é correto afirmar que a estrutura genética dos mesmos seja também muito semelhante, uma vez que a classificação dos 'topcrosses' foi estatisticamente diferente entre um e outro testador, como se comprovou pelo teste de correlação de Spearman, cujo valor de $\hat{\mathrm{r}}$ igual a 0,18 não foi significativo.

As progênies 'topcrosses' também não diferiram quanto à capacidade geral e específica de combinação, o que provavelmente está mais associado ao bom 
desempenho dos testadores do que à falta de diferenciação genética entre as subpopulações. Na literatura sobre este assunto, vários autores, dentre eles Hull (1945) e Rawlings \& Thompson (1962) concluem que testadores com baixo desempenho, supostamente com uma baixa freqüência de alelos favoráveis, são os mais efetivos na identificação de diferenças genéticas, o que não é o caso dos testadores utilizados neste trabalho.

Como já afirmado inicialmente, as diferenças porventura existentes entre progênies 'topcrosses' são um indicativo de variações nas freqüências gênicas das mesmas. Como a fonte de variação tamanho efetivo não foi incluída no modelo estatístico, um presumível efeito desta foi investigado através do agrupamento das

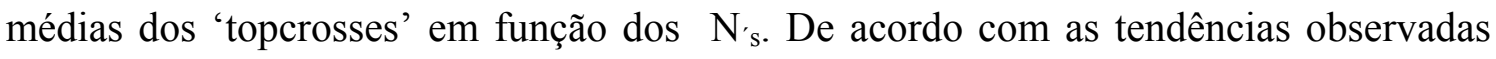
nas Figuras 10, 11 e 12, é possível dizer que há evidências de divergência genética entre subpopulações com diferentes $\mathrm{N}_{\text {s. }}$. Os dois testadores foram efetivos na discriminação entre $\mathrm{N}_{\text {s, }}$ com maior destaque para o híbrido P 3041 (Figura 10). A distinção entre $\mathrm{N}_{\mathrm{s}}$ também se verificou quando se tomou a média dos 'topcrosses' baseada nos dois testadores (Figura 11). Estas, quando apresentadas segundo os níveis de seleção, demonstraram que, com seleção positiva, houve uma inversão da tendência de queda do $\mathrm{N}_{2}$ para o $\mathrm{N}_{1}$, devido, provavelmente, ao efeito do híbrido $\mathrm{P} 3041$.

\subsection{Análise de cruzamentos dialélicos}

Os resultados da análise da variância dos experimentos 9, 10 e 11, segundo o esquema de cruzamentos dialélicos, para o caráter produção de grãos (PG), são apresentados na Tabela 37.

Não houve diferença estatística significativa de subpopulações dentro de grupos; para o efeito entre grupos, somente as subpopulações com $\mathrm{N}_{3}$, cujas médias para os grupos I e II foram 4,9 e 4,2 t/ha, apresentaram diferença estatística significativa, demonstrando que, no caso das subpopulações com $\mathrm{N}_{1}$ e $\mathrm{N}_{2}$, as médias entre os grupos com seleção positiva e negativa não divergiram, como se esperava. 
Verificou-se que o efeito da heterose média foi significativo para as combinações híbridas de todos os grupos de subpopulações com distintos tamanhos efetivos, o que demonstra que estes, quando cruzados, apresentaram potencial heterótico. Entretanto, a heterose de subpopulações dos grupos I e II não apresentaram significância, evidenciando a não existência de variabilidade suficiente no efeito heterótico das subpopulações constituintes dos grupos.

O efeito médio da heterose, no híbrido, foi de aproximadamente $24 \%$, $17 \%$ e $24 \%$ superior à média dos pais, respectivamente às subpopulações de $\mathrm{N}_{1}, \mathrm{~N}_{2}$ e $\mathrm{N}_{3}$, conforme mostrado nas Tabelas 38, 39 e 40, valores estes que são superiores aos híbridos mais produtivos encontrados por Gorgulho \& Miranda Filho (2001).

Quanto ao efeito da heterose específica, também não se verificou diferença estatística significativa entre os cruzamentos das subpopulações com $\mathrm{N}_{1}, \mathrm{~N}_{2} \mathrm{e}$ $\mathrm{N}_{3}$, o que significa que as subpopulações comportaram-se de maneira relativamente homogênea nos cruzamentos.

A produção (t/ha) das subpopulações e das combinações híbridas são

apresentadas nas Tabelas 41, 42 e 43, as quais se referem ao $N_{1}, N_{2}$ e $N_{3}$, respectivamente. Constatou-se que o número de híbridos superiores à testemunha foram $44 \%, 0 \%$ e $24 \%$, na mesma ordem dos $N_{\text {ss }}$ citados. Em relação aos genitores, os híbridos foram superiores em $24 \%, 17 \%$ e $24 \%$, seguindo-se a mesma ordem anterior. Estas porcentagens, evidentemente, devem coincidir com aquelas obtidas através da heterose média, expressas anteriormente.

\subsection{Estimativas de componentes da variância}

A determinação de componentes da variância genética, de caracteres de interesse para seleção, tem-se revelado de grande importância para o melhoramento, tendo em vista a vasta literatura sobre o assunto. Neste trabalho, a estimação de componentes da variância genética teve como principal objetivo destacar a metodologia empregada na obtenção dos materiais genéticos, qual seja, a realização de cruzamentos planta a planta, com cadeias de tamanho 3, conforme esquema apresentado 
anteriormente. Esta metodologia, pela sua simplicidade, pode vir a ser uma alternativa a delineamentos genéticos de mais difícil execução, como, por exemplo, o Delineamento I de Comstock \& Robinson (1948).

Nas Tabelas 44 a 47 apresentam-se os valores dos quadrados médios da análise agrupada dos experimentos 1,2, 3 e 4, com progênies de cruzamentos em cadeia, por local, para os caracteres PE, CE, DE, PR, AP e AE. Neste caso, é importante destacar que os quadrados médios relativos às progênies mostraram-se estatisticamente significativos para todos os caracteres, nos dois locais. Apresentam-se também nas referidas tabelas, as médias e os coeficientes de variação de cada caráter. Com relação a estes, destaca-se, negativamente, o coeficiente de variação de 22,3\% do caráter PR, no Local 2, classificado como alto de acordo com Scapim et al. (1995).

Os quadrados médios da análise da variância agrupada conjunta, valores médios e coeficientes de variação para os caracteres anteriormente referidos são apresentados nas Tabelas 48 e 49. Similarmente ao que já ocorrera na análise por local, o efeito de progênies também foi significativo para todos os caracteres. Os coeficientes de variação foram praticamente a média dos obtidos por local e todos se encontram em níveis aceitáveis para esses caracteres.

Análises da variância conjunta também foram realizadas para progênies de irmãos germanos e $S_{1}$, cujos quadrados médios, valores médios e coeficientes de variação, para todos os caracteres, são apresentados nas Tabelas 50, 51, 52 e 53, sendo as duas primeiras referentes a irmãos germanos, e as duas últimas a $\mathrm{S}_{1 \text { 's. }}$ Com esses dois tipos de materiais genéticos, o efeito de progênies também foi significativo para todos os caracteres. Quanto aos coeficientes de variação, valores altos para o caráter PR foram encontrados tanto para irmãos germanos quanto para $\mathrm{S}_{1^{\prime} \mathrm{s}}: 21,1 \%$ e $24,6 \%$, respectivamente. $\mathrm{O}$ coeficiente de variação para PE também foi elevado: 18,7\% e 19,4\%, na mesma ordem citada, mas ainda classificado como médio, de acordo com Scapim et al. (1995). Para os outros caracteres os níveis encontrados são aceitáveis.

As estimativas da variância genética aditiva $\left(\mathrm{s}_{\mathrm{A}}^{2}\right)$ e genética dominante $\left(\mathrm{s}_{\mathrm{D}}^{2}\right)$, por local, para os seis caracteres avaliados, com progênies de cruzamentos em 
cadeia, são apresentadas na Tabela 54. Para o caráter PE, as estimativas da $\mathrm{s}_{\mathrm{A}}^{2}$ e $\mathrm{s}_{\mathrm{D}}^{2}$, expressas em $(\mathrm{g} / \mathrm{pl})^{2}$, foram 239,0 e 358,0 no Local 1, e 241,0 e 9,0 no Local 2, respectivamente. Verificou-se que, enquanto houve um certo equilíbrio nas estimativas da $\mathrm{s}_{\mathrm{A}}^{2}$ nos dois locais, as estimativas da $\mathrm{S}_{\mathrm{D}}^{2}$, por sua vez, foram muito discrepantes. Quanto aos erros associados a essas estimativas, foram muito baixos nos dois locais.

Vale ressaltar que a estimativa da $\mathrm{S}_{\mathrm{A}}^{2}$ obtida neste trabalho é bastante inferior àquela obtida por Nass \& Miranda Filho (1999) com progênies de meios irmãos, para este mesmo composto, que foi de $761,7(\mathrm{~g} / \mathrm{pl})^{2}$ no primeiro de ciclo de seleção. Entretanto este valor decresceu para 99,2 (g/pl) ${ }^{2}$ no segundo ciclo de seleção, com base em progênies de irmãos germanos (Nass et al, 2000).

Hallauer \& Miranda Filho (1995) reportaram estimativas médias, de um total de 99 trabalhos, de 469,1 e $286,8(\mathrm{~g} / \mathrm{pl})^{2}$ para as estimativas da $\mathrm{s}_{\mathrm{A}}^{2}$ e $\mathrm{s}_{\mathrm{D}}^{2}$, respectivamente. Vencovsky et al. (1988), de um total de 58 trabalhos, apresentaram estimativa média da $\mathrm{s}_{\mathrm{A}}^{2}$ de $309,0(\mathrm{~g} / \mathrm{pl})^{2}$. Em face destes resultados da literatura, pode-se dizer que a magnitude da variabilidade genética do composto GN-04, principalmente da $\mathrm{s}_{\mathrm{A}}^{2}$, não apresenta uma condição muito favorável para exploração em um programa de seleção recorrente. Os caracteres $\mathrm{CE}, \mathrm{AP}$ e $\mathrm{AE}$, nos dois locais, e DE no Local 1, apresentaram estimativas negativas da $\mathrm{s}_{\mathrm{D}}^{2}$ e os erros respectivos, em geral, superaram a própria estimativa da $\mathrm{S}_{\mathrm{D}}^{2}$. Componentes da variância, por definição, não podem ser negativos, mas tais resultados aparecem com uma certa freqüência na literatura. Hallauer \& Miranda Filho (1995) reportaram estimativas negativas da $\mathrm{S}_{\mathrm{D}}^{2}$ para os caracteres precocidade e acamamento. Os mesmos autores afirmam que estimativas negativas em milho parecem ser causadas por um modelo, amostragem ou técnica experimental inadequados. Entretanto, quando o valor paramétrico é muito baixo ou próximo de zero, as estimativas podem ser negativas por simples erro de amostragem. Silva (1990), utilizando o Delineamento I, obteve estimativas negativas das ${ }_{\mathrm{A}}^{2}$ para os caracteres 
número de grãos por fileira e diâmetro da espiga, e da $\mathrm{S}_{\mathrm{D}}^{2}$, para os caracteres peso de 100 sementes, número de grãos por fileira e altura da espiga.

Para o caracteres da espiga, CE e DE, as estimativas da $\mathrm{s}_{\mathrm{A}}^{2}$ foram, respectivamente, 1,3016 e 0,1476 (cm/espiga) ${ }^{2}$ no Local 1 , e 1,6716 e 0,1780 $(\mathrm{cm} / \text { espiga })^{2}$ no Local 2, o que indica haver uma maior variabilidade genética para o caráter CE. Resultados similares a estes foram encontrados por Galal et al. (1977), Obilana et al. (1979) e Santos (1985), para o CE. Para o DE, os valores citados na literatura, em geral, são bastante inferiores aos encontrados neste trabalho: Hallauer \& Miranda Filho (1995) reportaram um valor médio de 0,0460, com base em 35 trabalhos, e Silva (1990), com base em 10 trabalhos, cita um valor médio de 0,0538. Quanto à estimativa da $\mathrm{S}_{\mathrm{D}}^{2}$, para o DE, esta foi de 0,0228 no Local 2 , um valor que é aproximadamente 2,5 vezes superior ao encontrado por Hallauer \& Miranda Filho (1995).

No que concerne ao caráter $\mathrm{PR}$, as estimativas de $\mathrm{s}_{\mathrm{A}}^{2}$, expressas em (espigas/pl) ${ }^{2}$, nos locais 1 e 2, foram 0,0220 e 0,3168, respectivamente. Estes valores demonstram um grande efeito ambiental, sendo a expressão da variabilidade genética aditiva no Local 2 superior em aproximadamente 14 vezes à do Local 1. As estimativas de $\mathrm{S}_{\mathrm{D}}^{2}$ foram positivas nos dois locais, mas, no Local 1 , o erro é muito superior à $\hat{\mathrm{S}}_{\mathrm{D}}^{2}$, e no Local 2, as estimativas do erro e de $\mathrm{s}_{\mathrm{D}}^{2}$ são praticamente equivalentes.

Quanto aos caracteres AP e AE, as estimativas de $\mathrm{s}_{\mathrm{A}}^{2}$, expressas em $(\mathrm{cm} / \mathrm{pl})^{2}$, foram respectivamente 317,4 e 140,7 no Local 1, e 337,9 e 172,7 no Local 2. Nass \& Miranda Filho (1999) obtiveram para este mesmo composto, com progênies de meios irmãos, estimativas da $\mathrm{s}_{\mathrm{A}}^{2}$ de 364,9 para $\mathrm{AP}$ e 223,1 para AE, uma maior divergência, portanto, com relação a este último caráter. As estimativas da $\mathrm{s}_{\mathrm{D}}^{2}$ foram negativas, em ambos os locais, para os dois caracteres, como já referido. 
As estimativas dos componentes da variância genética, com base na análise agrupada conjunta dos experimentos 1, 2, 3 e 4, são apresentadas na Tabela 55. Para o caráter PE, as estimativas de $\mathrm{s}_{\mathrm{A}}^{2}$ e $\mathrm{s}_{\mathrm{D}}^{2}$, expressas em $(\mathrm{g} / \mathrm{pl})^{2}$ foram 128,0 e 185,0, respectivamente, bastante inferiores, portanto, aos resultados já citados de Hallauer \& Miranda Filho (1995), Nass \& Miranda Filho (1999) e Vencovsky et al. (1988). Como já ocorrera quando da análise por local, as estimativas dos erros respectivos mostraram-se insignificantes em relação às estimativas dos componentes da variância anteriormente citados. Contudo, deve-se ressaltar que a população base (GN-04) utilizada neste estudo já foi submetida a dois ciclos de seleção recorrente, sendo, portanto, esperada uma redução da variabilidade em relação à população estudada por Nass \& Miranda Filho (1999).

Para os caracteres da espiga, $\mathrm{CE}$ e DE, as estimativas de $\mathrm{s}_{\mathrm{A}}^{2}$, expressas em (cm/espiga $)^{2}$, foram 1,4900 e 0,1704, respectivamente. Hallauer \& Miranda Filho (1995) reportaram, uma estimativa média de $\mathrm{s}_{\mathrm{A}}^{2}$ similar à encontrada neste estudo para o caráter $\mathrm{CE}$, a qual foi de 1,5240. Os mesmos autores reportaram para o caráter DE uma estimativa média de $\mathrm{s}_{\mathrm{A}}^{2}$ de 0,0460 , valor este que é inferior em aproximadamente 4 vezes ao obtido neste estudo. Isto evidencia que é possível obter ganhos com seleção recorrente intrapopulacional para os dois caracteres, levando-se em conta também que os efeitos de dominância são nulos ou próximos de zero, haja vista as estimativas negativas de $S_{D}^{2}$

Quanto ao caráter PR, expresso em (espigas $/ \mathrm{pl})^{2}$, as estimativas de $\mathrm{s}_{\mathrm{A}}^{2} \mathrm{e}$ $\mathrm{S}_{\mathrm{D}}^{2}$ foram 0,0200 e 0,0188 , respectivamente, evidenciando uma contribuição ligeiramente superior dos efeitos aditivos dos genes, resultado este que confirma as estimativas obtidas nos dois locais. Hallauer \& Miranda Filho (1995), com base em 39 estimativas, relataram um valor médio de 0,0459 e 0,0118 para as estimativas de $\mathrm{s}_{\mathrm{A}}^{2} \mathrm{e}$ 
$\mathrm{S}_{\mathrm{D}}^{2}$, respectivamente, corroborando, assim, uma maior contribuição dos efeitos aditivos dos genes para esse caráter.

Para os caracteres AP e AE, as estimativas de $\mathrm{s}_{\mathrm{A}}^{2}$, expressas em $(\mathrm{cm} / \mathrm{pl})^{2}$, foram 256,6 e 136,8, as quais não divergem muito daquelas encontradas por Hallauer \& Miranda Filho (1995), mas são inferiores 1,42 e 1,63 vezes, respectivamente para AP e $\mathrm{AE}$, àquelas obtidas por Nass \& Miranda Filho (1999) com esse mesmo composto. Como já ocorrera na análise por local, aqui também as estimativas da $\mathrm{s}_{\mathrm{D}}^{2}$ foram negativas.

Estimativas de $\mathrm{s}_{\mathrm{A}}^{2}$ também são apresentadas com base na análise conjunta do experimento 5, com progênies de irmãos germanos (Tabela 56) e do experimento 6, com progênies $\mathrm{S}_{1}$ (Tabela 57). Entretanto, com esses materiais não é possível estimar componentes da variância genética diretamente, a não ser que algumas hipóteses sejam estabelecidas e que, na prática, dificilmente ocorrerão. Neste estudo, admitiu-se $s_{A}^{2}$ igual à $s_{D}^{2}$ para o caráter $P E$ e $S_{D}^{2}$ igual a zero para os demais. As estimativas dos erros não foram calculadas, mas certamente são altas em virtude do tamanho reduzido da amostra de progênies avaliadas: 75 de irmãos germanos e 77 de $\mathrm{S}_{1}$.

Verificou-se que, devido às hipóteses assumidas, os estimadores da $\mathrm{s}_{\mathrm{A}}^{2}$ para $\mathrm{PE}$, tanto com irmãos germanos quanto com $\mathrm{S}_{1^{\prime} \text { s }}$, conduziram ao mesmo valor numérico, que foi de $276,0(\mathrm{~g} / \mathrm{pl})^{2}$. Este resultado não é tão discrepante dos obtidos por local com progênies de cruzamentos em cadeia, contudo, é mais que o dobro do obtido na análise conjunta dos experimentos com estas mesmas progênies.

Em face das estimativas obtidas com progênies em cadeia, com base na análise conjunta, constatou-se que as estimativas com progênies de irmãos germanos apresentaram valores bem próximos para os caracteres $\mathrm{CE}, \mathrm{DE}$ e $\mathrm{PR}$, ao passo que com progênies $S_{1}$ isto ocorreu apenas para o caráter PR. Para AP e AE, tanto com irmãos germanos quanto com $\mathrm{S}_{1}$ 's, os resultados foram bastante divergentes. 


\section{CONCLUSÕES}

A interpretação dos resultados deste trabalho permitem chegar às seguintes conclusões:

- O tamanho efetivo reduzido das subpopulações provocou o surgimento de valores médios inferiores ou superiores à média da população original para todos os caracteres avaliados, em conseqüência da deriva genética;

- O efeito do tamanho efetivo foi significativo para a maioria dos caracteres avaliados;

- O efeito da seleção correspondeu às expectativas teóricas, sendo mais acentuado nas subpopulações com menor tamanho efetivo;

- A seleção positiva atenuou os efeitos depressivos da endogamia ;

- Os valores médios de todos os caracteres foram afetados pela redução no tamanho efetivo das subpopulações, notadamente para peso de espigas;

- A depressão por endogamia, em maior ou menor intensidade, afetou todos os caracteres avaliados;

- As progênies 'topcrosses' não diferiram quanto à capacidade de combinação, mas quando agrupadas segundo os tamanhos efetivos, verificou-se um melhor desempenho daquelas com maiores $\mathrm{N}_{\mathrm{s}}$;

- A seleção divergente entre subpopulações pode resultar em diferenciação genética suficiente para expressão da heterose em cruzamentos entre subpopulações com mesmo tamanho efetivo; 
- O delineamento de cruzamentos em cadeia de tamanho 3, tendo em vista a facilidade de execução, pode ser uma alternativa a delineamentos de execução mais complexa para estimar componentes da variância. 
ANEXO A 
(A)

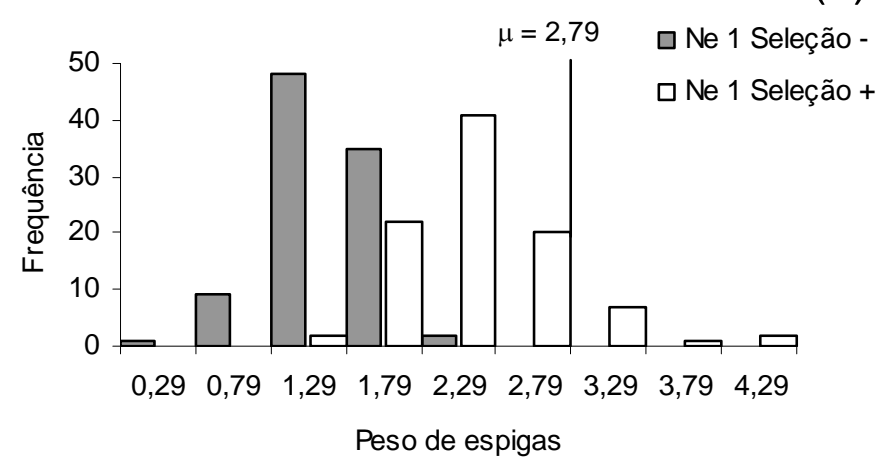

(B)

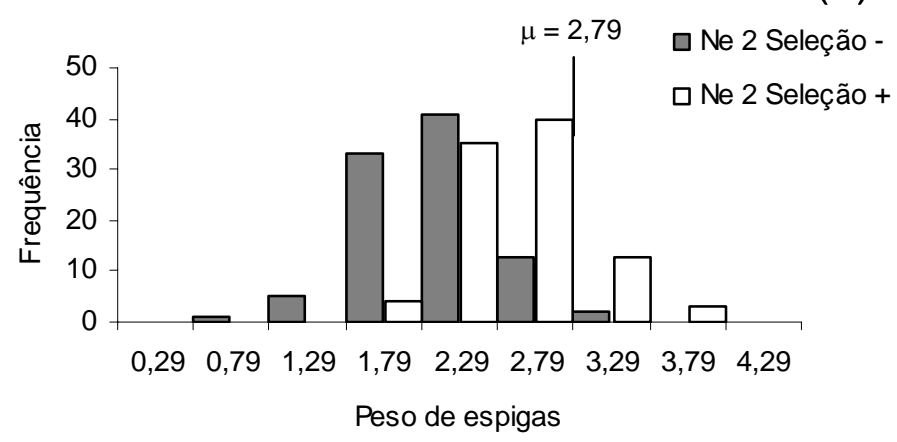

(C)

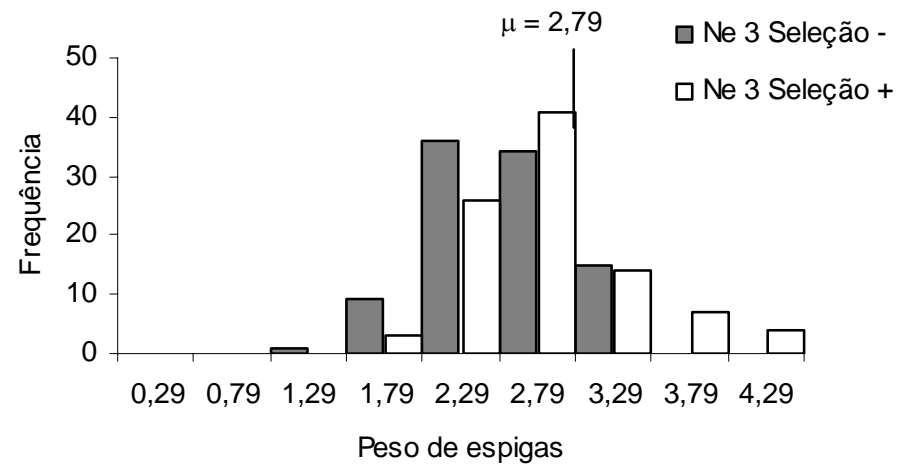

Figura 2 - Distribuição de valores da variável peso de espigas $\left(\mathrm{kg} / 4 \mathrm{~m}^{2}\right)$ com seleção positiva e negativa, em subpopulações (A) tamanho efetivo 1, (B) tamanho efetivo 2 e (C) tamanho efetivo 3 
(A)

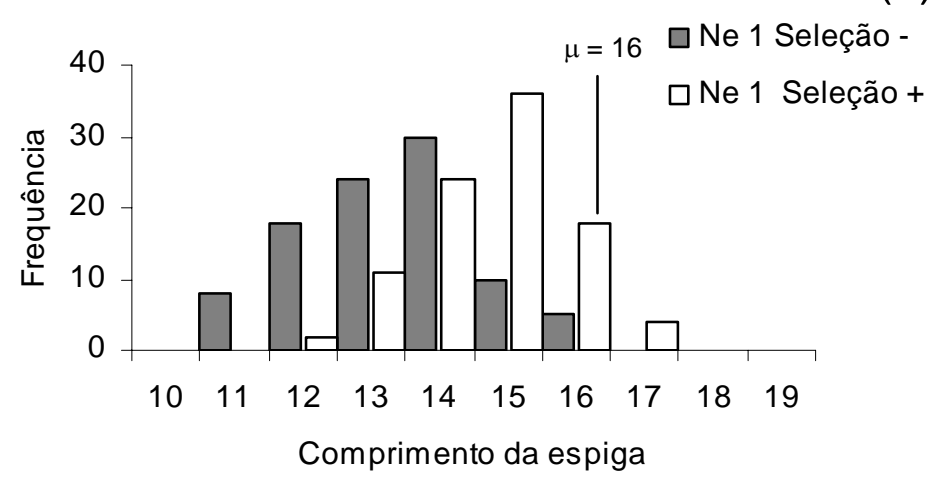

(B)

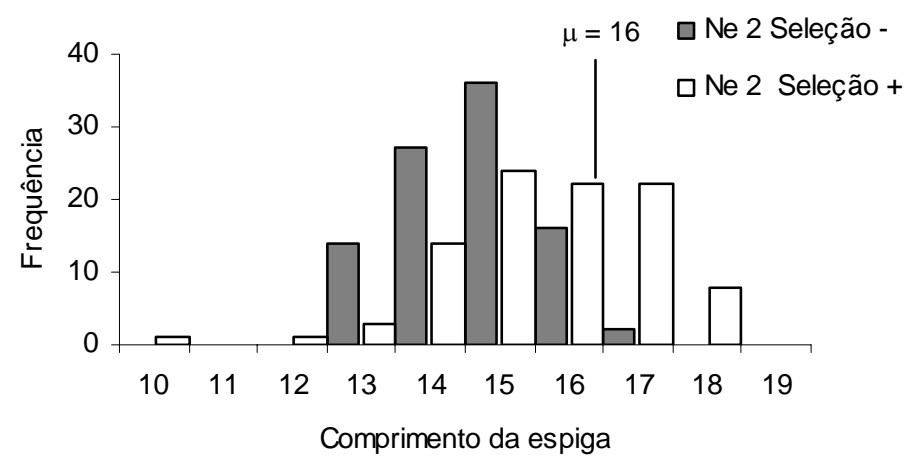

(C)

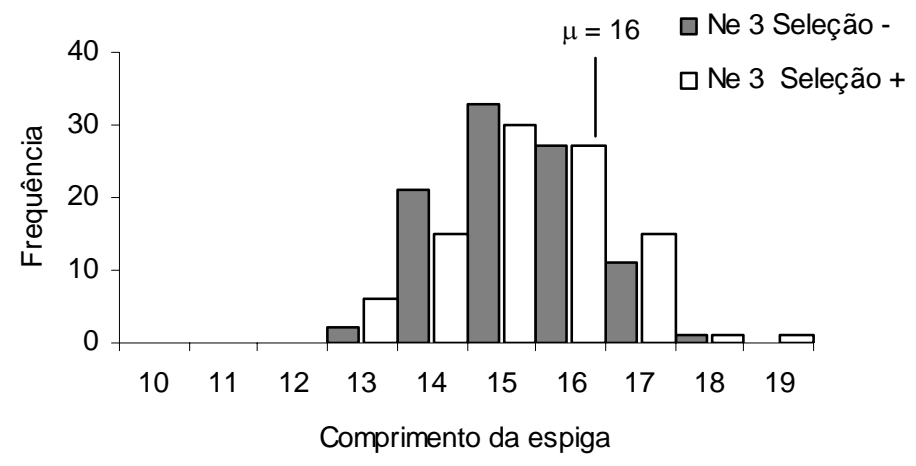

Figura 3 - Distribuição de valores da variável comprimento da espiga $(\mathrm{cm})$ com seleção positiva e negativa, em subpopulações (A) tamanho efetivo 1, (B) tamanho efetivo 2 e (C) tamanho efetivo 3 
(A)

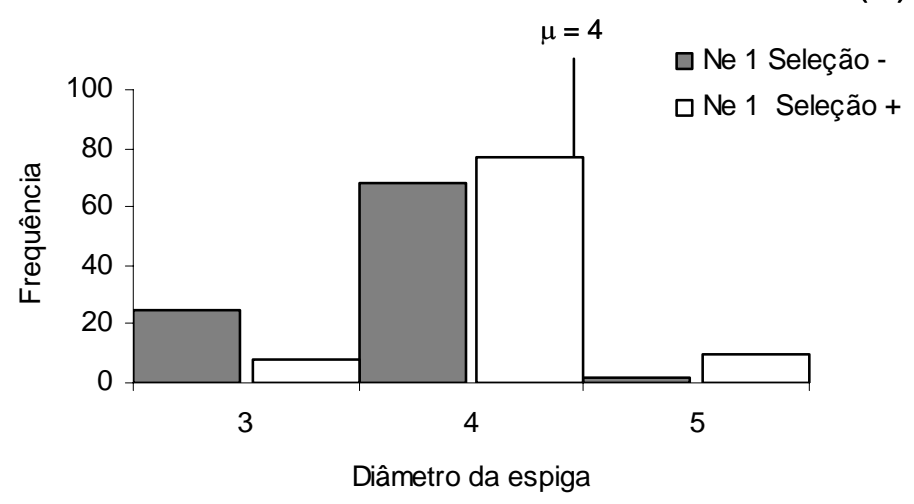

(B)

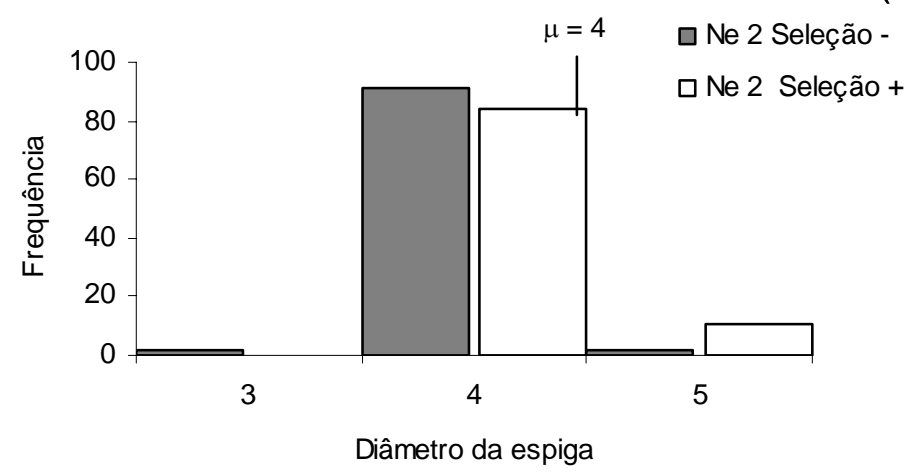

(C)

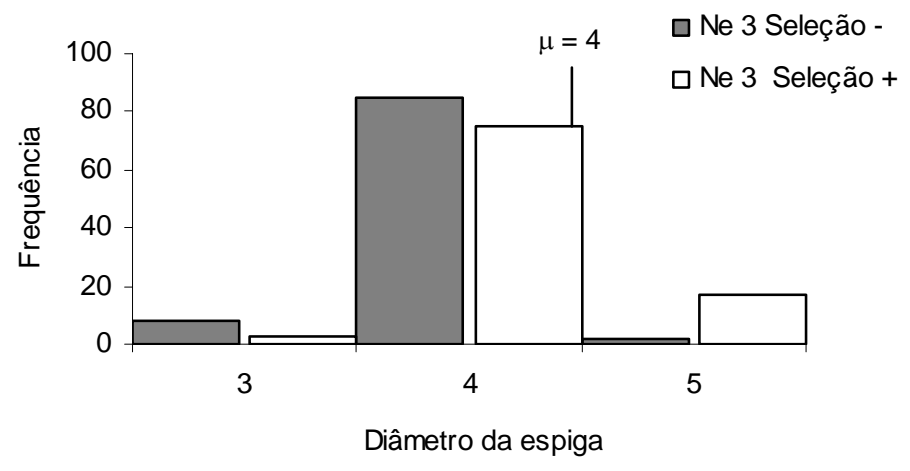

Figura 4 - Distribuição de valores da variável diâmetro da espiga $(\mathrm{cm})$ com seleção positiva e negativa, em subpopulações (A) tamanho efetivo 1, (B) tamanho efetivo 2 e (C) tamanho efetivo 3 
(A)

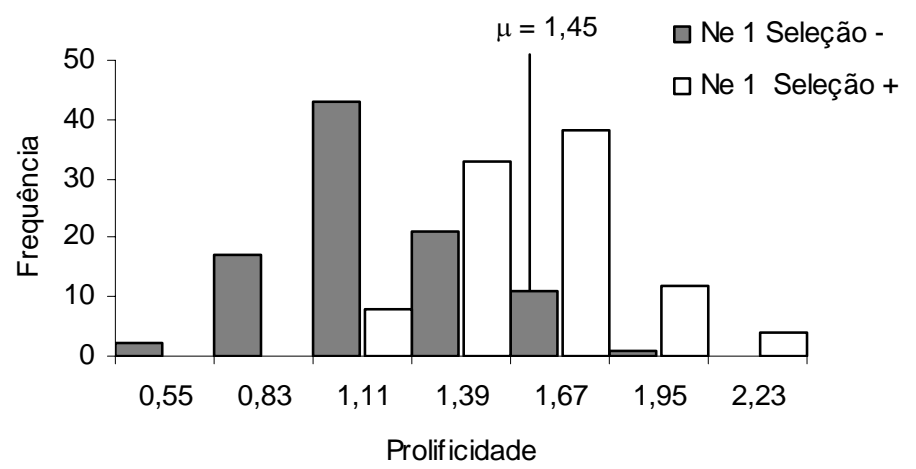

(B)

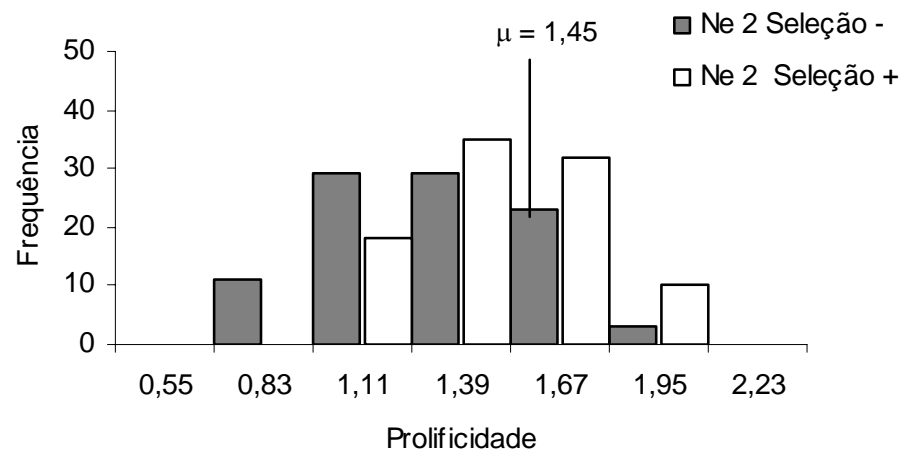

(C)

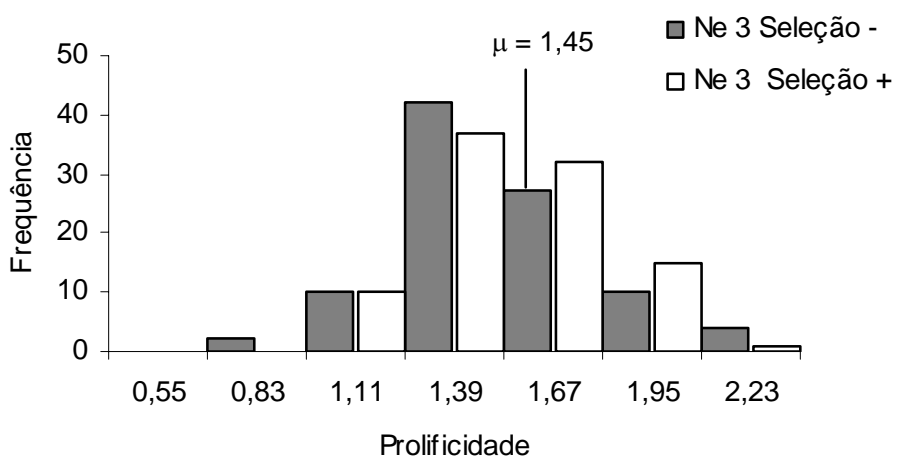

Figura 5 - Distribuição de valores da variável prolificidade (espigas/pl.) com seleção positiva e negativa, em subpopulações (A) tamanho efetivo 1, (B) tamanho efetivo 2 e (C) tamanho efetivo 3 
(A)

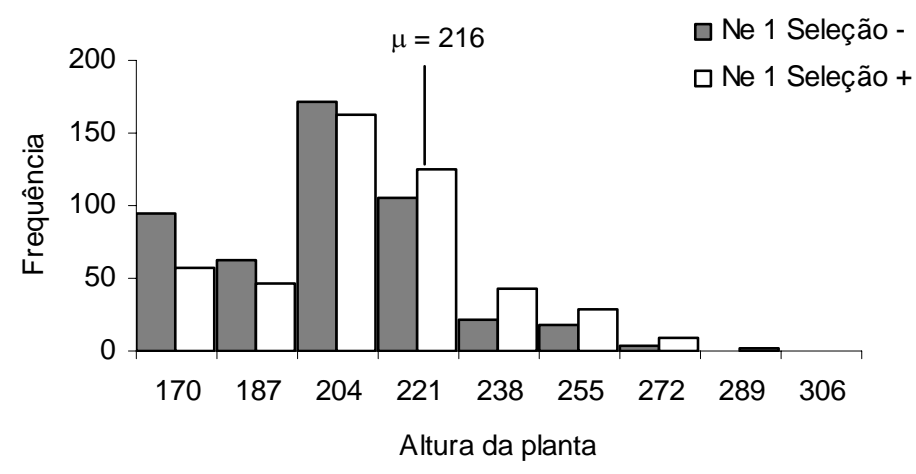

(B)

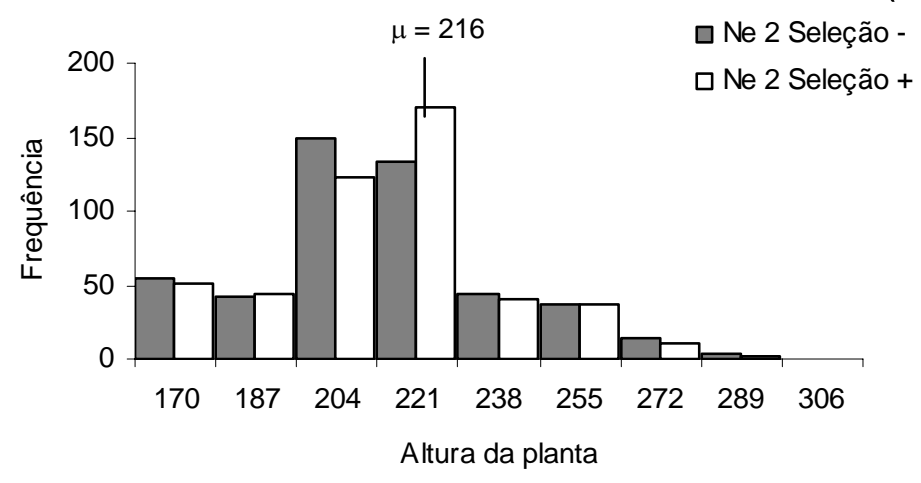

(C)

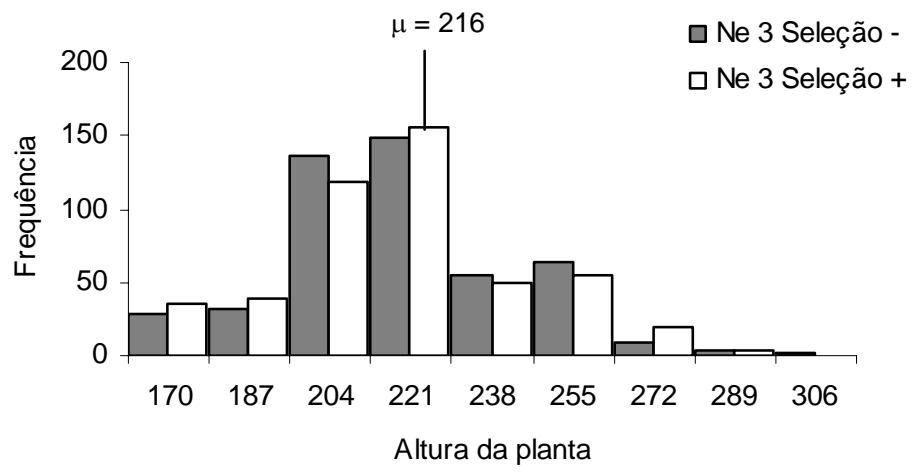

Figura 6 - Distribuição de valores do caráter altura da planta $(\mathrm{cm})$ com seleção positiva e negativa, em subpopulações (A) tamanho efetivo 1, (B) tamanho efetivo 2 e (C) tamanho efetivo 3 
(A)

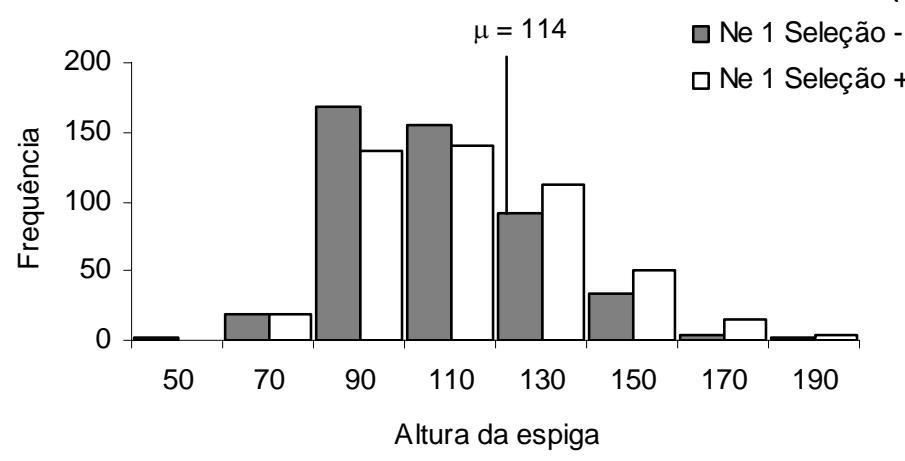

(B)

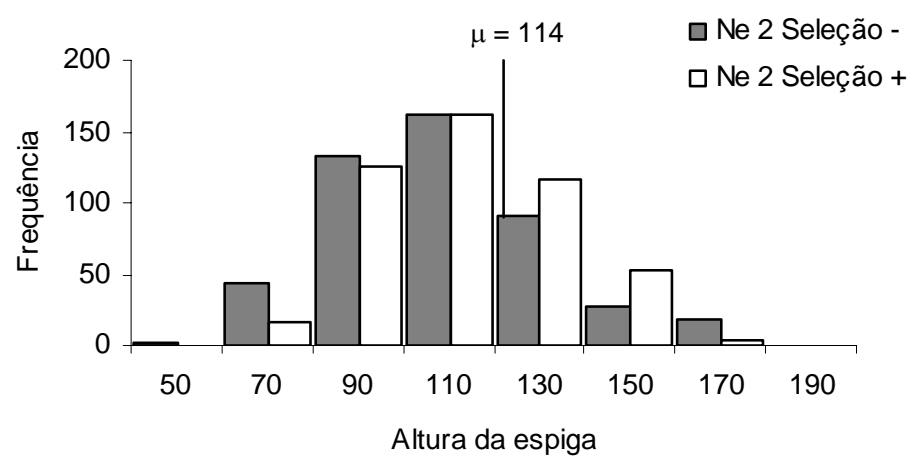

(C)

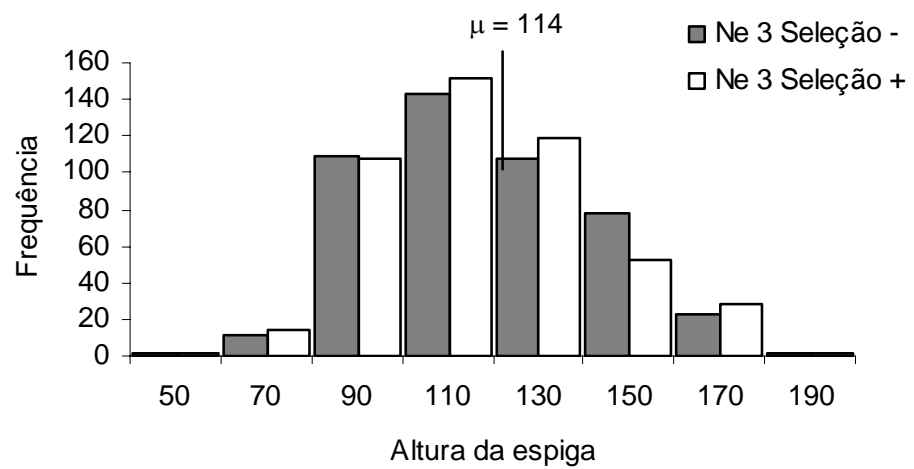

Figura 7 - Distribuição de valores do caráter altura da espiga $(\mathrm{cm})$ com seleção positiva e negativa, em subpopulações (A) tamanho efetivo 1, (B) tamanho efetivo 2 e (C) tamanho efetivo 3 

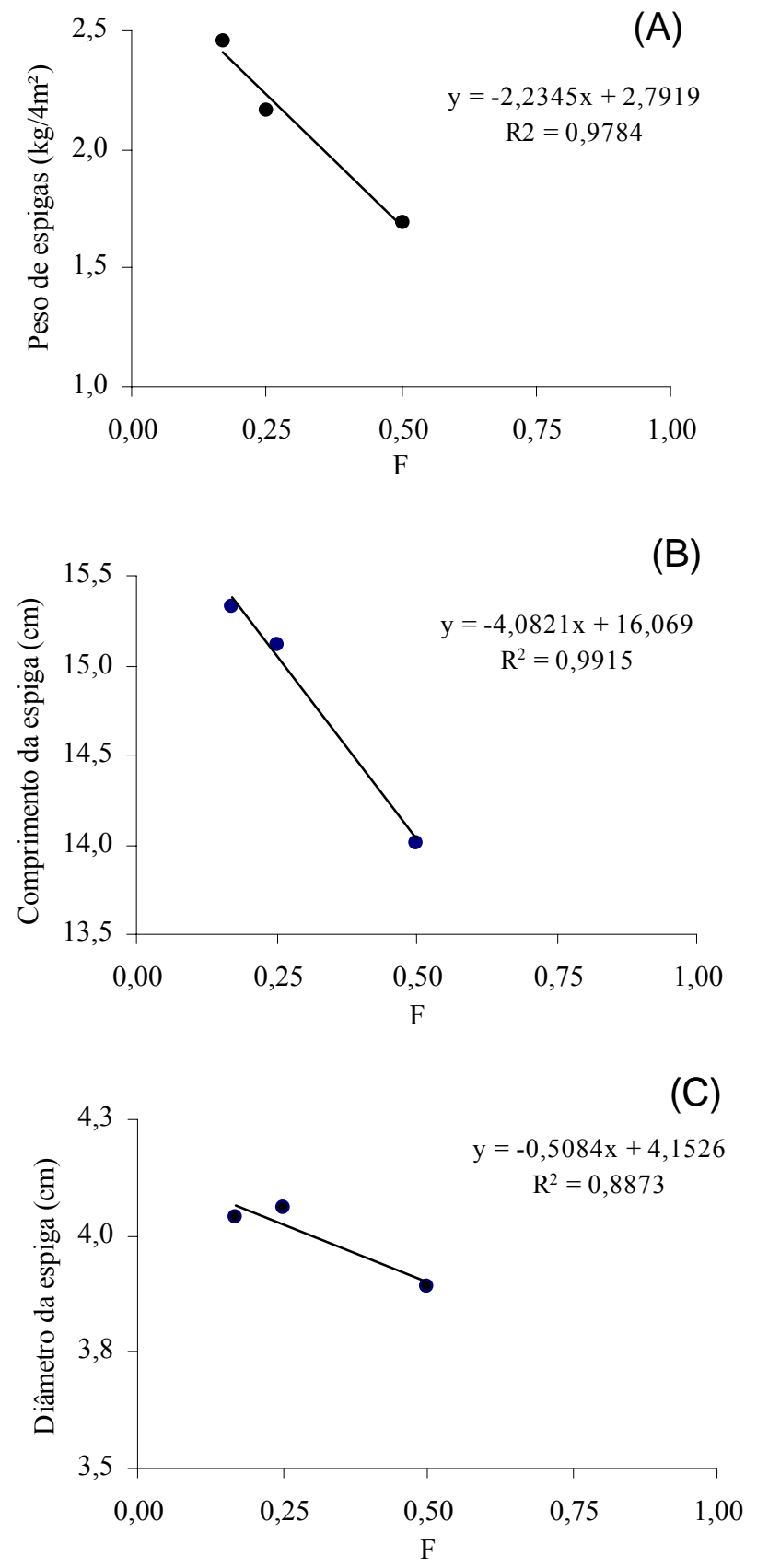

Figura 8 - Depressão por endogamia para o caráter (A) peso de espigas, (B) comprimento da espiga e (C) diâmetro da espiga 

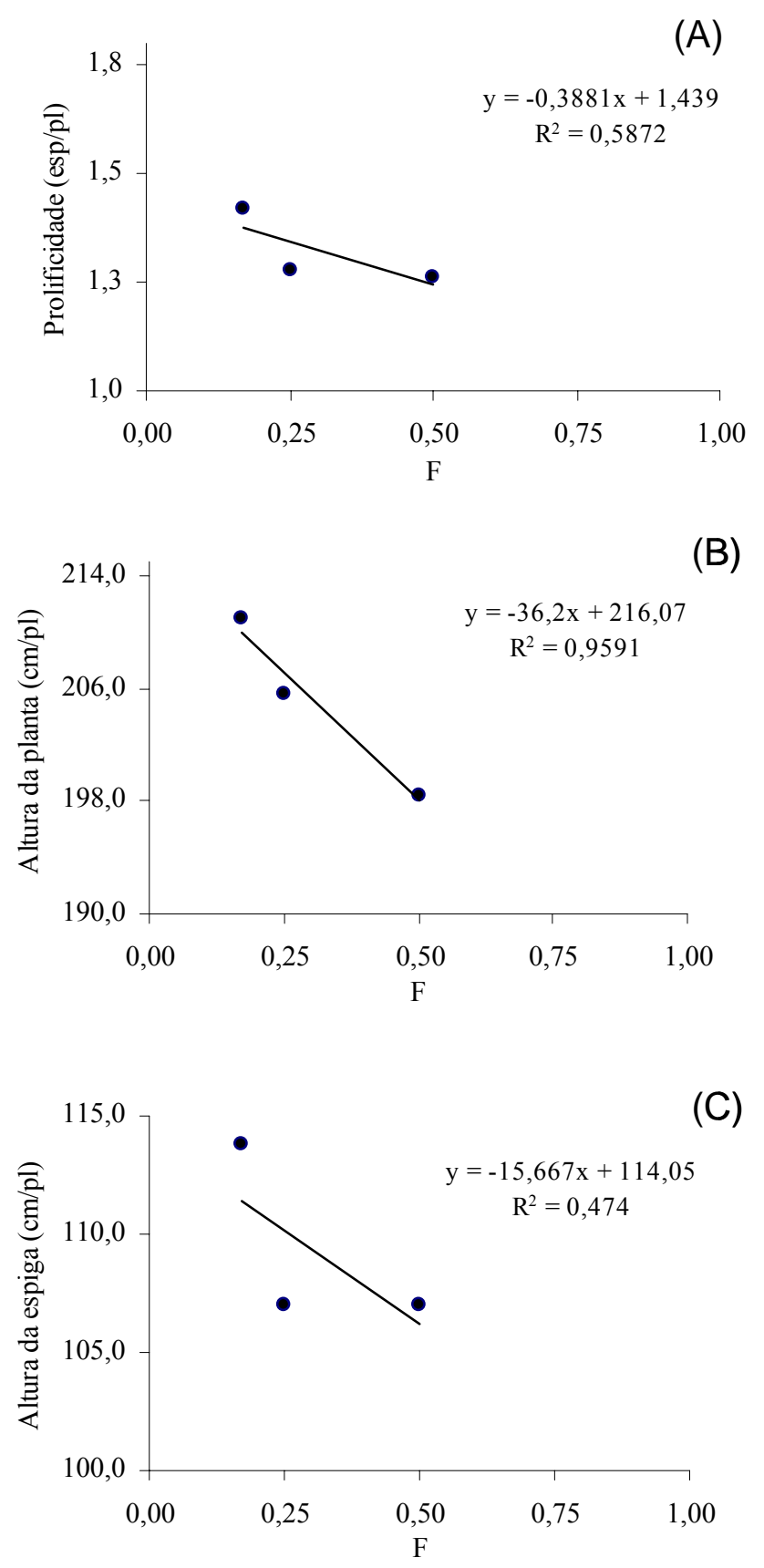

Figura 9 - Depressão por endogamia para o caráter (A) prolificidade, (B) altura da planta e (C) altura da espiga 


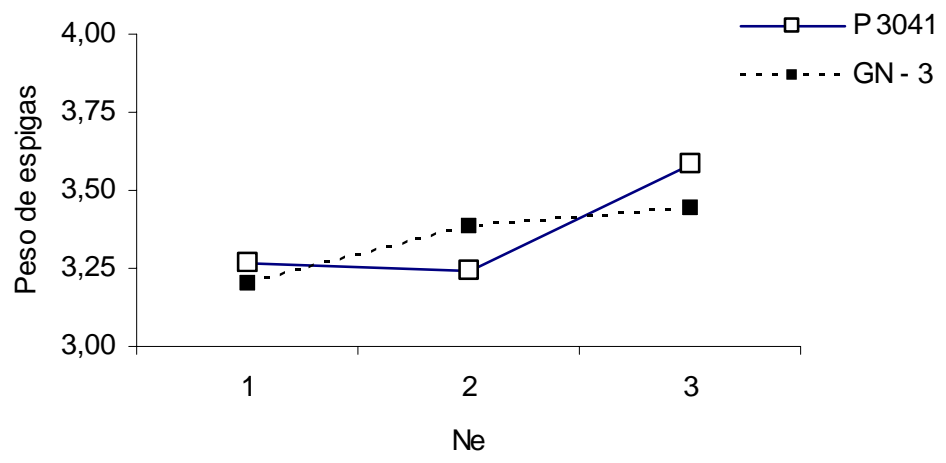

Figura 10 - Valores médios dos 'topcrosses' em função dos tamanhos efetivos das subpopulações, por testador, para o caráter PE $\left(\mathrm{kg} / 4 \mathrm{~m}^{2}\right)$

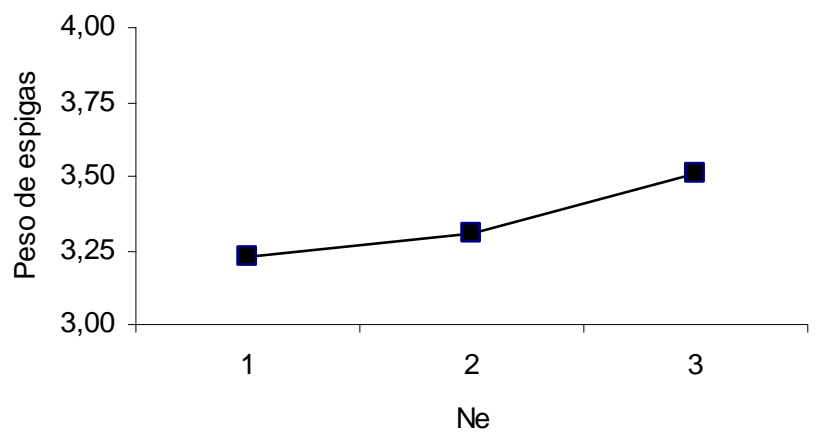

Figura 11 - Valores médios dos 'topcrosses' em função dos tamanhos efetivos das subpopulações, para o caráter PE $\left(\mathrm{kg} / 4 \mathrm{~m}^{2}\right)$

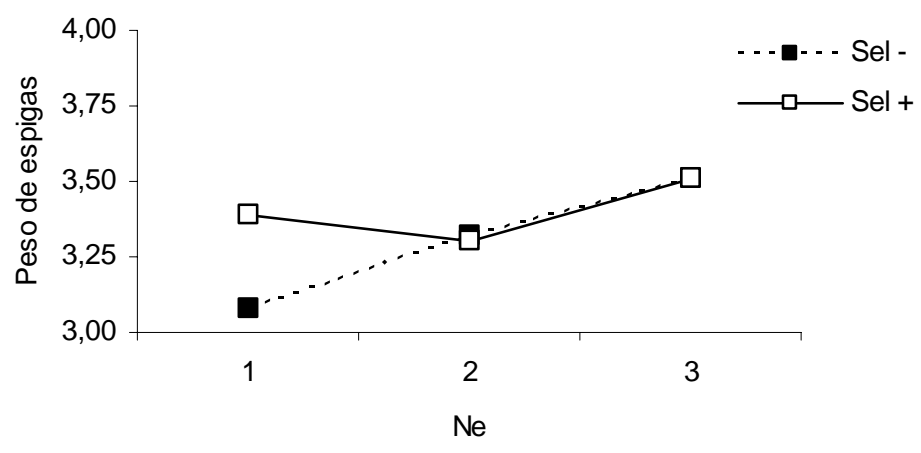

Figura 12 - Valores médios dos 'topcrosses' em função dos tamanhos efetivos das subpopulações, por nível de seleção, para o caráter PE $\left(\mathrm{kg} / 4 \mathrm{~m}^{2}\right)$ 
ANEXO B 
Tabela 12. Quadrados médios da análise da variância conjunta do experimento 7, com subpopulações de tamanho reduzido, para os caracteres peso de espigas (PE), comprimento da espiga (CE), diâmetro da espiga (DE) e prolificidade (PR)

\begin{tabular}{|c|c|c|c|c|c|}
\hline \multirow[t]{2}{*}{ Fonte de Variação } & \multirow[t]{2}{*}{ G.L. } & \multicolumn{4}{|c|}{ Quadrados médios } \\
\hline & & $\begin{array}{c}\mathrm{PE} \\
\left(\mathrm{kg} / 4 \mathrm{~m}^{2}\right)^{2}\end{array}$ & $\begin{array}{c}\mathrm{CE} \\
(\mathrm{cm} / \mathrm{esp} .)^{2}\end{array}$ & $\begin{array}{c}\mathrm{DE} \\
(\mathrm{cm} / \mathrm{esp} .)^{2}\end{array}$ & $\begin{array}{c}\text { PR } \\
\text { (esp./pl })^{2}\end{array}$ \\
\hline Bloco/Local & 17 & $0,3405^{*}$ & 1,0976 & 0,1531 & 0,0339 \\
\hline Local & 1 & 1,5634 & $68,2386^{*}$ & 0,2578 & $8,6874 *$ \\
\hline Tamanho efetivo & 2 & $28,7017 *$ & $95,1764 *$ & 1,6573 & $1,4921 *$ \\
\hline Seleção & 1 & $47,7310^{*}$ & $100,1811 *$ & $5,4963 *$ & $5,6003^{*}$ \\
\hline Tamanho efetivo x Seleção & 2 & $5,1059 *$ & 21,3294 & 0,2486 & $2,0450^{*}$ \\
\hline Subpopulações/Tamanho efetivo x Seleção & (24) & $1,3634^{*}$ & $10,5144^{*}$ & $1,1052^{*}$ & $0,2986^{*}$ \\
\hline Subpopulações $/ \mathrm{N}_{1^{-}}$ & 4 & 0,6614 & $21,2671^{*}$ & $2,6752^{*}$ & $0,4197 *$ \\
\hline Subpopulações $/ \mathrm{N}_{1}^{+}$ & 4 & $3,0656^{*}$ & $6,2430^{*}$ & $1,7294^{*}$ & 0,1506 \\
\hline Subpopulações/ $\mathrm{N}_{2}^{-}$ & 4 & $1,1843^{*}$ & $4,7095^{*}$ & 0,0265 & $0,2345^{*}$ \\
\hline Subpopulações $/ \mathrm{N}_{2}^{+}$ & 4 & 0,7004 & $19,5244^{*}$ & $0,5895^{*}$ & $0,5293^{*}$ \\
\hline Subpopulações $/ \mathrm{N}_{3}^{-}$ & 4 & 0,7834 & 2,5182 & $0,3122 *$ & $0,3501 *$ \\
\hline Subpopulações $/ \mathrm{N}_{3}{ }^{+}$ & 4 & $1,7851^{*}$ & $8,8243 *$ & $1,2987^{*}$ & 0,1075 \\
\hline Local x Subpop./Tamanho Efetivo x seleção & 24 & $0,4188^{*}$ & $1,4109^{*}$ & 0,0947 & 0,0618 \\
\hline Tamanho Efetivo x Local & 2 & 0,2461 & 0,2325 & 0,0187 & 0,0504 \\
\hline Seleção x Local & 1 & 0,0003 & 0,3144 & 0,0016 & 0,0357 \\
\hline Tamanho Efetivo x Seleção x Local & 2 & 0,2029 & 0,7574 & 0,1118 & 0,0294 \\
\hline Erro & 493 & 0,1216 & 0,8617 & 0,0992 & 0,0415 \\
\hline C.V\% & & 16,6 & 6,3 & 7,9 & 15,5 \\
\hline
\end{tabular}

${ }^{1} \mathrm{~N}_{1}{ }^{-} \ldots \mathrm{N}_{3}{ }^{+}$: simbolizam as combinações de níveis do fator de tratamento tamanho efetivo x seleção

* efeito significativo em nível de probabilidade igual ou inferior a $5 \%$, pelo teste $\mathrm{F}$ Quadrados médios sem asterisco não foram significativos 
Tabela 13. Quadrados médios da análise da variância conjunta do experimento 7, com subpopulações de tamanho reduzido, para os caracteres altura da planta (AP) e altura da espiga (AE)

\begin{tabular}{|c|c|c|c|}
\hline \multirow[t]{2}{*}{ Fonte de Variação } & \multirow[t]{2}{*}{ G.L. } & \multicolumn{2}{|c|}{ Quadrados médios } \\
\hline & & $\begin{array}{c}\text { AP } \\
(\mathrm{cm} / \mathrm{pl} .)^{2}\end{array}$ & $\begin{array}{c}\mathrm{AE} \\
(\mathrm{cm} / \mathrm{pl} .)^{2}\end{array}$ \\
\hline Bloco/Local & 17 & $1111,5468^{*}$ & $369,0587 *$ \\
\hline Local & 1 & $25736,9375^{*}$ & $108674,6892 *$ \\
\hline Tamanho efetivo & 2 & $7669,1455^{*}$ & 2911,3619 \\
\hline Seleção & 1 & 1284,0050 & 1258,1902 \\
\hline Tamanho efetivo x Seleção & 2 & 969,2352 & 632,8648 \\
\hline Subpopulações/Tamanho efetivo x Seleção & (24) & $1763,5506^{*}$ & $1014,6765^{*}$ \\
\hline Subpopulações/ $/ \mathrm{N}_{1^{-}}$ & 4 & $2950,6332 *$ & $748,2087^{*}$ \\
\hline Subpopulações/ $\mathrm{N}_{1}^{+}$ & 4 & $1791,2620^{*}$ & $2001,2019^{*}$ \\
\hline Subpopulações/ $\mathrm{N}_{2}^{-}$ & 4 & $1847,7970^{*}$ & $1145,1949^{*}$ \\
\hline Subpopulações $/ \mathrm{N}_{2}{ }^{+}$ & 4 & $1349,6531^{*}$ & $994,5485^{*}$ \\
\hline Subpopulações $/ \mathrm{N}_{3}{ }^{-}$ & 4 & 364,9104 & 306,5329 \\
\hline Subpopulações/ $\mathrm{N}_{3}{ }^{+}$ & 4 & $2277,0480^{*}$ & $892,3724 *$ \\
\hline Local x Subpopulações/Tamanho Efetivo x seleção & 24 & $309,2453 *$ & $199,4906^{*}$ \\
\hline Tamanho Efetivo x Local & 2 & 278,9097 & 161,7619 \\
\hline Seleção x Local & 1 & 330,8850 & 0,0007 \\
\hline Tamanho Efetivo x Seleção x Local & 2 & 326,38464 & 28,9490 \\
\hline Erro & 493 & 148,9470 & 90,5707 \\
\hline C.V\% & & 6,0 & 8,8 \\
\hline
\end{tabular}

${ }^{1} \mathrm{~N}_{1}{ }^{-} \ldots \mathrm{N}_{3}{ }^{+}$: simbolizam as combinações de níveis do fator de tratamento tamanho efetivo x seleção

* efeito significativo em nível de probabilidade igual ou inferior a 5\%, pelo teste $\mathrm{F}$

Quadrados médios sem asterisco não foram significativos 
Tabela 14. Quadrados médios da análise da variância do experimento 7, com subpopulações de tamanho reduzido, para os caracteres peso de espigas (PE), comprimento da espiga (CE), diâmetro da espiga (DE) e prolificidade (PR). ESALQ/Genética, 2003

\begin{tabular}{|c|c|c|c|c|c|}
\hline \multirow[t]{2}{*}{ Fonte de Variação } & \multirow[t]{2}{*}{ GL } & \multicolumn{4}{|c|}{ Quadrados médios } \\
\hline & & $\begin{array}{c}\mathrm{PE} \\
\left(\mathrm{kg} / 4 \mathrm{~m}^{2}\right)^{2}\end{array}$ & $\begin{array}{c}\mathrm{CE} \\
(\mathrm{cm} / \mathrm{esp} .)^{2}\end{array}$ & $\begin{array}{c}\mathrm{DE} \\
(\mathrm{cm} / \mathrm{esp} .)^{2}\end{array}$ & $\begin{array}{c}\text { PR } \\
\text { (esp./pl) } \\
2\end{array}$ \\
\hline Bloco & 8 & $0,5691 *$ & 1,5620 & 0,1898 & 0,0359 \\
\hline Tamanho efetivo & 2 & $15,2963 *$ & $49,1815^{*}$ & $0,9593 *$ & $0,9728 *$ \\
\hline Seleção & 1 & $22,7941 *$ & $42,4037 *$ & $2,7000^{*}$ & $3,1019 *$ \\
\hline Tamanho efetivo x Seleção & 2 & 2,2733 & 13,5815 & 0,0333 & $1,2039 *$ \\
\hline Subpopulações/Tamanho efetivo x Seleção & $(24)$ & $1,0159 *$ & $5,5555^{*}$ & $0,6630^{*}$ & $0,1760 *$ \\
\hline Subpopulações $/ \mathrm{N}_{1}^{-1}$ & 4 & $0,4121 *$ & $9,6444 *$ & $1,2000^{*}$ & $0,2200 *$ \\
\hline Subpopulações $/ \mathrm{N}_{1}^{+}$ & 4 & $1,5295^{*}$ & $3,4667^{*}$ & $1,1889^{*}$ & 0,0484 \\
\hline Subpopulações $/ \mathrm{N}_{2}^{-}$ & 4 & $0,7958^{*}$ & $2,3111 *$ & 0,0333 & 0,1281 \\
\hline Subpopulações $/ \mathrm{N}_{2}{ }^{+}$ & 4 & $0,3784^{*}$ & $8,1333^{*}$ & $0,3000^{*}$ & $0,3473 *$ \\
\hline Subpopulações/ $\mathrm{N}_{3}^{-}$ & 4 & 0,2045 & 0,9667 & $0,3111^{*}$ & $0,2819^{*}$ \\
\hline Subpopulações $/ \mathrm{N}_{3}{ }^{+}$ & 4 & $2,7752^{*}$ & $8,8111^{*}$ & $0,9444^{*}$ & 0,0303 \\
\hline Erro & 232 & 0,1190 & 0,9634 & 0,1151 & 0,0559 \\
\hline C.V\% & & 16,0 & 6,8 & 8,5 & 16,4 \\
\hline
\end{tabular}

${ }^{1} \mathrm{~N}_{1}{ }^{-} \ldots \mathrm{N}_{3}{ }^{+}$: simbolizam as combinações de níveis do fator de tratamento tamanho efetivo X seleção

* efeito significativo em nível de probabilidade igual ou inferior a 5\%, pelo teste $\mathrm{F}$ Quadrados médios sem asterisco não foram significativos 
Tabela 15. Quadrados médios da análise da variância do experimento 7, com subpopulações de tamanho reduzido, para os caracteres peso de espigas (PE), comprimento da espiga (CE), diâmetro da espiga (DE) e prolificidade (PR). Anhembi, 2003

\begin{tabular}{|c|c|c|c|c|c|}
\hline \multirow[t]{2}{*}{ Fonte de Variação } & \multirow[t]{2}{*}{ GL } & \multicolumn{4}{|c|}{ Quadrados médios } \\
\hline & & $\begin{array}{c}\mathrm{PE} \\
\left(\mathrm{kg} / 4 \mathrm{~m}^{2}\right)^{2}\end{array}$ & $\begin{array}{c}\mathrm{CE} \\
(\mathrm{cm} / \mathrm{esp} .)^{2}\end{array}$ & $\begin{array}{c}\mathrm{DE} \\
(\mathrm{cm} / \mathrm{esp} .)^{2}\end{array}$ & $\begin{array}{c}\text { PR } \\
\text { (esp./pl) } \\
2\end{array}$ \\
\hline Bloco & 9 & 0,1372 & 0,6848 & 0,1204 & 0,2901 \\
\hline Tamanho efetivo & 2 & $13,5602 *$ & $46,0633^{*}$ & 0,7033 & 1,0945 \\
\hline Seleção & 1 & $25,0563 *$ & $58,9633 *$ & $2,8033^{*}$ & $2,5025^{*}$ \\
\hline Tamanho efetivo x Seleção & 2 & $3,0779 *$ & 8,2233 & 0,3433 & $1,7041^{*}$ \\
\hline Subpopulações/Tamanho efetivo x Seleção & 24 & $0,7524^{*}$ & $6,4150^{*}$ & $0,5300^{*}$ & $4,4377^{*}$ \\
\hline Subpopulações $/ \mathrm{N}_{1}^{-1}$ & 4 & $0,4503 *$ & $12,7700^{*}$ & $1,6700^{*}$ & $0,2134^{*}$ \\
\hline Subpopulações $/ \mathrm{N}_{1}^{+}$ & 4 & $1,7222^{*}$ & $3,5500^{*}$ & $0,6300^{*}$ & $0,1550^{*}$ \\
\hline Subpopulações/ $\mathrm{N}_{2}^{-}$ & 4 & $0,6156^{*}$ & $2,8300^{*}$ & 0,0300 & $0,3107 *$ \\
\hline Subpopulações $/ \mathrm{N}_{2}^{+}$ & 4 & $0,7506^{*}$ & $12,4700^{*}$ & $0,3000^{*}$ & $0,1960 *$ \\
\hline Subpopulações/ $\mathrm{N}_{3}^{-}$ & 4 & $0,8392 *$ & $2,4200^{*}$ & 0,0800 & $0,1213^{*}$ \\
\hline Subpopulações $/ \mathrm{N}_{3}{ }^{+}$ & 4 & 0,1365 & $4,4500^{*}$ & $0,4700^{*}$ & $0,1131 *$ \\
\hline Erro & 261 & 0,1239 & 0,7714 & 0,0851 & 0,0287 \\
\hline C.V\% & & 17,2 & 5,8 & 7,3 & 14,2 \\
\hline
\end{tabular}

${ }^{1} \mathrm{~N}_{1}{ }^{-} \ldots \mathrm{N}_{3}{ }^{+}$: simbolizam as combinações de níveis do fator de tratamento tamanho efetivo x seleção

* efeito significativo em nível de probabilidade igual ou inferior a 5\%, pelo teste $\mathrm{F}$ Quadrados médios sem asterisco não foram significativos 
Tabela 16. Quadrados médios da análise da variância do experimento 7, com subpopulações de tamanho reduzido, para os caracteres altura da planta (AP) e altura da espiga (AE), por local

\begin{tabular}{|c|c|c|c|c|c|}
\hline \multirow[t]{4}{*}{ Fonte de Variação } & \multirow[t]{4}{*}{ GL } & \multicolumn{4}{|c|}{ Quadrados médios } \\
\hline & & \multicolumn{2}{|c|}{ L1 } & \multicolumn{2}{|c|}{ L2 } \\
\hline & & $\mathrm{AP}$ & $\mathrm{AE}$ & $\mathrm{AP}$ & $\mathrm{AE}$ \\
\hline & & $(\mathrm{cm} / \mathrm{pl})^{2}$ & $(\mathrm{~cm} / \mathrm{pl})^{2}$ & $(\mathrm{~cm} / \mathrm{pl})^{2}$ & $(\mathrm{~cm} / \mathrm{pl})^{2}$ \\
\hline Bloco & $8 / 9^{2}$ & 1952,8353* & $679,7148^{*}$ & $363,7348^{*}$ & 92,9200 \\
\hline Tamanho efetivo & 2 & $5106,8164 *$ & 2111,3037 & $2715,3733^{*}$ & 897,9600 \\
\hline Seleção & 1 & 1386,2935 & 598,5333 & 164,2800 & 663,0533 \\
\hline Tamanho efetivo x Seleção & 2 & 1097,7468 & 423,5111 & 147,8800 & 228,0133 \\
\hline Subpop./Tamanho efetivo x Seleção & (24) & $1257,7602 *$ & $797,9407^{*}$ & $790,4400^{*}$ & $395,0200 *$ \\
\hline Subpopulações $/ \mathrm{N}_{1}^{-1}$ & 4 & $1693,9111^{*}$ & $695,2444 *$ & $1455,0800^{*}$ & $188,4800^{*}$ \\
\hline Subpopulações $/ \mathrm{N}_{1}{ }^{+}$ & 4 & $1652,5778^{*}$ & $1486,3555^{*}$ & $537,8000^{*}$ & $629,5200^{*}$ \\
\hline Subpopulações $/ \mathrm{N}_{2}^{-}$ & 4 & $1708,2222 *$ & $1156,2222 *$ & $982,8800 *$ & $404,7200^{*}$ \\
\hline Subpopulações $/ \mathrm{N}_{2}^{+}$ & 4 & $1211,6889 *$ & $743,4222 *$ & $297,4800 *$ & $321,8000^{*}$ \\
\hline Subpopulações $/ \mathrm{N}_{3}^{-}$ & 4 & 148,2500 & 189,6444 & $276,2000^{*}$ & $362,7200 *$ \\
\hline Subpopulações $/ \mathrm{N}_{3}{ }^{+}$ & 4 & $1131,9111^{*}$ & $516,7556^{*}$ & $1193,2000^{*}$ & $462,8800^{*}$ \\
\hline Erro & $232 / 261^{2}$ & 187,4315 & 122,1899 & 114,7386 & $62,4648^{*}$ \\
\hline C.V\% & & 6,47 & 8,98 & 5,40 & 8,28 \\
\hline
\end{tabular}

${ }^{1} \mathrm{Ne} 1^{-} \ldots \mathrm{Ne} 3^{+}$: simbolizam as combinações de níveis do fator de tratamento tamanho efetivo x seleção

${ }^{2}$ Graus de liberdade dos locais 1 e 2 , respectivamente

* efeito significativo em nível de probabilidade igual ou inferior a 5\%, pelo teste $\mathrm{F}$

Quadrados médios sem asterisco não foram significativos 
Tabela 17. Valores médios do caráter peso de espigas $\left(\mathrm{kg} / 4 \mathrm{~m}^{2}\right)$, dados de dois locais, para o fator de tratamento tamanho efetivo x seleção

\begin{tabular}{|c|c|c|c|c|}
\hline \multirow{2}{*}{\multicolumn{5}{|c|}{ Seleção $^{1}$}} \\
\hline & & & & \\
\hline Negativa (A) & 1,23 & 1,89 & 2,32 & $1,81^{b}$ \\
\hline Positiva (B) & 2,15 & 2,45 & 2,59 & $2,39^{\mathrm{a}}$ \\
\hline$\overline{\bar{X}}$ & $1.69^{\mathrm{b}}$ & $2,17^{\mathrm{a}}$ & $2,46^{\mathrm{a}}$ & - \\
\hline $\mathrm{B}-\mathrm{A}$ & 0,92 & 0,56 & 0,27 & - \\
\hline
\end{tabular}

${ }^{1}$ Médias na mesma linha ou coluna, seguidas de mesma letra, não diferem pelo teste de Tukey $(\mathrm{p} \leq 0,05)$. Esta observação estende-se às situações correlatas

Tabela 18. Valores médios do caráter comprimento da espiga (cm/esp.), dados de dois locais, para o fator de tratamento tamanho efetivo x seleção

\begin{tabular}{|c|c|c|c|c|}
\hline \multirow{2}{*}{\multicolumn{5}{|c|}{$\begin{array}{l}\text { Tamanho efetivo } \\
\text { Seleção }\end{array}$}} \\
\hline & & & & \\
\hline Negativa (A) & 13,31 & 14,61 & 15,27 & $14,40^{b}$ \\
\hline Positiva (B) & 14,71 & 15,64 & 15,37 & $15,24^{\mathrm{a}}$ \\
\hline $\bar{X}$ & $14,01^{b}$ & $15,12^{\mathrm{a}}$ & $15,32^{\mathrm{a}}$ & - \\
\hline $\mathrm{B}-\mathrm{A}$ & 1,40 & 1,03 & 0,10 & - \\
\hline
\end{tabular}

Tabela 19. Valores médios do caráter variável diâmetro da espiga (cm/esp.), dados de dois locais, para o fator de tratamento tamanho efetivo x seleção

\begin{tabular}{|c|c|c|c|c|}
\hline Tamanho efetivo & 1 & 2 & 3 & $\bar{X}$ \\
\hline Seleção & & & & \\
\hline Negativa (A) & 3,76 & 4,00 & 3,94 & $3,90^{\mathrm{b}}$ \\
\hline Positiva (B) & 4,02 & 4,12 & 4,15 & $4,10^{\mathrm{a}}$ \\
\hline$\overline{\bar{X}}$ & $3,89^{\mathrm{a}}$ & $4,06^{\mathrm{a}}$ & $4,04^{\mathrm{a}}$ & - \\
\hline $\mathrm{B}-\mathrm{A}$ & 0,26 & 0,12 & 0,21 & - \\
\hline
\end{tabular}


Tabela 20. Valores médios do caráter prolificidade (esp./pl), dados de dois locais, para o fator de tratamento tamanho efetivo x seleção

\begin{tabular}{|c|c|c|c|c|}
\hline Tamanho efetivo & 1 & 2 & 3 & $\bar{X}$ \\
\hline \multicolumn{5}{|l|}{ Seleção } \\
\hline Negativa (A) & 1,05 & 1,19 & 1,42 & $1,22^{\mathrm{b}}$ \\
\hline Positiva (B) & 1,46 & 1,37 & 1,42 & $1,42^{\mathrm{a}}$ \\
\hline$\overline{\bar{X}}$ & $1,26^{\mathrm{b}}$ & $1,28^{\mathrm{ab}}$ & $1,42^{\mathrm{a}}$ & - \\
\hline $\mathrm{B}-\mathrm{A}$ & 0,41 & 0,18 & 0,00 & - \\
\hline
\end{tabular}

Tabela 21. Valores médios do caráter altura da planta $(\mathrm{cm} / \mathrm{pl})$, dados de dois locais, para o fator de tratamento tamanho efetivo x seleção

\begin{tabular}{|c|c|c|c|c|}
\hline Tamanho efetivo & 1 & 2 & 3 & $\bar{X}$ \\
\hline Seleção & & & & \\
\hline Negativa (A) & 194,21 & 205,27 & 210,94 & $203,47^{\mathrm{a}}$ \\
\hline Positiva (B) & 202,43 & 205,94 & 211,07 & $206,48^{\mathrm{a}}$ \\
\hline $\bar{X}$ & $198,32^{b}$ & $205,60^{\mathrm{ab}}$ & $211,00^{\mathrm{a}}$ & - \\
\hline $\mathrm{B}-\mathrm{A}$ & 8,22 & 0,67 & 0,13 & - \\
\hline
\end{tabular}

Tabela 22. Valores médios do caráter altura da espiga $(\mathrm{cm} / \mathrm{pl})$, dados de dois locais, para o fator de tratamento tamanho efetivo x seleção

\begin{tabular}{|c|c|c|c|c|}
\hline Tamanho efetivo & 1 & 2 & 3 & $\bar{X}$ \\
\hline Seleção & & & & \\
\hline Negativa (A) & 103,98 & 104,98 & 114,32 & $107,76^{\mathrm{a}}$ \\
\hline Positiva (B) & 109,98 & 108,99 & 113,23 & $110,73^{\mathrm{a}}$ \\
\hline $\bar{X}$ & $106,98^{\mathrm{a}}$ & $106,99^{\mathrm{a}}$ & $113,77^{\mathrm{a}}$ & - \\
\hline $\mathrm{B}-\mathrm{A}$ & 6,00 & 4,01 & $-1,09$ & - \\
\hline
\end{tabular}


Tabela 23. Valor médio $(\bar{X})$, depressão por endogamia (I) e relação valor médio/testemunha $(\bar{X} / T)$ para os caracteres peso de espigas (PE), comprimento da espiga (CE) e diâmetro da espiga (DE), obtidos em 30 subpopulações de tamanho efetivo reduzido, com seleção. ESALQ/Genética, 2003

\begin{tabular}{|c|c|c|c|c|c|c|c|c|c|c|c|}
\hline \multirow[t]{2}{*}{$\mathrm{N}$} & \multirow[t]{2}{*}{ Sel. } & \multirow[t]{2}{*}{ Subp. } & \multicolumn{3}{|c|}{$\mathrm{PE}$} & \multicolumn{3}{|c|}{$\mathrm{CE}$} & \multicolumn{3}{|c|}{$\mathrm{DE}$} \\
\hline & & & $\underset{\left(\mathrm{kg} / 4 \mathrm{~m}^{2}\right)}{\bar{X}}$ & $\mathrm{I}(\%)$ & $\begin{array}{c}\bar{X} / T \\
(\%)\end{array}$ & $\begin{array}{c}\bar{X} \\
(\mathrm{~cm} / \mathrm{esp})\end{array}$ & $\mathrm{I}(\%)$ & $\begin{array}{c}\bar{X} / T \\
(\%)\end{array}$ & $\begin{array}{c}\bar{X} \\
(\mathrm{~cm} / \mathrm{esp})\end{array}$ & $\mathrm{I}(\%)$ & $\begin{array}{c}\bar{X} / T \\
(\%)\end{array}$ \\
\hline 1 & $\mathrm{P}$ & 1 & 1,94 & 32,87 & 58 & 14,00 & 11,34 & 78 & 3,56 & 14,01 & 71 \\
\hline 1 & $\mathrm{P}$ & 2 & 2,88 & 0,35 & 87 & 15,33 & 2,91 & 85 & 4,56 & $-10,14$ & 91 \\
\hline 1 & $\mathrm{P}$ & 3 & 1,98 & 31,49 & 60 & 13,77 & 12,79 & 77 & 3,89 & 6,04 & 78 \\
\hline 1 & $\mathrm{P}$ & 4 & 1,96 & 32,18 & 59 & 14,44 & 8,55 & 80 & 4,00 & 3,38 & 80 \\
\hline 1 & $\mathrm{P}$ & 5 & 1,93 & 33,22 & 58 & 14,00 & 11,34 & 78 & 3,89 & 6,04 & 78 \\
\hline 1 & $\mathrm{~N}$ & 6 & 1,36 & 52,94 & 41 & 12,33 & 21,91 & 69 & 3,78 & 8,70 & 76 \\
\hline 1 & $\mathrm{~N}$ & 7 & 1,43 & 50,52 & 43 & 13,78 & 12,73 & 77 & 3,78 & 8,70 & 76 \\
\hline 1 & $\mathrm{~N}$ & 8 & 1,27 & 56,06 & 38 & 11,44 & 27,55 & 64 & 4,00 & 3,38 & 80 \\
\hline 1 & $\mathrm{~N}$ & 9 & 0,90 & 68,86 & 27 & 13,22 & 16,28 & 73 & 3,11 & 24,88 & 62 \\
\hline 1 & $\mathrm{~N}$ & 10 & 1,38 & 52,25 & 42 & 13,88 & 12,10 & 77 & 4,00 & 3,38 & 80 \\
\hline 2 & $\mathrm{P}$ & 11 & 2,86 & 1,04 & 86 & 16,11 & $-2,03$ & 90 & 4,11 & 0,72 & 82 \\
\hline 2 & $\mathrm{P}$ & 12 & 2,52 & 12,80 & 76 & 14,22 & 9,94 & 79 & 4,11 & 0,72 & 82 \\
\hline 2 & $\mathrm{P}$ & 13 & 2,30 & 20,42 & 69 & 14,44 & 8,55 & 80 & 4,00 & 3,38 & 80 \\
\hline 2 & $\mathrm{P}$ & 14 & 2,52 & 12,80 & 76 & 16,22 & $-2,72$ & 90 & 4,44 & $-7,25$ & 89 \\
\hline 2 & $\mathrm{P}$ & 15 & 2,66 & 7,96 & 80 & 15,77 & 0,13 & 88 & 4,00 & 3,38 & 80 \\
\hline 2 & $\mathrm{~N}$ & 16 & 2,16 & 25,26 & 65 & 14,77 & 6,46 & 82 & 4,00 & 3,38 & 80 \\
\hline 2 & $\mathrm{~N}$ & 17 & 1,81 & 37,37 & 55 & 14,55 & 7,85 & 81 & 3,89 & 6,04 & 78 \\
\hline 2 & $\mathrm{~N}$ & 18 & 2,35 & 18,69 & 71 & 14,55 & 7,85 & 81 & 4,00 & 3,38 & 80 \\
\hline 2 & $\mathrm{~N}$ & 19 & 1,66 & 42,56 & 50 & 13,77 & 12,79 & 77 & 4,00 & 3,38 & 80 \\
\hline 2 & $\mathrm{~N}$ & 20 & 1,73 & 40,14 & 52 & 13,66 & 13,49 & 76 & 3,89 & 6,04 & 78 \\
\hline 3 & $\mathrm{P}$ & 21 & 3,56 & $-23,18$ & 107 & 15,44 & 2,22 & 86 & 4,56 & $-10,14$ & 91 \\
\hline 3 & $\mathrm{P}$ & 22 & 2,63 & 9,00 & 79 & 16,44 & $-4,12$ & 91 & 4,00 & 3,38 & 80 \\
\hline 3 & $\mathrm{P}$ & 23 & 2,13 & 26,30 & 64 & 14,22 & 9,94 & 79 & 3,67 & 11,35 & 73 \\
\hline 3 & $\mathrm{P}$ & 24 & 2,51 & 13,15 & 76 & 14,22 & 9,94 & 79 & 4,22 & $-1,93$ & 84 \\
\hline 3 & $\mathrm{P}$ & 25 & 2,30 & 20,42 & 69 & 14,33 & 9,25 & 80 & 4,11 & 0,72 & 82 \\
\hline 3 & $\mathrm{~N}$ & 26 & 2,19 & 24,22 & 66 & 15,55 & 1,52 & 86 & 3,78 & 8,70 & 76 \\
\hline 3 & $\mathrm{~N}$ & 27 & 2,35 & 18,69 & 71 & 14,88 & 5,76 & 83 & 4,00 & 3,38 & 80 \\
\hline 3 & $\mathrm{~N}$ & 28 & 2,38 & 17.65 & 72 & 15,00 & 5,00 & 83 & 4,22 & $-1,93$ & 84 \\
\hline 3 & $\mathrm{~N}$ & 29 & 2,40 & 16,96 & 72 & 15,00 & 5,00 & 83 & 3,89 & 6,04 & 78 \\
\hline 3 & $\mathrm{~N}$ & 30 & 2,61 & 9,69 & 79 & 14,66 & 7,16 & 81 & 3,78 & 8,70 & 76 \\
\hline
\end{tabular}


Tabela 24. Valor médio $(\bar{X})$, depressão por endogamia (I) e relação valor médio/testemunha $(\bar{X} / T)$ para os caracteres prolificidade $(\mathrm{PR})$, altura da planta (AP) e altura da espiga (AE), obtidos em 30 subpopulações de tamanho efetivo reduzido, com seleção. ESALQ/Genética, 2003

\begin{tabular}{|c|c|c|c|c|c|c|c|c|c|c|c|}
\hline \multirow[t]{2}{*}{$\mathrm{N}$} & \multirow[t]{2}{*}{ Sel. } & \multirow[t]{2}{*}{ Subp. } & \multicolumn{3}{|c|}{ PR } & \multicolumn{3}{|c|}{ AP } & \multicolumn{3}{|c|}{$\mathrm{AE}$} \\
\hline & & & $\begin{array}{c}\bar{X} \\
(\mathrm{esp} / \mathrm{pl})\end{array}$ & $\mathrm{I}(\%)$ & $\begin{array}{c}\bar{X} / \mathrm{T} \\
(\%)\end{array}$ & $\begin{array}{c}\bar{X} \\
(\mathrm{~cm} / \mathrm{pl}) \\
\end{array}$ & $\mathrm{I}(\%)$ & $\begin{array}{l}\bar{X} / T \\
(\%)\end{array}$ & $\begin{array}{c}\bar{X} \\
(\mathrm{~cm} / \mathrm{pl})\end{array}$ & $\mathrm{I}(\%)$ & $\begin{array}{l}\bar{X} / T \\
(\%)\end{array}$ \\
\hline 1 & $\mathrm{P}$ & 1 & 1,56 & 1,92 & 139 & 223,56 & 0,62 & 118 & 138,89 & $-7,62$ & 129 \\
\hline 1 & $\mathrm{P}$ & 2 & 1,63 & $-2,56$ & 146 & 224,89 & 0,03 & 118 & 136,44 & $-5,73$ & 126 \\
\hline 1 & $\mathrm{P}$ & 3 & 1,51 & 5,13 & 135 & 205,78 & 8,53 & 108 & 112,67 & 12,69 & 104 \\
\hline 1 & $\mathrm{P}$ & 4 & 1,59 & 0,00 & 142 & 198,44 & 11,79 & 104 & 116,22 & 9,94 & 108 \\
\hline 1 & $\mathrm{P}$ & 5 & 1,71 & $-7,69$ & 153 & 196,67 & 12,58 & 104 & 114,22 & 11,49 & 106 \\
\hline 1 & $\mathrm{~N}$ & 6 & 1,38 & 13,46 & 123 & 175,78 & 21,86 & 93 & 106,89 & 17,17 & 99 \\
\hline 1 & $\mathrm{~N}$ & 7 & 1,20 & 25,00 & 107 & 208,89 & 7,14 & 110 & 127,11 & 1,50 & 118 \\
\hline 1 & $\mathrm{~N}$ & 8 & 1,04 & 35,26 & 93 & 199,56 & 11,29 & 105 & 109,56 & 15,10 & 101 \\
\hline 1 & $\mathrm{~N}$ & 9 & 1,13 & 29,49 & 101 & 194,00 & 13,76 & 102 & 124,00 & 3,91 & 115 \\
\hline 1 & $\mathrm{~N}$ & 10 & 0,97 & 39,74 & 87 & 209,11 & 7,05 & 110 & 116,44 & 9,77 & 108 \\
\hline 2 & $\mathrm{P}$ & 11 & 1,40 & 12,18 & 125 & 226,67 & $-0,76$ & 119 & 126,00 & 2,36 & 117 \\
\hline 2 & $\mathrm{P}$ & 12 & 1,44 & 9,62 & 129 & 208,67 & 7,24 & 110 & 120,00 & 7,01 & 111 \\
\hline 2 & $\mathrm{P}$ & 13 & 1,64 & $-3,21$ & 146 & 199,33 & 11,39 & 105 & 114,89 & 10,97 & 106 \\
\hline 2 & $\mathrm{P}$ & 14 & 1,22 & 23,72 & 109 & 210,00 & 6,65 & 111 & 114,00 & 11,66 & 106 \\
\hline 2 & $\mathrm{P}$ & 15 & 1,72 & $-8,33$ & 154 & 224,89 & 0,03 & 118 & 136,00 & $-5,39$ & 126 \\
\hline 2 & $\mathrm{~N}$ & 16 & 1,42 & 10,90 & 127 & 209,11 & 7,05 & 110 & 117,56 & 8,90 & 109 \\
\hline 2 & $\mathrm{~N}$ & 17 & 1,21 & 24,36 & 108 & 225,11 & $-0,07$ & 118 & 131,78 & $-2,12$ & 122 \\
\hline 2 & $\mathrm{~N}$ & 18 & 1,38 & 13,46 & 123 & 227,11 & $-0,96$ & 120 & 125,78 & 2,53 & 116 \\
\hline 2 & $\mathrm{~N}$ & 19 & 1,14 & 28,85 & 102 & 198,00 & 11,98 & 104 & 102,00 & 20,96 & 94 \\
\hline 2 & $\mathrm{~N}$ & 20 & 1,34 & 16,03 & 120 & 199,56 & 11,29 & 105 & 115,11 & 10,80 & 107 \\
\hline 3 & $\mathrm{P}$ & 21 & 1,48 & 7,05 & 132 & 227,33 & $-1,05$ & 120 & 128,44 & 0,47 & 119 \\
\hline 3 & $\mathrm{P}$ & 22 & 1,59 & 0,00 & 142 & 226,22 & $-0,56$ & 119 & 138,67 & $-7,45$ & 128 \\
\hline 3 & $\mathrm{P}$ & 23 & 1,59 & 0,00 & 142 & 203,78 & 9,42 & 107 & 119,11 & 7,70 & 110 \\
\hline 3 & $\mathrm{P}$ & 24 & 1,52 & 4,49 & 136 & 208,22 & 7,44 & 110 & 122,44 & 5,12 & 113 \\
\hline 3 & $\mathrm{P}$ & 25 & 1,62 & $-1,92$ & 145 & 225,11 & $-0,07$ & 118 & 130,44 & $-1,08$ & 121 \\
\hline 3 & $\mathrm{~N}$ & 26 & 1,61 & $-1,28$ & 144 & 220,69 & 1,90 & 116 & 130,89 & $-1,43$ & 121 \\
\hline 3 & $\mathrm{~N}$ & 27 & 1,73 & $-8,97$ & 154 & 214,89 & 4,48 & 113 & 122,67 & 4,94 & 114 \\
\hline 3 & $\mathrm{~N}$ & 28 & 1,26 & 21,15 & 113 & 219,78 & 2,30 & 116 & 127,56 & 1,15 & 118 \\
\hline 3 & $\mathrm{~N}$ & 29 & 1,57 & 1,28 & 140 & 224,67 & 0,13 & 118 & 134,67 & $-4,35$ & 125 \\
\hline 3 & $\mathrm{~N}$ & 30 & 1,64 & $-3,21$ & 146 & 215,33 & 4,28 & 113 & 131,78 & $-2,12$ & 122 \\
\hline
\end{tabular}


Tabela 25. Valor médio $(\bar{X})$, depressão por endogamia (I) e relação valor médio/testemunha $(\bar{X} / T)$ para os caracteres peso de espigas (PE), comprimento da espiga (CE) e diâmetro da espiga (DE), obtidos em 30 subpopulações de tamanho efetivo reduzido, com seleção. Anhembi, 2003

\begin{tabular}{|c|c|c|c|c|c|c|c|c|c|c|c|}
\hline \multirow[t]{2}{*}{$\mathrm{N}$} & \multirow[t]{2}{*}{ Sel. } & \multirow[t]{2}{*}{ Subp. } & \multicolumn{3}{|c|}{$\mathrm{PE}$} & \multicolumn{3}{|c|}{$\mathrm{CE}$} & \multicolumn{3}{|c|}{$\mathrm{DE}$} \\
\hline & & & $\underset{\left(\mathrm{kg} / 4 \mathrm{~m}^{2}\right)}{\bar{X}}$ & $\mathrm{I}(\%)$ & $\begin{array}{c}\overline{\mathrm{X}} / \mathrm{T} \\
(\%)\end{array}$ & $\begin{array}{c}\bar{X} \\
(\mathrm{~cm} / \mathrm{esp})\end{array}$ & $\mathrm{I}(\%)$ & $\begin{array}{c}\bar{X} / T \\
(\%)\end{array}$ & $\underset{(\mathrm{cm} / \mathrm{esp})}{\bar{X}}$ & $\mathrm{I}(\%)$ & $\begin{array}{c}\bar{X} / T \\
(\%)\end{array}$ \\
\hline 1 & $\mathrm{P}$ & 1 & 1,75 & 34,94 & 60 & 15,00 & 8,37 & 83 & 3,90 & 6,25 & 78 \\
\hline 1 & P & 2 & 2,82 & $-4,83$ & 97 & 16,10 & 1,65 & 89 & 4,50 & $-8,17$ & 90 \\
\hline 1 & $\mathrm{P}$ & 3 & 2,07 & 23,05 & 71 & 15,10 & 7,76 & 84 & 3,90 & 6,25 & 78 \\
\hline 1 & $\mathrm{P}$ & 4 & 1,88 & 30,11 & 65 & 14,70 & 10,20 & 82 & 4,00 & 3,85 & 80 \\
\hline 1 & $\mathrm{P}$ & 5 & 2,24 & 16,73 & 77 & 14,60 & 10,81 & 81 & 4,00 & 3,85 & 80 \\
\hline 1 & $\mathrm{~N}$ & 6 & 1,32 & 50,93 & 45 & 13,00 & 20,59 & 72 & 4,00 & 3,85 & 80 \\
\hline 1 & $\mathrm{~N}$ & 7 & 0,99 & 63,20 & 34 & 13,90 & 15,09 & 77 & 3,50 & 15,87 & 70 \\
\hline 1 & $\mathrm{~N}$ & 8 & 1,35 & 49,81 & 46 & 12,10 & 26,08 & 67 & 4,10 & 1,44 & 82 \\
\hline 1 & $\mathrm{~N}$ & 9 & 0,92 & 65,80 & 32 & 14,60 & 10,81 & 81 & 3,20 & 23,08 & 64 \\
\hline 1 & $\mathrm{~N}$ & 10 & 1,35 & 49,81 & 46 & 14,80 & 9,59 & 82 & 4,10 & 1,44 & 82 \\
\hline 2 & $\mathrm{P}$ & 11 & 2,31 & 14,13 & 79 & 16,40 & $-0,18$ & 91 & 4,00 & 3,85 & 80 \\
\hline 2 & $\mathrm{P}$ & 12 & 2,39 & 11,15 & 82 & 15,10 & 7,76 & 84 & 4,10 & 1,44 & 82 \\
\hline 2 & P & 13 & 1,96 & 27,14 & 67 & 14,40 & 12,03 & 80 & 4,00 & 3,85 & 80 \\
\hline 2 & $\mathrm{P}$ & 14 & 2,71 & $-0,74$ & 93 & 17,00 & $-3,85$ & 94 & 4,40 & $-5,77$ & 88 \\
\hline 2 & $\mathrm{P}$ & 15 & 2,23 & 17,10 & 77 & 16,70 & $-2,02$ & 93 & 4,00 & 3,85 & 80 \\
\hline 2 & $\mathrm{~N}$ & 16 & 1,73 & 35,69 & 59 & 15,20 & 7,15 & 84 & 4,00 & 3,85 & 80 \\
\hline 2 & $\mathrm{~N}$ & 17 & 1,99 & 26,02 & 68 & 15,00 & 8,37 & 83 & 4,00 & 3,85 & 80 \\
\hline 2 & $\mathrm{~N}$ & 18 & 2,20 & 18,22 & 76 & 15,70 & 4,09 & 87 & 4,10 & 1,44 & 82 \\
\hline 2 & $\mathrm{~N}$ & 19 & 1,62 & 39,78 & 56 & 14,50 & 11,42 & 81 & 4,00 & 3,85 & 80 \\
\hline 2 & $\mathrm{~N}$ & 20 & 1,67 & 37,92 & 57 & 14,40 & 12,03 & 80 & 4,10 & 1,44 & 82 \\
\hline 3 & $\mathrm{P}$ & 21 & 2,65 & 1,49 & 91 & 15,20 & 7,15 & 84 & 4,50 & $-8,17$ & 90 \\
\hline 3 & $\mathrm{P}$ & 22 & 2,55 & 5,20 & 88 & 16,50 & $-0,79$ & 92 & 4,10 & 1,44 & 82 \\
\hline 3 & $\mathrm{P}$ & 23 & 2,64 & 1,86 & 91 & 16,00 & 2,26 & 89 & 4,00 & 3,85 & 80 \\
\hline 3 & $\mathrm{P}$ & 24 & 2,54 & 5,58 & 87 & 15,00 & 8,37 & 83 & 4,30 & $-3,37$ & 86 \\
\hline 3 & $\mathrm{P}$ & 25 & 2,36 & 12,27 & 81 & 16,30 & 0,43 & 91 & 4,00 & 3,85 & 80 \\
\hline 3 & $\mathrm{~N}$ & 26 & 1,79 & 33,46 & 62 & 16,00 & 2,26 & 89 & 3,90 & 6,25 & 78 \\
\hline 3 & $\mathrm{~N}$ & 27 & 2,28 & 15,24 & 78 & 15,90 & 2,87 & 88 & 4,00 & 3,85 & 80 \\
\hline 3 & $\mathrm{~N}$ & 28 & 2,29 & 14,87 & 79 & 14,90 & 8,98 & 83 & 4,00 & 3,85 & 80 \\
\hline 3 & $\mathrm{~N}$ & 29 & 2,58 & 4,09 & 89 & 15,70 & 4,09 & 87 & 4,00 & 3,85 & 80 \\
\hline 3 & $\mathrm{~N}$ & 30 & 2,36 & 12,27 & 81 & 15,10 & 7,76 & 84 & 3,80 & 8,65 & 76 \\
\hline
\end{tabular}


Tabela 26. Valor médio $(\overline{\mathrm{X}})$, depressão por endogamia (I) e relação valor médio/testemunha $(\bar{X} / T)$ para os caracteres prolificidade $(\mathrm{PR})$, altura da planta (AP) e altura da espiga (AE), obtidos em 30 subpopulações de tamanho efetivo reduzido, com seleção. Anhembi, 2003

\begin{tabular}{|c|c|c|c|c|c|c|c|c|c|c|c|}
\hline \multirow[t]{2}{*}{$\mathrm{N}$} & \multirow[t]{2}{*}{ Sel. } & \multirow[t]{2}{*}{ Subp. } & \multicolumn{3}{|c|}{ PR } & \multicolumn{3}{|c|}{$\mathrm{AP}$} & \multicolumn{3}{|c|}{$\mathrm{AE}$} \\
\hline & & & $\begin{array}{c}\bar{X} \\
(\operatorname{esp} / p l)\end{array}$ & $\mathrm{I}(\%)$ & $\begin{array}{c}\bar{X} / T \\
(\%)\end{array}$ & $\begin{array}{c}\bar{X} \\
(\mathrm{~cm} / \mathrm{pl})\end{array}$ & $\mathrm{I}(\%)$ & $\begin{array}{c}\bar{X} / T \\
(\%)\end{array}$ & $\begin{array}{c}\bar{X} \\
(\mathrm{~cm} / \mathrm{pl})\end{array}$ & $\mathrm{I}(\%)$ & $\begin{array}{c}\bar{X} / T \\
(\%)\end{array}$ \\
\hline 1 & $\mathrm{P}$ & 1 & 1,33 & $-2,31$ & 129 & 194,80 & 5,98 & 118 & 102,40 & $-3,38$ & 123 \\
\hline 1 & $\mathrm{P}$ & 2 & 1,46 & $-12,31$ & 142 & 205,80 & 0,67 & 121 & 106,80 & $-7,82$ & 129 \\
\hline 1 & $\mathrm{P}$ & 3 & 1,25 & 3,85 & 121 & 192,80 & 6,95 & 115 & 90,00 & 9,14 & 108 \\
\hline 1 & $\mathrm{P}$ & 4 & 1,15 & 11,54 & 112 & 196,20 & 5,30 & 115 & 93,40 & 5,70 & 113 \\
\hline 1 & $\mathrm{P}$ & 5 & 1,42 & $-9,23$ & 138 & 185,40 & 10,52 & 117 & 88,80 & 10,35 & 107 \\
\hline 1 & $\mathrm{~N}$ & 6 & 1,18 & 9,23 & 115 & 171,80 & 17,08 & 121 & 84,20 & 14,99 & 101 \\
\hline 1 & $\mathrm{~N}$ & 7 & 0,92 & 29,23 & 89 & 195,20 & 5,79 & 119 & 96,20 & 2,88 & 116 \\
\hline 1 & $\mathrm{~N}$ & 8 & 0,86 & 33,85 & 84 & 202,80 & 2,12 & 128 & 91,80 & 7,32 & 111 \\
\hline 1 & $\mathrm{~N}$ & 9 & 0,99 & 23,85 & 96 & 187,40 & 9,55 & 113 & 92,20 & 6,92 & 111 \\
\hline 1 & $\mathrm{~N}$ & 10 & 0,80 & 38,46 & 78 & 197,60 & 4,63 & 117 & 91,40 & 7,72 & 110 \\
\hline 2 & $\mathrm{P}$ & 11 & 1,18 & 9,23 & 115 & 203,80 & 1,64 & 114 & 97,40 & 1,67 & 117 \\
\hline 2 & $\mathrm{P}$ & 12 & 1,23 & 5,38 & 119 & 192,80 & 6,95 & 124 & 93,80 & 5,30 & 113 \\
\hline 2 & $\mathrm{P}$ & 13 & 1,33 & $-2,31$ & 129 & 193,00 & 6,85 & 127 & 89,00 & 10,15 & 107 \\
\hline 2 & $\mathrm{P}$ & 14 & 1,10 & 15,38 & 107 & 196,60 & 5,11 & 115 & 94,40 & 4,69 & 114 \\
\hline 2 & $\mathrm{P}$ & 15 & 1,46 & $-12,31$ & 142 & 203,60 & 1,73 & 114 & 104,40 & $-5,40$ & 126 \\
\hline 2 & $\mathrm{~N}$ & 16 & 1,18 & 9,23 & 115 & 200,40 & 3,28 & 127 & 89,00 & 10,15 & 107 \\
\hline 2 & $\mathrm{~N}$ & 17 & 1,34 & $-3,08$ & 130 & 215,00 & $-3,77$ & 121 & 102,60 & $-3,58$ & 124 \\
\hline 2 & $\mathrm{~N}$ & 18 & 1,02 & 21,54 & 99 & 190,40 & 8,10 & 116 & 87,80 & 11,36 & 106 \\
\hline 2 & $\mathrm{~N}$ & 19 & 0,90 & 30,77 & 87 & 196,40 & 5,21 & 124 & 91,00 & 8,13 & 110 \\
\hline 2 & $\mathrm{~N}$ & 20 & 0,97 & 25,38 & 94 & 191,60 & 7,52 & 123 & 87,20 & 11,96 & 105 \\
\hline 3 & $\mathrm{P}$ & 21 & 1,25 & 3,85 & 121 & 209,00 & $-0,87$ & 120 & 94,80 & 4,29 & 114 \\
\hline 3 & $\mathrm{P}$ & 22 & 1,30 & 0,00 & 126 & 213,80 & $-3,19$ & 118 & 106,00 & $-7,02$ & 128 \\
\hline 3 & $\mathrm{P}$ & 23 & 1,23 & 5,38 & 119 & 192,60 & 7,04 & 121 & 94,40 & 4,69 & 114 \\
\hline 3 & $\mathrm{P}$ & 24 & 1,16 & 10,77 & 113 & 191,80 & 7,43 & 115 & 92,00 & 7,12 & 111 \\
\hline 3 & $\mathrm{P}$ & 25 & 1,44 & $-10,77$ & 140 & 212,80 & $-2,71$ & 115 & 106,00 & $-7,02$ & 128 \\
\hline 3 & $\mathrm{~N}$ & 26 & 1,28 & 1,54 & 124 & 203,80 & 1,64 & 117 & 95,80 & 3,28 & 115 \\
\hline 3 & $\mathrm{~N}$ & 27 & 1,30 & 0,00 & 126 & 194,40 & 6,17 & 121 & 93,00 & 6,11 & 112 \\
\hline 3 & $\mathrm{~N}$ & 28 & 1,10 & 15,38 & 107 & 207,60 & $-0,20$ & 119 & 107,40 & $-8,43$ & 129 \\
\hline 3 & $\mathrm{~N}$ & 29 & 1,40 & $-7,69$ & 136 & 206,60 & 0,28 & 128 & 96,00 & 3,08 & 116 \\
\hline 3 & $\mathrm{~N}$ & 30 & 1,32 & $-1,54$ & 128 & 201,60 & 2,70 & 113 & 103,40 & $-4,39$ & 125 \\
\hline
\end{tabular}


Tabela 27. Valor médio ( $\bar{X})$, depressão por endogamia (I) e relação valor médio/testemunha $(\bar{X} / T)$, dados de dois locais, para os caracteres peso de espigas (PE), comprimento da espiga (CE) e diâmetro da espiga (DE), obtidos em 30 subpopulações de tamanho efetivo reduzido, com seleção

\begin{tabular}{|c|c|c|c|c|c|c|c|c|c|c|c|}
\hline \multirow[t]{2}{*}{$\mathrm{N}$} & \multirow[t]{2}{*}{ Sel. } & \multirow[t]{2}{*}{ Subp. } & \multicolumn{3}{|c|}{$\mathrm{PE}$} & \multicolumn{3}{|c|}{$\mathrm{CE}$} & \multicolumn{3}{|c|}{ DE } \\
\hline & & & $\underset{\left(\mathrm{kg} / 4 \mathrm{~m}^{2}\right)}{\bar{X}}$ & $\mathrm{I}(\%)$ & $\begin{array}{c}\bar{X} / T \\
(\%)\end{array}$ & $\begin{array}{c}\bar{X} \\
(\mathrm{~cm} / \mathrm{pl})\end{array}$ & $\mathrm{I}(\%)$ & $\begin{array}{c}\bar{X} / \mathrm{T} \\
(\%)\end{array}$ & $\begin{array}{c}\bar{X} \\
(\%)\end{array}$ & $\mathrm{I}(\%)$ & $\begin{array}{c}\bar{X} / \mathrm{T} \\
(\%)\end{array}$ \\
\hline 1 & $\mathrm{P}$ & 1 & 1,85 & 33,69 & 59 & 14,50 & 9,77 & 81 & 3,73 & 10,12 & 75 \\
\hline 1 & $\mathrm{P}$ & 2 & 2,85 & $-2,15$ & 91 & 15,72 & 2,18 & 87 & 4,53 & $-9,16$ & 91 \\
\hline 1 & $\mathrm{P}$ & 3 & 2,03 & 27,24 & 65 & 14,44 & 10,14 & 80 & 3,89 & 6,27 & 78 \\
\hline 1 & $\mathrm{P}$ & 4 & 1,92 & 31,18 & 62 & 14,57 & 9,33 & 81 & 4,00 & 3,61 & 80 \\
\hline 1 & $\mathrm{P}$ & 5 & 2,09 & 25,09 & 67 & 14,30 & 11,01 & 79 & 3,94 & 5,06 & 79 \\
\hline 1 & $\mathrm{~N}$ & 6 & 1,34 & 51,97 & 43 & 12,67 & 21,16 & 70 & 3,89 & 6,27 & 78 \\
\hline 1 & $\mathrm{~N}$ & 7 & 1,21 & 56,63 & 39 & 13,84 & 13,88 & 77 & 3,64 & 12,29 & 73 \\
\hline 1 & $\mathrm{~N}$ & 8 & 1,31 & 53,05 & 42 & 11,77 & 26,76 & 65 & 4,05 & 2,41 & 81 \\
\hline 1 & $\mathrm{~N}$ & 9 & 0,91 & 67,38 & 29 & 13,91 & 13,44 & 77 & 3,16 & 23,86 & 63 \\
\hline 1 & $\mathrm{~N}$ & 10 & 1,37 & 50,90 & 44 & 14,34 & 10,77 & 80 & 4,05 & 2,41 & 81 \\
\hline 2 & $\mathrm{P}$ & 11 & 2,58 & 7,53 & 83 & 16,26 & $-1,18$ & 90 & 4,06 & 2,17 & 81 \\
\hline 2 & $\mathrm{P}$ & 12 & 2,46 & 11,83 & 79 & 14,66 & 8,77 & 81 & 4,11 & 0,96 & 82 \\
\hline 2 & $\mathrm{P}$ & 13 & 2,13 & 23,66 & 68 & 14,42 & 10,27 & 80 & 4,00 & 3,61 & 80 \\
\hline 2 & $\mathrm{P}$ & 14 & 2,61 & 6,45 & 84 & 16,61 & $-3,36$ & 92 & 4,42 & $-6,51$ & 88 \\
\hline 2 & $\mathrm{P}$ & 15 & 2,45 & 12,19 & 79 & 16,24 & $-1,06$ & 90 & 4,00 & 3,61 & 80 \\
\hline 2 & $\mathrm{~N}$ & 16 & 1,95 & 30,11 & 63 & 14,99 & 6,72 & 83 & 4,00 & 3,61 & 80 \\
\hline 2 & $\mathrm{~N}$ & 17 & 1,90 & 31,90 & 61 & 14,78 & 8,03 & 82 & 3,94 & 5,06 & 79 \\
\hline 2 & $\mathrm{~N}$ & 18 & 2,27 & 18,64 & 73 & 15,13 & 5,85 & 84 & 4,05 & 2,41 & 81 \\
\hline 2 & $\mathrm{~N}$ & 19 & 1,64 & 41,22 & 53 & 14,14 & 12,01 & 79 & 4,00 & 3,61 & 80 \\
\hline 2 & $\mathrm{~N}$ & 20 & 1,70 & 39,07 & 54 & 14,03 & 12,69 & 78 & 3,99 & 3,86 & 80 \\
\hline 3 & $\mathrm{P}$ & 21 & 3,10 & $-11,11$ & 99 & 15,32 & 4,67 & 85 & 4,53 & $-9,16$ & 91 \\
\hline 3 & $\mathrm{P}$ & 22 & 2,59 & 7,17 & 83 & 16,47 & $-2,49$ & 92 & 4,05 & 2,41 & 81 \\
\hline 3 & $\mathrm{P}$ & 23 & 2,39 & 14,34 & 77 & 15,11 & 5,97 & 84 & 3,83 & 7,71 & 77 \\
\hline 3 & $\mathrm{P}$ & 24 & 2,53 & 9,32 & 81 & 14,61 & 9,09 & 81 & 4,26 & $-2,65$ & 85 \\
\hline 3 & $\mathrm{P}$ & 25 & 2,33 & 16,49 & 75 & 15,32 & 4,67 & 85 & 4,06 & 2,17 & 81 \\
\hline 3 & $\mathrm{~N}$ & 26 & 1,99 & 28,67 & 64 & 15,78 & 1,80 & 88 & 3,84 & 7,47 & 77 \\
\hline 3 & $\mathrm{~N}$ & 27 & 2,32 & 16,85 & 74 & 15,39 & 4,23 & 86 & 4,00 & 3,61 & 80 \\
\hline 3 & $\mathrm{~N}$ & 28 & 2,34 & 16,13 & 75 & 14,95 & 6,97 & 83 & 4,11 & 0,96 & 82 \\
\hline 3 & $\mathrm{~N}$ & 29 & 2,49 & 10,75 & 80 & 15,35 & 4,48 & 85 & 3,94 & 5,06 & 79 \\
\hline 3 & $\mathrm{~N}$ & 30 & 2,49 & 10,75 & 80 & 14,88 & 7,41 & 83 & 3,79 & 8,67 & 76 \\
\hline
\end{tabular}


Tabela 28. Valor médio $(\bar{X})$, depressão por endogamia (I) e relação valor médio/testemunha $(\bar{X} / T)$, dados de dois locais, para os caracteres prolificidade (PR), altura da planta (AP) e altura da espiga (AE), obtidos em 30 subpopulações de tamanho efetivo reduzido, com seleção

\begin{tabular}{|c|c|c|c|c|c|c|c|c|c|c|c|}
\hline \multirow[t]{2}{*}{$\mathrm{N}$} & \multirow[t]{2}{*}{ Sel. } & \multirow[t]{2}{*}{ Subp. } & \multicolumn{3}{|c|}{ PR } & \multicolumn{3}{|c|}{ AP } & \multicolumn{3}{|c|}{$\mathrm{AE}$} \\
\hline & & & $\begin{array}{c}\bar{X} \\
(\operatorname{esp} / p l)\end{array}$ & $\mathrm{I}(\%)$ & $\begin{array}{l}\bar{X} / T \\
(\%)\end{array}$ & $\begin{array}{c}\bar{X} \\
(\mathrm{~cm} / \mathrm{pl})\end{array}$ & $\mathrm{I}(\%)$ & $\begin{array}{c}\bar{X} / T \\
(\%)\end{array}$ & $\begin{array}{c}\bar{X} \\
(\mathrm{~cm} / \mathrm{pl})\end{array}$ & $\mathrm{I}(\%)$ & $\begin{array}{c}\bar{X} / T \\
(\%)\end{array}$ \\
\hline 1 & $P$ & 1 & 1,44 & 0,69 & 133 & 194,80 & 5,98 & 109 & 120,64 & \begin{tabular}{|l|}
$-5,78$ \\
\end{tabular} & 126 \\
\hline 1 & $\mathrm{P}$ & 2 & 1,54 & $-6,21$ & 143 & 205,80 & 0,67 & 115 & 121,62 & $-6,64$ & 127 \\
\hline 1 & $\mathrm{P}$ & 3 & 1,38 & 4,83 & 128 & 192,80 & 6,95 & 108 & 101,33 & 11,15 & 106 \\
\hline 1 & $\mathrm{P}$ & 4 & 1,37 & 5,52 & 127 & 196,20 & 5,30 & 110 & 104,81 & 8,10 & 109 \\
\hline 1 & $\mathrm{P}$ & 5 & 1,57 & $-8,28$ & 145 & 185,40 & 10,52 & 104 & 101,51 & 11,00 & 106 \\
\hline 1 & $\mathrm{~N}$ & 6 & 1,28 & 11,72 & 119 & 171,80 & 17,08 & 96 & 95,54 & 16,23 & 100 \\
\hline 1 & $\mathrm{~N}$ & 7 & 1,06 & 26,90 & 98 & 195,20 & 5,79 & 109 & 111,66 & 2,10 & 116 \\
\hline 1 & $\mathrm{~N}$ & 8 & 0,95 & 34,48 & 88 & 202,80 & 2,12 & 113 & 100,68 & 11,72 & 105 \\
\hline 1 & $\mathrm{~N}$ & 9 & 1,06 & 26,90 & 98 & 187,40 & 9,55 & 105 & 108,10 & 5,22 & 113 \\
\hline 1 & $\mathrm{~N}$ & 10 & 0,89 & 38,62 & 82 & 197,60 & 4,63 & 110 & 103,92 & 8,88 & 108 \\
\hline 2 & $\mathrm{P}$ & 11 & 1,29 & 11,03 & 119 & 203,80 & 1,64 & 114 & 111,70 & 2,06 & 116 \\
\hline 2 & $\mathrm{P}$ & 12 & 1,34 & 7,59 & 124 & 192,80 & 6,95 & 108 & 106,90 & 6,27 & 111 \\
\hline 2 & $\mathrm{P}$ & 13 & 1,49 & $-2,76$ & 138 & 193,00 & 6,85 & 108 & 101,94 & 10,62 & 106 \\
\hline 2 & $\mathrm{P}$ & 14 & 1,16 & 20,00 & 107 & 196,60 & 5,11 & 110 & 104,20 & 8,64 & 109 \\
\hline 2 & $\mathrm{P}$ & 15 & 1,59 & $-9,66$ & 147 & 203,60 & 1,73 & 114 & 120,20 & $-5,39$ & 125 \\
\hline 2 & $\mathrm{~N}$ & 16 & 1,30 & 10,34 & 120 & 200,40 & 3,28 & 112 & 103,28 & 9,44 & 108 \\
\hline 2 & $\mathrm{~N}$ & 17 & 1,27 & 12,41 & 118 & 215,00 & $-3,77$ & 120 & 117,19 & $-2,75$ & 122 \\
\hline 2 & $\mathrm{~N}$ & 18 & 1,20 & 17,24 & 111 & 190,40 & 8,10 & 106 & 106,79 & 6,37 & 111 \\
\hline 2 & $\mathrm{~N}$ & 19 & 1,02 & 29,66 & 94 & 196,40 & 5,21 & 110 & 96,50 & 15,39 & 101 \\
\hline 2 & $\mathrm{~N}$ & 20 & 1,15 & 20,69 & 106 & 191,60 & 7,52 & 107 & 101,16 & 11,30 & 105 \\
\hline 3 & $\mathrm{P}$ & 21 & 1,37 & 5,52 & 127 & 209,00 & $-0,87$ & 117 & 111,62 & 2,13 & 116 \\
\hline 3 & $\mathrm{P}$ & 22 & 1,45 & 0,00 & 134 & 213,80 & $-3,19$ & 119 & 122,33 & $-7,26$ & 127 \\
\hline 3 & $\mathrm{P}$ & 23 & 1,41 & 2,76 & 131 & 192,60 & 7,04 & 108 & 106,76 & 6,39 & 111 \\
\hline 3 & $\mathrm{P}$ & 24 & 1,34 & 7,59 & 124 & 191,80 & 7,43 & 107 & 107,22 & 5,99 & 112 \\
\hline 3 & $\mathrm{P}$ & 25 & 1,53 & $-5,52$ & 142 & 212,80 & $-2,71$ & 119 & 118,22 & $-3,66$ & 123 \\
\hline 3 & $\mathrm{~N}$ & 26 & 1,44 & 0,69 & 133 & 203,80 & 1,64 & 114 & 113,34 & 0,62 & 118 \\
\hline 3 & $\mathrm{~N}$ & 27 & 1,51 & $-4,14$ & 140 & 194,40 & 6,17 & 109 & 107,83 & 5,45 & 112 \\
\hline 3 & $\mathrm{~N}$ & 28 & 1,18 & 18,62 & 109 & 207,60 & $-0,20$ & 116 & 117,48 & $-3,01$ & 122 \\
\hline 3 & $\mathrm{~N}$ & 29 & 1,48 & $-2,07$ & 137 & 206,60 & 0,28 & 115 & 115,33 & $-1,12$ & 120 \\
\hline 3 & $\mathrm{~N}$ & 30 & 1,48 & $-2,07$ & 137 & 201,60 & 2,70 & 113 & 117,59 & $-3,10$ & 122 \\
\hline
\end{tabular}


Tabela 29. Valor médio $(\bar{X})$ de 5 subpopulações, agrupadas de acordo com o tamanho efetivo e a seleção, depressão por endogamia (I) e a relação valor médio/testemunha $(\bar{X} / T)$ obtidos para os caracteres peso de espigas (PE), comprimento da espiga (CE) e diâmetro da espiga (DE). ESALQ/Genética, 2003

\begin{tabular}{cc|ccc|ccc|ccc}
\hline $\mathrm{N}$ & Sel. & \multicolumn{3}{|c|}{$\mathrm{PE}$} & \multicolumn{3}{c|}{$\mathrm{CE}$} & \multicolumn{3}{c}{$\mathrm{DE}$} \\
\cline { 3 - 10 } & & $\begin{array}{c}\overline{\mathrm{X}} \\
\left(\mathrm{kg} / 4 \mathrm{~m}^{2}\right)\end{array}$ & $\mathrm{I}(\%)$ & $\begin{array}{c}\overline{\mathrm{X}} / \mathrm{T} \\
(\%)\end{array}$ & $\begin{array}{c}\overline{\mathrm{X}} \\
(\mathrm{cm} / \mathrm{esp} .)\end{array}$ & $\mathrm{I}(\%)$ & $\begin{array}{c}\overline{\mathrm{X}} / \mathrm{T} \\
(\%)\end{array}$ & $\begin{array}{c}\overline{\mathrm{X}} \\
(\mathrm{cm} / \mathrm{esp} .)\end{array}$ & $\mathrm{I}(\%)$ & $\begin{array}{c}\overline{\mathrm{X}} / \mathrm{T} \\
(\%)\end{array}$ \\
\hline 1 & $\mathrm{~N}$ & 1,27 & 56,06 & 38 & 12,93 & 18,11 & 72 & 3,73 & 9,90 & 75 \\
1 & $\mathrm{P}$ & 2,14 & 25,95 & 64 & 14,31 & 9,37 & 80 & 3,98 & 3,86 & 80 \\
2 & $\mathrm{~N}$ & 1,94 & 32,87 & 58 & 14,27 & 9,63 & 79 & 3,96 & 4,35 & 79 \\
2 & $\mathrm{P}$ & 2,57 & 11,07 & 77 & 15,36 & 2,72 & 85 & 4,13 & 0,24 & 83 \\
3 & $\mathrm{~N}$ & 2,39 & 17,30 & 72 & 15,02 & 4,88 & 83 & 3,93 & 5,07 & 79 \\
3 & $\mathrm{P}$ & 2,63 & 9,00 & 79 & 14,93 & 5,45 & 83 & 4,11 & 0,72 & 82 \\
\hline
\end{tabular}

Tabela 30. Valor médio $(\bar{X})$ de 5 subpopulações, agrupadas de acordo com o tamanho efetivo e a seleção, depressão por endogamia (I) e a relação valor médio/testemunha $(\bar{X} / T)$ obtidos para os caracteres prolificidade $(P R)$, altura da planta (AP) e altura da espiga (AE). ESALQ/Genética, 2003

\begin{tabular}{cc|ccc|ccc|ccc}
\hline N & Sel. & \multicolumn{3}{|c|}{ PR } & \multicolumn{3}{c|}{ AP } & \multicolumn{3}{c}{ AE } \\
\cline { 3 - 10 } & & $\begin{array}{c}\overline{\mathrm{X}} \\
(\mathrm{esp} / \mathrm{pl})\end{array}$ & $\mathrm{I}(\%)$ & $\begin{array}{c}\overline{\mathrm{X}} / \mathrm{T} \\
(\%)\end{array}$ & $\begin{array}{c}\overline{\mathrm{X}} \\
(\mathrm{cm} / \mathrm{pl} .)\end{array}$ & $\mathrm{I}(\%)$ & $\begin{array}{c}\overline{\mathrm{X}} / \mathrm{T} \\
(\%)\end{array}$ & $\begin{array}{c}\overline{\mathrm{X}} \\
(\mathrm{cm} / \mathrm{pl} .)\end{array}$ & $\mathrm{I}(\%)$ & $\begin{array}{c}\overline{\mathrm{X}} / \mathrm{T} \\
(\%)\end{array}$ \\
\hline 1 & $\mathrm{~N}$ & 1,14 & 28,30 & 102 & 197,47 & 12,22 & 104 & 116,80 & 9,49 & 108 \\
1 & $\mathrm{P}$ & 1,60 & $-0,63$ & 143 & 209,87 & 6,71 & 110 & 123,69 & 4,15 & 115 \\
2 & $\mathrm{~N}$ & 1,30 & 18,24 & 116 & 211,78 & 5,86 & 111 & 118,44 & 8,22 & 110 \\
2 & $\mathrm{P}$ & 1,49 & 6,29 & 133 & 213,91 & 4,91 & 113 & 122,18 & 5,32 & 113 \\
3 & $\mathrm{~N}$ & 1,56 & 1,89 & 139 & 219,07 & 2,62 & 115 & 129,51 & $-0,36$ & 120 \\
3 & $\mathrm{P}$ & 1,56 & 1,89 & 139 & 218,13 & 3,04 & 115 & 127,82 & 0,95 & 118 \\
\hline
\end{tabular}


Tabela 31. Valor médio $(\bar{X})$ de 5 subpopulações, agrupadas de acordo com o tamanho efetivo e a seleção, depressão por endogamia (I) e a relação valor médio/testemunha $(\bar{X} / T)$ obtidos para os caracteres peso de espigas (PE), comprimento da espiga (CE) e diâmetro da espiga (DE). Anhembi, 2003

\begin{tabular}{cc|ccc|ccc|ccc}
\hline N & Sel. & \multicolumn{3}{|c|}{$\mathrm{PE}$} & \multicolumn{3}{c|}{$\mathrm{CE}$} & \multicolumn{3}{c}{$\mathrm{DE}$} \\
\cline { 3 - 10 } & & $\begin{array}{c}\overline{\mathrm{X}} \\
\left(\mathrm{kg} / 4 \mathrm{~m}^{2}\right)\end{array}$ & $\mathrm{I}(\%)$ & $\begin{array}{c}\overline{\mathrm{X}} / \mathrm{T} \\
(\%)\end{array}$ & $\begin{array}{c}\overline{\mathrm{X}} \\
(\mathrm{cm} / \mathrm{esp} .)\end{array}$ & $\mathrm{I}(\%)$ & $\begin{array}{c}\overline{\mathrm{X}} / \mathrm{T} \\
(\%)\end{array}$ & $\begin{array}{c}\overline{\mathrm{X}} \\
(\mathrm{cm} / \mathrm{esp} .)\end{array}$ & $\mathrm{I}(\%)$ & $\begin{array}{c}\overline{\mathrm{X}} / \mathrm{T} \\
(\%)\end{array}$ \\
\hline 1 & $\mathrm{~N}$ & 1,19 & 55,76 & 41 & 13,68 & 16,43 & 76 & 3,78 & 9,13 & 76 \\
1 & $\mathrm{P}$ & 2,15 & 20,07 & 74 & 15,10 & 7,76 & 84 & 4,06 & 2,40 & 81 \\
2 & $\mathrm{~N}$ & 1,84 & 31,60 & 63 & 14,96 & 8,61 & 83 & 4,04 & 2,88 & 81 \\
2 & $\mathrm{P}$ & 2,32 & 13,75 & 80 & 15,92 & 2,75 & 88 & 4,10 & 1,44 & 82 \\
3 & $\mathrm{~N}$ & 2,26 & 15,98 & 78 & 15,52 & 5,19 & 86 & 3,94 & 5,29 & 79 \\
3 & $\mathrm{P}$ & 2,55 & 5,20 & 88 & 15,80 & 3,48 & 88 & 4,18 & $-0,48$ & 84 \\
\hline
\end{tabular}

Tabela 32. Valor médio $(\overline{\mathrm{X}})$ de 5 subpopulações, agrupadas de acordo com o tamanho efetivo e a seleção, depressão por endogamia (I) e a relação valor médio/testemunha $(\bar{X} / T)$ obtidos para os caracteres prolificidade $(\mathrm{PR})$, altura da planta (AP) e altura da espiga (AE). Anhembi, 2003

\begin{tabular}{cc|ccc|ccc|ccc}
\hline N & Sel. & \multicolumn{3}{|c|}{$\mathrm{PR}$} & \multicolumn{3}{c|}{$\mathrm{AP}$} & \multicolumn{3}{c}{ AE } \\
\cline { 3 - 10 } & & $\begin{array}{c}\overline{\mathrm{X}} \\
(\mathrm{esp} / \mathrm{pl} .)\end{array}$ & $\mathrm{I}(\%)$ & $\begin{array}{c}\overline{\mathrm{X}} / \mathrm{T} \\
(\%)\end{array}$ & $\begin{array}{c}\overline{\mathrm{X}} \\
(\mathrm{cm} / \mathrm{pl} \mathrm{l})\end{array}$ & $\mathrm{I}(\%)$ & $\begin{array}{c}\overline{\mathrm{X}} / \mathrm{T} \\
(\%)\end{array}$ & $\begin{array}{c}\overline{\mathrm{X}} \\
(\mathrm{cm} / \mathrm{pl} .)\end{array}$ & $\mathrm{I}(\%)$ & $\begin{array}{c}\overline{\mathrm{X}} / \mathrm{T} \\
(\%)\end{array}$ \\
\hline 1 & $\mathrm{~N}$ & 0,95 & 26,92 & 92 & 190,96 & 7,83 & 114 & 91,16 & 7,97 & 110 \\
1 & $\mathrm{P}$ & 1,32 & $-1,54$ & 128 & 195,00 & 5,88 & 116 & 96,28 & 2,80 & 116 \\
2 & $\mathrm{~N}$ & 1,08 & 16,92 & 105 & 198,76 & 4,07 & 118 & 91,52 & 7,60 & 110 \\
2 & $\mathrm{P}$ & 1,26 & 3,08 & 122 & 197,96 & 4,45 & 118 & 95,80 & 3,28 & 115 \\
3 & $\mathrm{~N}$ & 1,28 & 1,54 & 124 & 202,80 & 2,12 & 121 & 99,12 & $-0,07$ & 119 \\
3 & $\mathrm{P}$ & 1,28 & 1,54 & 124 & 204,00 & 1,54 & 121 & 98,64 & 0,41 & 119 \\
\hline
\end{tabular}


Tabela 33. Valor médio $(\overline{\mathrm{X}})$ de 5 subpopulações, com dados de dois locais, agrupadas de acordo com o tamanho efetivo e a seleção, depressão por endogamia (I) e a relação valor médio/testemunha $(\bar{X} / T)$, obtidos para os caracteres peso de espigas (PE), comprimento da espiga (CE) e diâmetro da espiga (DE)

\begin{tabular}{cc|ccc|ccc|ccc}
\hline $\mathrm{N}$ & Sel. & \multicolumn{3}{|c|}{$\mathrm{PE}$} & \multicolumn{3}{c|}{$\mathrm{CE}$} & \multicolumn{3}{c}{$\mathrm{DE}$} \\
\cline { 3 - 10 } & $\begin{array}{c}\overline{\mathrm{X}} \\
\left(\mathrm{kg} / 4 \mathrm{~m}^{2}\right)\end{array}$ & $\mathrm{I}(\%)$ & $\begin{array}{c}\overline{\mathrm{X}} / \mathrm{T} \\
(\%)\end{array}$ & $\begin{array}{c}\overline{\mathrm{X}} \\
(\mathrm{cm} / \mathrm{esp} .)\end{array}$ & $\mathrm{I}(\%)$ & $\begin{array}{c}\overline{\mathrm{X}} / \mathrm{T} \\
(\%)\end{array}$ & $\begin{array}{c}\overline{\mathrm{X}} \\
(\mathrm{cm} / \mathrm{esp} .)\end{array}$ & $\mathrm{I}(\%)$ & $\begin{array}{c}\overline{\mathrm{X}} / \mathrm{T} \\
(\%)\end{array}$ \\
\hline 1 & $\mathrm{~N}$ & 1,23 & 55,91 & 39 & 13,31 & 17,17 & 74 & 3,76 & 9,40 & 75 \\
1 & $\mathrm{P}$ & 2,15 & 22,94 & 69 & 14,71 & 8,46 & 82 & 4,02 & 3,13 & 80 \\
2 & $\mathrm{~N}$ & 1,89 & 32,26 & 61 & 14,61 & 9,09 & 81 & 4,00 & 3,61 & 80 \\
2 & $\mathrm{P}$ & 2,45 & 12,19 & 79 & 15,64 & 2,68 & 87 & 4,12 & 0,72 & 82 \\
3 & $\mathrm{~N}$ & 2,32 & 16,85 & 74 & 15,27 & 4,98 & 85 & 3,94 & 5,06 & 79 \\
3 & $\mathrm{P}$ & 2,59 & 7,17 & 83 & 15,37 & 4,36 & 85 & 4,15 & 0,00 & 83 \\
\hline
\end{tabular}

Tabela 34. Valor médio $(\overline{\mathrm{X}})$ de 5 subpopulações, com dados de dois locais, agrupadas de acordo com o tamanho efetivo e a seleção, depressão por endogamia (I) e a relação valor médio/testemunha $(\bar{X} / T)$, obtidos para os caracteres prolificidade (PR), altura da planta (AP) e altura da espiga (AE)

\begin{tabular}{cc|ccc|ccc|ccc}
\hline N & Sel. & \multicolumn{3}{|c|}{ PR } & \multicolumn{3}{c|}{ AP } & \multicolumn{3}{c}{ AE } \\
\cline { 3 - 10 } & & $\begin{array}{c}\overline{\mathrm{X}} \\
(\mathrm{esp} / \mathrm{pl})\end{array}$ & $\mathrm{I}(\%)$ & $\begin{array}{c}\overline{\mathrm{X}} / \mathrm{T} \\
(\%)\end{array}$ & $\begin{array}{c}\overline{\mathrm{X}} \\
(\mathrm{cm} / \mathrm{pl})\end{array}$ & $\mathrm{I}(\%)$ & $\begin{array}{c}\overline{\mathrm{X}} / \mathrm{T} \\
(\%)\end{array}$ & $\begin{array}{c}\overline{\mathrm{X}} \\
(\mathrm{cm} / \mathrm{pl})\end{array}$ & $\mathrm{I}(\%)$ & $\begin{array}{c}\overline{\mathrm{X}} / \mathrm{T} \\
(\%)\end{array}$ \\
\hline 1 & $\mathrm{~N}$ & 1,05 & 27,59 & 97 & 194,21 & 10,12 & 108 & 103,98 & 8,83 & 108 \\
1 & $\mathrm{P}$ & 1,46 & $-0,69$ & 135 & 202,43 & 6,32 & 113 & 109,98 & 3,57 & 115 \\
2 & $\mathrm{~N}$ & 1,19 & 17,93 & 110 & 205,27 & 5,00 & 115 & 104,98 & 7,95 & 109 \\
2 & $\mathrm{P}$ & 1,37 & 5,52 & 127 & 205,94 & 4,69 & 115 & 108,99 & 4,44 & 114 \\
3 & $\mathrm{~N}$ & 1,42 & 2,07 & 131 & 210,94 & 2,38 & 118 & 114,32 & $-0,24$ & 119 \\
3 & $\mathrm{P}$ & 1,42 & 2,07 & 131 & 211,07 & 2,32 & 118 & 113,23 & 0,72 & 118 \\
\hline
\end{tabular}


Tabela 35. Quadrados médios da análise da variância do experimento 8, com progênies ‘topcrosses', para o caráter peso de espigas (PE). ESALQ/Genética, 2003

\begin{tabular}{lcc}
\hline Fonte de Variação & GL & Quadrados médios $^{1}$ \\
\cline { 3 - 3 } & & $\begin{array}{c}\mathrm{PE} \\
\left(\mathrm{kg} / 4 \mathrm{~m}^{2}\right)^{2}\end{array}$ \\
\hline Bloco & 3 & $108,0823^{*}$ \\
Testador & 1 & 4,4554 \\
Progênies 'topcrosses' & 29 & 47,7264 \\
Progênies 'topcrosses' x Testador & 29 & 27,2049 \\
Resíduo & 177 & 21,5542 \\
\hline CV\% & - & 13,8 \\
\hline
\end{tabular}

${ }^{1}$ Quadrados médios multiplicados por $10^{2}$

* Efeito significativo em nível de probabilidade igual ou inferior a 5\%, pelo teste $\mathrm{F}$ Quadrados médios sem asterisco não foram significativos 
Tabela 36. Médias, capacidade geral de combinação (CGC) e capacidade específica de combinação (CEC) dos cruzamentos 'topcrosses' das subpopulações com o híbrido P 3041 (1) e o composto GN-03 (2), para o caráter peso de espigas $\left(\mathrm{kg} / 4 \mathrm{~m}^{2}\right)$. ESALQ/Genética, 2003

\begin{tabular}{|c|c|c|c|c|c|c|}
\hline \multirow[t]{2}{*}{ Subpop. } & \multicolumn{3}{|c|}{$\bar{x}$} & \multirow[t]{2}{*}{ CGC } & \multicolumn{2}{|c|}{$\mathrm{CEC}$} \\
\hline & Topcross & 1 & 2 & & 1 & 2 \\
\hline 1 & 3,39 & 3,62 & 3,16 & 0,04 & 0,22 & $-0,22$ \\
\hline 2 & 3,33 & 3,61 & 3,05 & $-0,02$ & 0,27 & $-0,27$ \\
\hline 3 & 3,33 & 3,36 & 3,30 & $-0,02$ & 0,02 & $-0,02$ \\
\hline 4 & 3,54 & 3,46 & 3,63 & 0,19 & $-0,09$ & 0,10 \\
\hline 5 & 3,37 & 3,58 & 3,17 & 0,02 & 0,20 & $-0,19$ \\
\hline 6 & 2,86 & 2,93 & 2,78 & $-0,49$ & 0,06 & $-0,07$ \\
\hline 7 & 3,20 & 2,96 & 3,45 & $-0,15$ & $-0,25$ & 0,26 \\
\hline 8 & 3,39 & 3,39 & 3,39 & 0,04 & $-0,01$ & 0,01 \\
\hline 9 & 3,06 & 3,15 & 2,97 & $-0,29$ & 0,08 & $-0,08$ \\
\hline 10 & 2,87 & 2,64 & 3,10 & $-0,48$ & $-0,24$ & 0,24 \\
\hline 11 & 3,39 & 3,48 & 3,29 & 0,04 & 0,08 & $-0,09$ \\
\hline 12 & 3,20 & 3,07 & 3,32 & $-0,15$ & $-0,14$ & 0,13 \\
\hline 13 & 3,32 & 3,34 & 3,30 & $-0,03$ & 0,01 & $-0,01$ \\
\hline 14 & 3,01 & 3,26 & 2,75 & $-0,34$ & 0,24 & $-0,25$ \\
\hline 15 & 3,60 & 3,40 & 3,79 & 0,25 & $-0,21$ & 0,20 \\
\hline 16 & 3,39 & 3,26 & 3,52 & 0,04 & $-0,14$ & 0,14 \\
\hline 17 & 3,47 & 3,42 & 3,52 & 0,12 & $-0,06$ & 0,06 \\
\hline 18 & 3,40 & 3,42 & 3,39 & 0,05 & 0,01 & 0,00 \\
\hline 19 & 3,20 & 2,81 & 3,59 & $-0,15$ & $-0,40$ & 0,40 \\
\hline 20 & 3,13 & 2,97 & 3,30 & $-0,22$ & $-0,17$ & 0,18 \\
\hline 21 & 3,50 & 3,61 & 3,39 & 0,15 & 0,10 & $-0,10$ \\
\hline 22 & 4,05 & 3,87 & 4,22 & 0,70 & $-0,19$ & 0,18 \\
\hline 23 & 3,62 & 3,58 & 3,67 & 0,27 & $-0,05$ & 0,06 \\
\hline 24 & 3,20 & 3,34 & 3,07 & $-0,15$ & 0,13 & $-0,12$ \\
\hline 25 & 3,16 & 3,35 & 2,97 & $-0,19$ & 0,18 & $-0,18$ \\
\hline 26 & 3,65 & 4,09 & 3,20 & 0,30 & 0,43 & $-0,44$ \\
\hline 27 & 3,44 & 3,30 & 3,59 & 0,09 & $-0,15$ & 0,16 \\
\hline 28 & 3,51 & 3,50 & 3,53 & 0,16 & $-0,02$ & 0,03 \\
\hline 29 & 3,41 & 3,61 & 3,20 & 0,06 & 0,19 & $-0,20$ \\
\hline 30 & 3,57 & 3,59 & 3,54 & 0,22 & 0,01 & $-0,02$ \\
\hline $\bar{x}$ & 3,35 & 3,36 & 3,34 & - & - & - \\
\hline$\hat{\mathrm{r}}^{1}$ & - & & & - & - & - \\
\hline
\end{tabular}

${ }^{1}$ Coeficiente de correlação de Spearman 
Tabela 37. Quadrados médios da análise da variância de tabelas dialélicas referentes às subpopulações de tamanho efetivo $\mathrm{N}_{1}, \mathrm{~N}_{2}$ e $\mathrm{N}_{3}$, para o caráter produção de grãos (PG). Guaíra - SP, 2003

\begin{tabular}{|c|c|c|c|c|}
\hline \multirow[t]{3}{*}{ Fonte de Variação } & \multirow[t]{3}{*}{ GL } & \multicolumn{3}{|c|}{ Quadrados médios $^{1}$} \\
\hline & & $\mathrm{N}_{1}$ & $\mathrm{~N}_{2}$ & $\mathrm{~N}_{3}$ \\
\hline & & $\begin{array}{c}\mathrm{PG} \\
\left(\mathrm{kg} / 4 \mathrm{~m}^{2}\right)^{2}\end{array}$ & $\begin{array}{c}\mathrm{PG} \\
\left(\mathrm{kg} / 4 \mathrm{~m}^{2}\right)^{2}\end{array}$ & $\begin{array}{c}\mathrm{PG} \\
\left(\mathrm{kg} / 4 \mathrm{~m}^{2}\right)^{2}\end{array}$ \\
\hline Tratamentos & 34 & $36,8824^{*}$ & $27,7941^{*}$ & $28,4847^{*}$ \\
\hline Entre grupos & 1 & 20,1640 & 1,6000 & $82,9440 *$ \\
\hline Grupo I & 4 & 18,8133 & 15,9733 & 20,8489 \\
\hline Grupo II & 4 & 13,0667 & 18,2356 & 11,1556 \\
\hline Heterose & 25 & $44,2528^{*}$ & $32,2628^{*}$ & $30,3008 *$ \\
\hline Heterose média & 1 & $648,9930 *$ & $292,5714^{*}$ & $553,1429 *$ \\
\hline Heterose do Grupo I & 4 & 13,5111 & 13,5611 & 2,4500 \\
\hline Heterose Grupo II & 4 & 27,4611 & 28,8111 & 8,3111 \\
\hline Heterose específica & 16 & 18,3406 & 21,5325 & 10,0838 \\
\hline Resíduo & 102 & 15,2055 & 13,2704 & 9,2650 \\
\hline
\end{tabular}

${ }^{1}$ Quadrados médios multiplicados por $10^{2}$

* Efeito significativo em nível de probabilidade igual ou inferior a 5\%, pelo teste $\mathrm{F}$ Quadrados médios sem asterisco não foram significativos 
Tabela 38. Estimativa da heterose específica $\left(\mathrm{s}_{\mathrm{ij}}\right)$, do efeito de subpopulações $\left(\mathrm{s}_{\mathrm{i}}\right.$ e $\left.\mathrm{s}_{\mathrm{j}}\right)$, do efeito heterótico de subpopulações $\left(h_{i}\right.$ e $\left.h_{j}\right)$, da média de grupos de subpopulações (u), do desvio entre grupos de subpopulações (d) e da heterose média $(\bar{h})$ para o caráter produção de grãos $\left(\mathrm{kg} / 4 \mathrm{~m}^{2}\right)$, analisado segundo o esquema de cruzamento dialélico parcial de subpopulações de tamanho efetivo 1. Guaíra - SP, 2003

\begin{tabular}{|c|c|c|c|c|c|c|c|}
\hline $\mathrm{GII}_{(\mathrm{i})}$ & $1^{\prime}$ & 2 & $3^{\prime}$ & $4 '$ & 5 & $\hat{s}_{i}$ & $\hat{h}_{i}$ \\
\hline 1 & $\begin{array}{l}0,2160 \\
(27,41)\end{array}$ & $\begin{array}{c}-0,0360 \\
(8,01)\end{array}$ & $\begin{array}{c}-0,2160 \\
(24,02)\end{array}$ & $\begin{array}{c}-0,1400 \\
(4,81)\end{array}$ & $\begin{array}{l}0,1780 \\
(21,70)\end{array}$ & 0,0980 & $-0,1326$ \\
\hline 2 & $\begin{array}{l}0,1240 \\
(34,17)\end{array}$ & $\begin{array}{l}0,1820 \\
(28,37)\end{array}$ & $\begin{array}{l}0,0120 \\
(49,86)\end{array}$ & $\begin{array}{c}-0,1020 \\
(17,36)\end{array}$ & $\begin{array}{c}-0,2140 \\
(13,67)\end{array}$ & 0,0280 & 0,0844 \\
\hline 3 & $\begin{array}{c}-0,4340 \\
(-4,81)\end{array}$ & $\begin{array}{c}-0,2060 \\
(0,23)\end{array}$ & $\begin{array}{l}0,1340 \\
(44,83)\end{array}$ & $\begin{array}{l}0,2200 \\
(22,66)\end{array}$ & $\begin{array}{l}0,2880 \\
(27,54)\end{array}$ & $-0,0020$ & $-0,1326$ \\
\hline 4 & $\begin{array}{l}0,1600 \\
(40,70)\end{array}$ & $\begin{array}{c}-0,0820 \\
(19,11)\end{array}$ & $\begin{array}{l}0,0480 \\
(58,64)\end{array}$ & $\begin{array}{c}-0,0460 \\
(23,56)\end{array}$ & $\begin{array}{l}-0,0780 \\
(23,59)\end{array}$ & $-0,2420$ & 0,1234 \\
\hline 5 & $\begin{array}{r}-0,0640 \\
(22,85) \\
\end{array}$ & $\begin{array}{l}0,1440 \\
(24,83)\end{array}$ & $\begin{array}{l}0,0240 \\
(47,78)\end{array}$ & $\begin{array}{l}0,0700 \\
(23,92) \\
\end{array}$ & $\begin{array}{r}-0,1720 \\
(14,08) \\
\end{array}$ & 0,1180 & 0,0574 \\
\hline$\hat{s}_{j}$ & $-0,0300$ & 0,2900 & $-0,5000$ & 0,0800 & 0,1600 & & \\
\hline$\hat{h}_{j}$ & $-0,0046$ & $-0,1326$ & 0,3024 & $-0,1036$ & $-0,0616$ & & \\
\hline $\begin{array}{l}\hat{u}= \\
1,9910\end{array}$ & $\hat{d}=0,0710$ & $\hat{\bar{h}}=0,4766$ & & & & & \\
\hline
\end{tabular}

Valores entre parênteses representam a heterose do cruzamento em relação à média dos pais, em \% 
Tabela 39. Estimativa da heterose específica $\left(\mathrm{s}_{\mathrm{ij}}\right)$, do efeito de subpopulações $\left(\mathrm{s}_{\mathrm{i}}\right.$ e $\left.\mathrm{s}_{\mathrm{j}}\right)$, do efeito heterótico de subpopulações $\left(h_{i}\right.$ e $\left.h_{j}\right)$, da média de grupos de subpopulações (u), do desvio entre grupos de subpopulações (d) e da heterose média $(\bar{h})$ para o caráter produção de grãos $\left(\mathrm{kg} / 4 \mathrm{~m}^{2}\right)$, analisado segundo o esquema de cruzamento dialélico parcial de subpopulações de tamanho efetivo 2. Guaíra - SP, 2003

\begin{tabular}{|c|c|c|c|c|c|c|c|}
\hline $\mathrm{GI}_{(\mathrm{i})} \mathrm{GII}_{(\mathrm{j})}$ & $1^{\prime}$ & $2^{\prime}$ & 3 & $4^{\prime}$ & 5 , & $\hat{s}_{i}$ & $\hat{h}_{i}$ \\
\hline 1 & $\begin{array}{l}0,3000 \\
(25,25)\end{array}$ & $\begin{array}{l}0,0240 \\
(27,48)\end{array}$ & $\begin{array}{l}-0,2000 \\
(11,53)\end{array}$ & $\begin{array}{l}-0,1060 \\
(32,35)\end{array}$ & $\begin{array}{l}-0,0180 \\
(13,48)\end{array}$ & $-0,1160$ & 0,0780 \\
\hline 2 & $\begin{array}{c}-0,1800 \\
(-9,00)\end{array}$ & $\begin{array}{l}0,0340 \\
(16,53)\end{array}$ & $\begin{array}{c}-0,3000 \\
(-4,51)\end{array}$ & $\begin{array}{l}0,1040 \\
(32,56)\end{array}$ & $\begin{array}{l}0,3420 \\
(22,22)\end{array}$ & $-0,076$ & -01220 \\
\hline 3 & $\begin{array}{c}-0,0720 \\
(-1,41)\end{array}$ & $\begin{array}{c}-0,2980 \\
(0,26)\end{array}$ & $\begin{array}{l}0,2780 \\
(26,55)\end{array}$ & $\begin{array}{l}0,1020 \\
(32,43)\end{array}$ & $\begin{array}{c}-0,0100 \\
(4,66)\end{array}$ & 0,1840 & $-0,0800$ \\
\hline 4 & $\begin{array}{l}0,1520 \\
(23,08)\end{array}$ & $\begin{array}{c}-0,0940 \\
(26,80)\end{array}$ & $\begin{array}{c}0,1720 \\
(37,33)\end{array}$ & $\begin{array}{c}-0,1240 \\
(37,72)\end{array}$ & $\begin{array}{c}-0,1060 \\
(14,29)\end{array}$ & $-0,1760$ & 0,1760 \\
\hline 5 & $\begin{array}{c}-0,2000 \\
(-6,10) \\
\end{array}$ & $\begin{array}{l}0,3340 \\
(34,73) \\
\end{array}$ & $\begin{array}{l}0,0500 \\
(16,62) \\
\end{array}$ & $\begin{array}{l}0,0240 \\
(29,73) \\
\end{array}$ & $\begin{array}{c}-0,2080 \\
(-4,14) \\
\end{array}$ & 0,1840 & $-0,0520$ \\
\hline$\hat{s}_{j}$ & 0,3240 & $-0,1060$ & 0,0940 & $-0,2360$ & $-0,0760$ & & \\
\hline$\hat{h}_{j}$ & $-0,1980$ & 0,0630 & 0,0170 & 0,2580 & $-0,1400$ & & \\
\hline $\begin{array}{l}\hat{u}= \\
1,8760\end{array}$ & $\hat{d}=0,0200$ & $\hat{\bar{h}}=0,3200$ & & & & & \\
\hline
\end{tabular}

Valores entre parênteses representam a heterose do cruzamento em relação à média dos pais, em $\%$ 
Tabela 40. Estimativa da heterose específica $\left(\mathrm{s}_{\mathrm{ij}}\right)$, do efeito de subpopulações $\left(\mathrm{s}_{\mathrm{i}}\right.$ e $\left.\mathrm{s}_{\mathrm{j}}\right)$, do efeito heterótico de subpopulações $\left(h_{i}\right.$ e $\left.h_{j}\right)$, da média de grupos de subpopulações (u), do desvio entre grupos de subpopulações (d) e da heterose média $(\bar{h})$ para o caráter produção de grãos $\left(\mathrm{kg} / 4 \mathrm{~m}^{2}\right)$, analisado segundo o esquema de cruzamento dialélico parcial de subpopulações de tamanho efetivo 3. Guaíra -SP, 2003

\begin{tabular}{|c|c|c|c|c|c|c|c|}
\hline $\mathrm{GII}_{(\mathrm{i})}$ & $1^{\prime}$ & $2^{\prime}$ & 3 ' & 4 & 5 , & $\hat{S}_{i}$ & $\hat{h}_{i}$ \\
\hline 1 & $\begin{array}{l}0,0320 \\
(29,14)\end{array}$ & $\begin{array}{l}0,0700 \\
(37,46)\end{array}$ & $\begin{array}{r}-0,1280 \\
(10,82)\end{array}$ & $\begin{array}{l}0,0300 \\
(22,67)\end{array}$ & $\begin{array}{c}-0,0040 \\
(22,92)\end{array}$ & 0,0880 & 0,0100 \\
\hline 2 & $\begin{array}{c}-0,2660 \\
(12,14)\end{array}$ & $\begin{array}{c}-0,0280 \\
(32,19)\end{array}$ & $\begin{array}{l}0,0840 \\
(21,88)\end{array}$ & $\begin{array}{c}0,052 \\
(23,99)\end{array}$ & $\begin{array}{c}0,1580 \\
(31,58)\end{array}$ & 0,0480 & 0,0080 \\
\hline 3 & $\begin{array}{l}0,1660 \\
(44,65)\end{array}$ & $\begin{array}{c}-0,2360 \\
(26,32)\end{array}$ & $\begin{array}{l}0,0960 \\
(28,09)\end{array}$ & $\begin{array}{c}0,0940 \\
(32,36)\end{array}$ & $\begin{array}{c}-0,1200 \\
(22,16)\end{array}$ & $-0,2320$ & 0,0760 \\
\hline 4 & $\begin{array}{c}-0,1280 \\
(15,07)\end{array}$ & $\begin{array}{l}0,2300 \\
(40,54)\end{array}$ & $\begin{array}{c}-0,1180 \\
(7,20)\end{array}$ & $\begin{array}{c}-0,0200 \\
(15,38)\end{array}$ & $\begin{array}{l}0,0360 \\
(20,30)\end{array}$ & 0,2380 & $-0,0650$ \\
\hline 5 & $\begin{array}{l}0,1960 \\
(38,84) \\
\end{array}$ & $\begin{array}{r}-0,0360 \\
(31,32) \\
\end{array}$ & $\begin{array}{c}0,066 \\
(20,00)\end{array}$ & $\begin{array}{r}-0,1560 \\
(11,36)\end{array}$ & $\begin{array}{r}-0,0700 \\
(18,56)\end{array}$ & $-0,1420$ & $-0,0290$ \\
\hline$\hat{s}_{j}$ & $-0,2040$ & $-0,1540$ & 0,1760 & 0,0460 & 0,1360 & & \\
\hline$\hat{h}_{j}$ & 0,0280 & 0,1450 & $-0,1120$ & $-0,0550$ & $-0,0060$ & & \\
\hline$\hat{u}=1,808$ & $\hat{d}=01440$ & $\hat{\bar{h}}=0,4400$ & & & & & \\
\hline
\end{tabular}

Valores entre parênteses representam a heterose do cruzamento em relação à média dos pais, em \% 
Tabela 41. Produção de grãos (t/ha, média de 4 repetições) para dois grupos de subpopulações de tamanho efetivo 1 e combinações híbridas. Guaíra - SP, 2003

\begin{tabular}{|c|c|c|c|c|c|c|}
\hline $\mathrm{GII}_{(\mathrm{i})}$ & $1^{\prime}$ & 2 ' & $3^{\prime}$ & $4^{\prime}$ & 5, & $\bar{g}_{i}$ \\
\hline 1 & $\begin{array}{c}6,45 \\
(100)\end{array}$ & $\begin{array}{l}5,90 \\
(92)\end{array}$ & $\begin{array}{l}5,55 \\
(86)\end{array}$ & $\begin{array}{l}5,45 \\
(85)\end{array}$ & $\begin{array}{c}6,45 \\
(100)\end{array}$ & $\begin{array}{l}5,40 \\
(84)\end{array}$ \\
\hline 2 & $\begin{array}{c}6,68 \\
(104)\end{array}$ & $\begin{array}{c}6,90 \\
(107)\end{array}$ & $\begin{array}{c}6.58 \\
(102)\end{array}$ & $\begin{array}{l}6,00 \\
(93)\end{array}$ & $\begin{array}{l}5,93 \\
(92)\end{array}$ & $\begin{array}{l}5,23 \\
(81)\end{array}$ \\
\hline 3 & $\begin{array}{l}4,70 \\
(73)\end{array}$ & $\begin{array}{l}5,35 \\
(83)\end{array}$ & $\begin{array}{l}6,30 \\
(98)\end{array}$ & $\begin{array}{l}6,23 \\
(97)\end{array}$ & $\begin{array}{c}6,60 \\
(103)\end{array}$ & $\begin{array}{l}5,15 \\
(80)\end{array}$ \\
\hline 4 & $\begin{array}{c}6,53 \\
(102)\end{array}$ & $\begin{array}{l}6,00 \\
(93)\end{array}$ & $\begin{array}{c}6,43 \\
(100)\end{array}$ & $\begin{array}{l}5,90 \\
(92)\end{array}$ & $\begin{array}{l}6,03 \\
(94)\end{array}$ & $\begin{array}{l}4,55 \\
(71)\end{array}$ \\
\hline 5 & $\begin{array}{l}6,25 \\
(97)\end{array}$ & $\begin{array}{c}6,85 \\
(107)\end{array}$ & $\begin{array}{c}6,65 \\
(104)\end{array}$ & $\begin{array}{c}6,48 \\
(101)\end{array}$ & $\begin{array}{l}6,08 \\
(95)\end{array}$ & $\begin{array}{l}5,45 \\
(85)\end{array}$ \\
\hline $\bar{g}_{j}$ & $\begin{array}{l}4,73 \\
(74)\end{array}$ & $\begin{array}{l}5,53 \\
(86)\end{array}$ & $\begin{array}{l}3,55 \\
(55)\end{array}$ & $\begin{array}{l}5,00 \\
(78)\end{array}$ & $\begin{array}{l}5,20 \\
(81)\end{array}$ & \\
\hline
\end{tabular}

Valores entre parênteses representam a comparação do rendimento, em \%, ao híbrido simples comercial A 5055

Tabela 42. Produção de grãos (t/ha, média de 4 repetições) para dois grupos de subpopulações de tamanho efetivo 2 e combinações híbridas. Guaíra -SP, 2003

\begin{tabular}{ccccccc}
\hline $\mathrm{GII}_{(\mathrm{j})}$ & $1^{\prime}$ & $2^{\prime}$ & 3, & $4^{\prime}$ & 5 & $\bar{g}_{i}$ \\
\hline 1 & & & & & & \\
\hline & 6,20 & 5,63 & 5,20 & 5,63 & 5,05 & 4,45 \\
2 & $(96)$ & $(87)$ & $(81)$ & $(87)$ & $(78)$ & $(69)$ \\
& 4,55 & 5,20 & 4,50 & 5,70 & 5,50 & 4,55 \\
& $(71)$ & $(81)$ & $(70)$ & $(88)$ & $(85)$ & $(71)$ \\
& 5,25 & 4,80 & 6,38 & 6,13 & 5,05 & 5,20 \\
& $(81)$ & $(74)$ & $(99)$ & $(95)$ & $(78)$ & $(81)$ \\
4 & 6,00 & 5,50 & 6,30 & 5,75 & 5,00 & 4,30 \\
& $(93)$ & $(85)$ & $(98)$ & $(89)$ & $(78)$ & $(67)$ \\
5 & 5,00 & 6,45 & 5,88 & 6,00 & 4,63 & 5,20 \\
& $(78)$ & $(100)$ & $(91)$ & $(93)$ & $(72)$ & $(81)$ \\
\hline $\bar{g}_{j}$ & 5,45 & 4,38 & 4,88 & 4,05 & 4,45 & \\
& $(84)$ & $(68)$ & $(76))$ & $(63))$ & $(69)$ & \\
\hline
\end{tabular}

Valores entre parênteses representam a comparação do rendimento, em \%, ao híbrido simples comercial A 5055 
Tabela 43. Produção de grãos (t/ha, média de 4 repetições) para dois grupos de subpopulações de tamanho efetivo 3 e combinações híbridas. Guaíra -SP, 2003

\begin{tabular}{ccccccc}
\hline $\mathrm{GII}_{(\mathrm{j})}$ & $1^{\prime}$ & $2^{\prime}$ & $3^{\prime}$ & $4^{\prime}$ & 5 & $\hat{g}_{i}$ \\
\hline & & & & & & \\
\hline & 5,65 & 6,10 & 5,38 & 5,75 & 5,90 & 5,10 \\
& $(97)$ & $(105)$ & $(93)$ & $(99)$ & $(102)$ & $(88)$ \\
& 4,85 & 5,80 & 5,85 & 5,75 & 6,25 & 5,00 \\
& $(84)$ & $(100)$ & $(101)$ & $(99)$ & $(108)$ & $(86)$ \\
3 & 5,75 & 5,10 & 5,70 & 5,68 & 5,38 & 4,30 \\
& $(99)$ & $(88)$ & $(98)$ & $(98)$ & $(93)$ & $(74)$ \\
4 & 5,25 & 6,50 & 5,40 & 5,63 & 6,00 & 5,48 \\
& $(91)$ & $(112)$ & $(93)$ & $(97)$ & $(103)$ & $(94)$ \\
5 & 5,68 & 5,45 & 5,48 & 4,90 & 5,35 & 4,53 \\
& $(98)$ & $(94)$ & $(94)$ & $(84)$ & $(92)$ & $(78)$ \\
\hline \multirow{2}{*}{5} & 3,65 & 3,78 & 4,60 & 4,28 & 4,50 & \\
\hline$\hat{g}_{j}$ & $(63)$ & $(65)$ & $(79)$ & $(74)$ & $(78)$ & \\
\hline
\end{tabular}

Números entre parênteses representam a comparação do rendimento, em \%, ao híbrido simples comercial A 5055 
Tabela 44. Quadrados médios da análise da variância agrupada dos experimentos 1, 2, 3 e 4, com progênies obtidas através de cruzamentos em cadeia, para os caracteres peso de espigas (PE), comprimento da espiga (CE), diâmetro da espiga (DE) e prolificidade (PR). ESALQ/Genética, 2003

\begin{tabular}{lccccc}
\hline Fonte de Variação & G.L. & \multicolumn{5}{c}{ Quadrados médios } \\
\cline { 3 - 7 } & & $\begin{array}{c}\mathrm{PE} \\
\left(\mathrm{kg} / 4 \mathrm{~m}^{2}\right)^{2}\end{array}$ & $\begin{array}{c}\mathrm{CE} \\
(\mathrm{cm} / \mathrm{esp} .)^{2}\end{array}$ & $\begin{array}{c}\mathrm{DE} \\
(\mathrm{cm} / \mathrm{esp} .)^{2}\end{array}$ & $\begin{array}{c}\text { PR } \\
(\mathrm{esp} . / \mathrm{pl})^{2}\end{array}$ \\
\hline Experimento & 3 & 0,6978 & 6,3767 & 1,0314 & $0,6304^{*}$ \\
Bloco/Experimento & 8 & 0,2118 & 2,6742 & 0,0793 & 0,0418 \\
Cadeia/Experimento & 68 & $0,5319^{*}$ & $4,9637^{*}$ & $0,5868^{*}$ & $0,1150^{*}$ \\
Progênies/Cadeia/Experimento & 144 & $0,3167^{*}$ & $2,0355^{*}$ & $0,2546^{*}$ & $0,0651^{*}$ \\
Resíduo & 424 & 0,1376 & 1,3709 & 0,1699 & 0,0288 \\
\hline $\bar{X}$ & & 2,60 & 16,39 & 4,33 & 1,16 \\
\hline CV \% & & 14,2 & 7,1 & 9,5 & 14,6 \\
\hline
\end{tabular}

* Efeito significativo em nível de probabilidade igual ou inferior a 5\%, pelo teste $\mathrm{F}$ Quadrados médios sem asterisco não foram significativos 
Tabela 45. Quadrados médios da análise da variância agrupada dos experimentos 1, 2, 3 e 4, com progênies obtidas através de cruzamentos em cadeia, para os caracteres altura da planta (AP) e altura da espiga (AE). ESALQ/Genética, 2003

\begin{tabular}{lccc}
\hline Fonte de Variação & G.L. & \multicolumn{2}{c}{ Quadrados médios } \\
\cline { 3 - 4 } & & $\mathrm{AP}$ & $\mathrm{AE}$ \\
& & $(\mathrm{cm} / \mathrm{pl} .)^{2}$ & $(\mathrm{~cm} / \mathrm{pl} .)^{2}$ \\
\hline Experimento & 3 & 3149,7532 & 607,1711 \\
Bloco/Experimento & 8 & $1392,9994^{*}$ & $261,7627^{*}$ \\
Cadeia/Experimento & 68 & $842,4740^{*}$ & $453,9867^{*}$ \\
Progênies/Cadeia/Experimento & 144 & $236,0405^{*}$ & $137,4444^{*}$ \\
Resíduo & 424 & 128,3356 & 72,0705 \\
\hline $\bar{X}$ & & 227,99 & 138,62 \\
\hline CV \% & & 4,97 & 6,12 \\
\hline
\end{tabular}

* Efeito significativo em nível de probabilidade igual ou inferior a 5\%, pelo teste $\mathrm{F}$ Quadrados médios sem asterisco não foram significativos 
Tabela 46. Quadrados médios da análise da variância agrupada dos experimentos 1, 2, 3 e 4, com progênies obtidas através de cruzamentos em cadeia, para os caracteres peso de espigas (PE), comprimento da espiga (CE), diâmetro da espiga (DE) e prolificidade (PR). Anhembi, 2003

\begin{tabular}{lccccc}
\hline Fonte de Variação & G.L. & \multicolumn{5}{c}{ Quadrados médios } \\
\cline { 3 - 7 } & & $\begin{array}{c}\mathrm{PE} \\
\left(\mathrm{kg} / 4 \mathrm{~m}^{2}\right)^{2}\end{array}$ & $\begin{array}{c}\mathrm{CE} \\
(\mathrm{cm} / \mathrm{esp} .)^{2}\end{array}$ & $\begin{array}{c}\mathrm{DE} \\
(\mathrm{cm} / \mathrm{esp} .)^{2}\end{array}$ & $\begin{array}{c}\text { PR } \\
(\mathrm{esp} . / \mathrm{pl})^{2}\end{array}$ \\
\hline Experimento & 3 & 1,7801 & 2,7501 & 0,4444 & 0,2204 \\
Bloco/Experimento & 8 & $1,8643^{*}$ & $4,9758^{*}$ & $0,9523^{*}$ & 0,1128 \\
Cadeia/Experimento & 68 & $0,4529^{*}$ & $6,8089^{*}$ & $0,7848^{*}$ & $0,2011^{*}$ \\
Progênies/Cadeia/Experimento & 144 & $0,2359^{*}$ & $3,0478^{*}$ & $0,3843^{*}$ & $0,1360^{*}$ \\
Resíduo & 424 & 0,1608 & 2,2693 & 0,2336 & 0,0891 \\
\hline $\bar{X}$ & & 2,83 & 16,92 & 4,54 & 1,34 \\
\hline CV \% & & 14,2 & 8,9 & 10,6 & 22,3 \\
\hline
\end{tabular}

* Efeito significativo em nível de probabilidade igual ou inferior a 5\%, pelo teste $\mathrm{F}$ Quadrados médios sem asterisco não foram significativos 
Tabela 47. Quadrados médios da análise da variância agrupada dos experimentos 1, 2, 3, e 4, com progênies obtidas através de cruzamentos em cadeia, para os caracteres altura da planta (AP) e altura da espiga (AE). Anhembi, 2003

\begin{tabular}{lccc}
\hline Fonte de Variação & G.L. & \multicolumn{2}{c}{ Quadrados médios } \\
\cline { 3 - 4 } & & $\begin{array}{c}\mathrm{AP} \\
(\mathrm{cm} / \mathrm{pl} .)^{2}\end{array}$ & $\begin{array}{c}\mathrm{AE} \\
(\mathrm{cm} / \mathrm{pl} .)^{2}\end{array}$ \\
\hline Experimento & 3 & 173,8906 & 261,2369 \\
Bloco/Experimento & 8 & $923,9943^{*}$ & $386,7643^{*}$ \\
Cadeia/Experimento & 68 & $999,8633^{*}$ & $539,7306^{*}$ \\
Progênies/Cadeia/Experimento & 144 & $239,5824^{*}$ & $151,1650^{*}$ \\
Resíduo & 424 & 116,4383 & 65,7065 \\
\hline $\bar{X}$ (cm/pl.) & & 213,62 & 115,57 \\
\hline $\mathrm{CV} \%$ & & 5,0 & 7,0 \\
\hline
\end{tabular}

* Efeito significativo em nível de probabilidade igual ou inferior a 5\%, pelo teste $\mathrm{F}$ Quadrados médios sem asterisco não foram significativos 
Tabela 48. Quadrados médios da análise da variância agrupada conjunta dos experimentos 1, 2, 3 e 4, com progênies obtidas através de cruzamentos em cadeia, para os caracteres peso de espigas (PE), comprimento da espiga (CE), diâmetro da espiga (DE) e prolificidade (PR)

\begin{tabular}{lccccc}
\hline Fonte de Variação & G.L. & \multicolumn{4}{c}{ Quadrados médios } \\
\cline { 3 - 6 } & & $\begin{array}{c}\text { PE } \\
\left(\mathrm{kg} / 4 \mathrm{~m}^{2}\right)^{2}\end{array}$ & $\begin{array}{c}\mathrm{CE} \\
(\mathrm{cm} / \mathrm{esp} .)^{2}\end{array}$ & $\begin{array}{c}\text { DE } \\
(\mathrm{cm} / \mathrm{esp} .)^{2}\end{array}$ & $\begin{array}{c}\text { PR } \\
(\mathrm{esp} . / \mathrm{pl})^{2}\end{array}$ \\
\hline Experimento & 3 & 0,2216 & 0,8643 & 0,4838 & 0,6465 \\
Local & 1 & 15,4343 & $92,7314^{*}$ & $14,1290^{*}$ & $10,1853^{*}$ \\
Cadeia/Experimento & 68 & $0,7017^{*}$ & $9,9292^{*}$ & $1,1564^{*}$ & $0,2323^{*}$ \\
Progênies/Cadeia/Experimento & 144 & $0,3699^{*}$ & $3,2323^{*}$ & $0,4066^{*}$ & $0,1294^{*}$ \\
Bloco/Local/Experimento & 16 & $1,0380^{*}$ & $3,8250^{*}$ & $0,5158^{*}$ & 0,0773 \\
Local x Experimento & 3 & 2,2564 & 8,2624 & 0,9921 & 0,2043 \\
Local x Cadeia/Experimento & 68 & $0,2831^{*}$ & 1,8434 & 0,2153 & 0,0838 \\
Local x Progênie/Cadeia/Experimento & 144 & $0,1826^{*}$ & 1,8511 & 0,2323 & 0,0716 \\
Resíduo & 848 & 0,1492 & 1,8201 & 0,2017 & 0,0589 \\
\hline $\bar{X}$ & & 2,72 & 16,66 & 4,44 & 1,25 \\
\hline CV \% & & 14,2 & 8,1 & 10,1 & 19,4 \\
\hline
\end{tabular}

* Efeito significativo em nível de probabilidade igual ou inferior a 5\%, pelo teste $\mathrm{F}$ Quadrados médios sem asterisco não foram significativos 
Tabela 49. Quadrados médios da análise da variância agrupada conjunta dos experimentos 1, 2, 3 e 4, com progênies obtidas através de cruzamentos em cadeia, para os caracteres altura da planta (AP) e altura da espiga (AE)

\begin{tabular}{lccc}
\hline Fonte de Variação & G.L. & \multicolumn{2}{c}{ Quadrados médios } \\
\cline { 3 - 4 } & & $\mathrm{AP}$ & $\mathrm{AE}$ \\
& & $(\mathrm{cm} / \mathrm{pl} .)^{2}$ & $(\mathrm{~cm} / \mathrm{pl} .)^{2}$ \\
\hline Experimento & 3 & 1602,5333 & 377,1865 \\
Local & 1 & $62906,7671^{*}$ & $168272,5079^{*}$ \\
Cadeia/Experimento & 68 & $1612,6194^{*}$ & $856,5020^{*}$ \\
Progênies/Cadeia/Experimento & 144 & $352,0196^{*}$ & $196,1457^{*}$ \\
Bloco/Local/Experimento & 16 & $1158,4969^{*}$ & $324,2635^{*}$ \\
Local x Experimento & 3 & 1721,1105 & 491,2214 \\
Local x Cadeia/Experimento & 68 & $229,7179^{*}$ & $137,2153^{*}$ \\
Local x Progênie/Cadeia/Experimento & 144 & 123,6033 & $92,4638^{*}$ \\
Resíduo & 848 & 122,3869 & 68,8885 \\
\hline $\bar{X}(\mathrm{~cm} / \mathrm{pl})$ & & 220,81 & 127,09 \\
\hline CV \% & & 5,0 & 6,5 \\
\hline
\end{tabular}

* Efeito significativo em nível de probabilidade igual ou inferior a 5\%, pelo teste $\mathrm{F}$ Quadrados médios sem asterisco não foram significativos 
Tabela 50. Quadrados médios da análise da variância conjunta do experimento 5, com progênies de irmãos germanos, para os caracteres peso de espigas (PE), comprimento da espiga (CE), diâmetro da espiga (DE) e prolificidade (PR)

\begin{tabular}{lccccc}
\hline Fonte de Variação & G.L. & \multicolumn{4}{c}{ Quadrados médios } \\
\cline { 3 - 7 } & & $\begin{array}{c}\text { PE } \\
\left(\mathrm{kg} / 4 \mathrm{~m}^{2}\right)^{2}\end{array}$ & $\begin{array}{c}\text { CE } \\
(\mathrm{cm} / \mathrm{esp})^{2}\end{array}$ & $\begin{array}{c}\text { DE } \\
(\mathrm{cm} / \mathrm{esp})^{2}\end{array}$ & $\begin{array}{c}\text { PR } \\
(\mathrm{esp} / \mathrm{pl})^{2}\end{array}$ \\
\hline Local & 1 & 3,7923 & 2,5689 & $13,8689^{*}$ & 0,1583 \\
Bloco/Local & 4 & $1,7348^{*}$ & 2,5089 & $0,8978^{*}$ & $0,2105^{*}$ \\
Progênies & 74 & $0,8199^{*}$ & $6,9125^{*}$ & $0,6488^{*}$ & $0,1467^{*}$ \\
Progênies x Local & 74 & $0,3228^{*}$ & $2,4022^{*}$ & 0,2383 & 0,08320 \\
Resíduo & 296 & 0,2279 & 1,4481 & 0,1861 & 0,0645 \\
\hline $\bar{X}$ & - & 2,55 & 16,65 & 4,53 & 1,20 \\
\hline CV \% & - & 18,7 & 7,2 & 9,5 & 21,1 \\
\hline
\end{tabular}

* Efeito significativo em nível de probabilidade igual ou inferior a 5\%, pelo teste $\mathrm{F}$ Quadrados médios sem asterisco não foram significativos 
Tabela 51. Quadrados médios da análise da variância conjunta do experimento 5, com progênies de irmãos germanos, para os caracteres altura da planta (AP) e altura da espiga (AE)

\begin{tabular}{lccc}
\hline Fonte de Variação & G.L. & \multicolumn{2}{c}{ Quadrados médios } \\
\cline { 3 - 4 } & & $\begin{array}{c}\mathrm{AP} \\
(\mathrm{cm} / \mathrm{pl} .)^{2}\end{array}$ & $\begin{array}{c}\mathrm{AE} \\
(\mathrm{cm} / \mathrm{pl} .)^{2}\end{array}$ \\
\hline Local & 1 & $46848,9295^{*}$ & $81917,9192^{*}$ \\
Bloco/Local & 4 & $1152,1482^{*}$ & 103,7233 \\
Progênies & 76 & $752,0006^{*}$ & $304,8419^{*}$ \\
Progênies x Local & 76 & $321,7434^{*}$ & $165,7966^{*}$ \\
Resíduo & 304 & 211,1899 & 98,3206 \\
\hline $\bar{X}$ & & 220,14 & 124,83 \\
\hline CV \% & & 6,6 & 7,9 \\
\hline
\end{tabular}

* Efeito significativo em nível de probabilidade igual ou inferior a 5\%, pelo teste $\mathrm{F}$ Quadrados médios sem asterisco não foram significativos 
Tabela 52. Quadrados médios da análise da variância conjunta do experimento 6, com

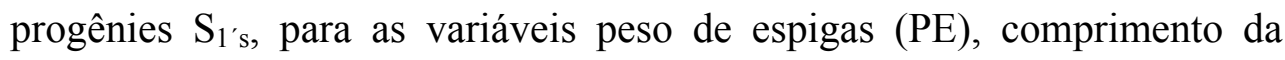
espiga (CE), diâmetro da espiga (DE) e prolificidade (PR)

\begin{tabular}{lccccc}
\hline Fonte de Variação & G.L. & \multicolumn{4}{c}{ Quadrados médios } \\
\cline { 3 - 7 } & & $\begin{array}{c}\text { PE } \\
\left(\mathrm{kg} / 4 \mathrm{~m}^{2}\right)^{2}\end{array}$ & $\begin{array}{c}\text { CE } \\
(\mathrm{cm} / \mathrm{esp})^{2}\end{array}$ & $\begin{array}{c}\text { DE } \\
(\mathrm{cm} / \mathrm{esp})^{2}\end{array}$ & $\begin{array}{c}\text { PR } \\
(\mathrm{esp} / \mathrm{pl})^{2}\end{array}$ \\
\hline Local & 1 & 6,6864 & 0,8658 & $3,1255^{*}$ & $3,4080^{*}$ \\
Bloco/Local & 4 & $1,1294^{*}$ & 3,1602 & $0,2619^{*}$ & 0,1491 \\
Progênies & 76 & $0,9108^{*}$ & $6,6695^{*}$ & $0,4382^{*}$ & $0,2580^{*}$ \\
Progênies x Local & 76 & $0,1424^{*}$ & 1,7737 & $0,1913^{*}$ & 0,0820 \\
Resíduo & 304 & 0,0934 & 1,6821 & 0,0996 & 0,0780 \\
\hline $\bar{X}$ & & 1,58 & 14,45 & 4,06 & 1,34 \\
\hline CV \% & & 19,4 & 9,0 & 7,8 & 24,6 \\
\hline
\end{tabular}

* Efeito significativo em nível de probabilidade igual ou inferior a 5\%, pelo teste $\mathrm{F}$ Quadrados médios sem asterisco não foram significativos 
Tabela 53. Quadrados médios da análise da variância conjunta do experimento 6, com progênies $S_{1 ' s}$, para as variáveis altura da planta (AP) e altura da espiga (AE)

\begin{tabular}{lccc}
\hline Fonte de Variação & G.L. & \multicolumn{2}{c}{ Quadrados médios } \\
\cline { 3 - 4 } & & $\mathrm{AP}$ & $\mathrm{AE}$ \\
& & $(\mathrm{cm} / \mathrm{pl} .)^{2}$ & $(\mathrm{~cm} / \mathrm{pl} .)^{2}$ \\
\hline Local & 1 & $57313,2967^{*}$ & $91518,2305^{*}$ \\
Bloco/Local & 4 & $566,1470^{*}$ & $326,0459^{*}$ \\
Progênies & 76 & $1403,9692^{*}$ & $610,3911^{*}$ \\
Progênies x Local & 76 & $309,5288^{*}$ & $132,8082^{*}$ \\
Resíduo & 304 & 211,1350 & 94,2567 \\
\hline $\bar{X}$ & - & 187,72 & 105,46 \\
\hline CV \% & & 7,7 & 9,2 \\
\hline
\end{tabular}

* Efeito significativo em nível de probabilidade igual ou inferior a 5\%, pelo teste $\mathrm{F}$ Quadrados médios sem asterisco não foram significativos 
Tabela 54. Estimativas da variância genética $\left(\hat{\mathrm{S}}_{\mathrm{gc}}^{2}\right)$, da variância genética aditiva $\left(\hat{\mathrm{S}}_{\mathrm{A}}^{2}\right)$ e da variância genética dominante $\left(\hat{\mathrm{S}}_{\mathrm{D}}^{2}\right)$ para seis caracteres do composto GN-04, com base na análise agrupada da variância dos experimentos 1, 2, 3, e 4, com progênies de cruzamentos em cadeia, em dois locais

\begin{tabular}{l|c|c|c|c|c|c|c}
\hline Caracteres & Unid. & \multicolumn{3}{c}{ L1 } & \multicolumn{2}{c}{ L2 } \\
\cline { 3 - 8 } & & $\hat{\mathrm{S}}_{\mathrm{gc}}^{2}$ & $\hat{\mathrm{S}}_{\mathrm{A}}^{2}$ & $\hat{\mathrm{S}}_{\mathrm{D}}^{2}$ & $\hat{\mathrm{S}}_{\mathrm{gc}}^{2}$ & $\hat{\mathrm{S}}_{\mathrm{A}}^{2}$ & $\hat{\mathrm{S}}_{\mathrm{D}}^{2}$ \\
\hline $\mathrm{PE}$ & $(\mathrm{g} / \mathrm{pl})^{2}$ & 149,2500 & $239,0000 \pm 2,1800$ & $358,0000 \pm 3,9000$ & 62,5000 & $241,0000 \pm 1,8028$ & $9,0000 \pm 3,0822$ \\
$\mathrm{CE}$ & $(\mathrm{cm} / \mathrm{esp} .)^{2}$ & 0,2215 & $1,3016 \pm 0,3877$ & $-0,4156 \pm 0,4928$ & 0,2595 & $1,6716 \pm 0,5355$ & $-0,6336 \pm 0,8407$ \\
$\mathrm{DE}$ & $(\mathrm{cm} / \mathrm{esp} .)^{2}$ & 0,0282 & $0,1476 \pm 0,0458$ & $-0,0348 \pm 0,0707$ & 0,0502 & $0,1780 \pm 0,0624$ & $0,0228 \pm 0,1015$ \\
$\mathrm{PR}$ & $(\text { esp./pl. })^{2}$ & 0,0121 & $0,0220 \pm 0,0093$ & $0,0003 \pm 0,0173$ & 0,0156 & $0,3168 \pm 0,0173$ & $0,0340 \pm 0,0332$ \\
$\mathrm{AP}$ & $(\mathrm{cm} / \mathrm{pl} .)^{2}$ & 35,9016 & $317,3948 \pm 64,4707$ & $-221,6572 \pm 80,9650$ & 41,0480 & $337,9028 \pm 76,1414$ & $-173,7108 \pm 144,4251$ \\
$\mathrm{AE}$ & $(\mathrm{cm} / \mathrm{pl} .)^{2}$ & 21,7913 & $140,6856 \pm 34,8470$ & $-53,5208 \pm 44,9936$ & 28,4862 & $172,6960 \pm 41,3026$ & $-58,7516 \pm 51,6234$ \\
\hline
\end{tabular}


Tabela 55. Estimativas da variância genética $\left(\hat{\mathrm{S}}_{\mathrm{gc}}^{2}\right)$, variância genética aditiva $\left(\hat{\mathrm{S}}_{\mathrm{A}}^{2}\right)$ e variância genética dominante $\left(\hat{\mathrm{S}}_{\mathrm{D}}^{2}\right)$ de seis caracteres do composto GN-04, com base na análise agrupada conjunta da variância dos experimentos $1,2,3$, e 4, com progênies de cruzamentos em cadeia

\begin{tabular}{l|c|c|c|c}
\hline Caracteres & Unid. & $\hat{\mathrm{S}}_{\mathrm{gc}}^{2}$ & $\hat{\mathrm{S}}_{\mathrm{A}}^{2}$ & $\hat{\mathrm{S}}_{\mathrm{D}}^{2}$ \\
\hline $\mathrm{PE}$ & $(\mathrm{g} / \mathrm{pl})^{2}$ & 78,0000 & $128,000 \pm 1,5000$ & $185,0000 \pm 2,5495$ \\
$\mathrm{CE}$ & $(\mathrm{cm} / \mathrm{esp} .)^{2}$ & 0,2302 & $1,4900 \pm 0,3915$ & $-0,5692 \pm 0,5423$ \\
$\mathrm{DE}$ & $(\mathrm{cm} / \mathrm{esp} .)^{2}$ & 0,0290 & $0,1704 \pm 0,0458$ & $-0,0544 \pm 0,0656$ \\
PR & $(\mathrm{esp} . \mathrm{pl})^{2}$ & 0,0096 & $0,0200 \pm 0,0100$ & $0,0188 \pm 0,0173$ \\
$\mathrm{AP}$ & $(\mathrm{cm} / \mathrm{pl})^{2}$ & 38,0694 & $256,5524 \pm 61,9499$ & $-104,2752 \pm 39,6304$ \\
$\mathrm{AE}$ & $(\mathrm{cm} / \mathrm{pl})^{2}$ & 17,2803 & $136,8012 \pm 33,0670$ & $-67,6800 \pm 39,6304$ \\
\hline
\end{tabular}

Tabela 56. Estimativas da variância genética $\left(\hat{\mathrm{S}}_{\mathrm{ig}}^{2}\right)$ e variância genética aditiva $\left(\hat{\mathrm{S}}_{\mathrm{A}}^{2}\right)$ de seis caracteres do composto GN-04, com base na análise conjunta da variância do experimento 5, com progênies de irmãos germanos

\begin{tabular}{l|c|c|c}
\hline Caracteres & Unid. & $\hat{\mathbf{S}}_{\text {ig }}^{2}$ & $\hat{\mathbf{S}}_{\mathrm{A}}^{2}$ \\
\hline PE & $(\mathrm{g} / \mathrm{pl})^{2}$ & 207,0000 & 276,0000 \\
$\mathrm{CE}$ & $(\mathrm{cm} / \mathrm{esp} .)^{2}$ & 0,7517 & 1,5034 \\
$\mathrm{DE}$ & $(\mathrm{cm} / \mathrm{esp} .)^{2}$ & 0,0684 & 0,1368 \\
PR & $(\mathrm{esp} . / \mathrm{pl})^{2}$ & 0,0106 & 0,0212 \\
$\mathrm{AP}$ & $(\mathrm{cm} / \mathrm{pl})^{2}$ & 71,7095 & 143,4190 \\
$\mathrm{AE}$ & $(\mathrm{cm} / \mathrm{pl})^{2}$ & 23,1742 & 46,3484 \\
\hline
\end{tabular}


Tabela 57. Estimativas da variância genética $\left(\hat{\mathrm{S}}_{\mathrm{s} 1}^{2}\right)$ e variância genética aditiva $\left(\hat{\mathrm{S}}_{\mathrm{A}}^{2}\right)$ de seis caracteres do composto GN-04, com base na análise conjunta da variância do experimento 6 , com progênies $\mathrm{S}_{1}$

\begin{tabular}{l|c|c|c}
\hline Caracteres & Unid. & $\hat{\mathrm{S}}_{\mathrm{S} 1}^{2}$ & $\hat{\mathrm{S}}_{\mathrm{A}}^{2}$ \\
\hline PE & $(\mathrm{g} / \mathrm{pl})^{2}$ & 320,2500 & 276,0000 \\
$\mathrm{CE}$ & $(\mathrm{cm} / \mathrm{esp} .)^{2}$ & 0,8160 & 0,8160 \\
$\mathrm{DE}$ & $(\mathrm{cm} / \mathrm{esp} .)^{2}$ & 0,0412 & 0,0412 \\
PR & $(\mathrm{esp} . / \mathrm{pl})^{2}$ & 0,0293 & 0,0293 \\
$\mathrm{AP}$ & $(\mathrm{cm} / \mathrm{pl})^{2}$ & 182,4067 & 182,4067 \\
$\mathrm{AE}$ & $(\mathrm{cm} / \mathrm{pl})^{2}$ & 79,5972 & 79,5972 \\
\hline
\end{tabular}




\section{REFERÊNCIAS BIBLIOGRÁFICAS}

ALlARD, R. W. Princípios do melhoramento genético das plantas. São Paulo: Edgard Blücher, 1960. 381p.

ALVES, G. F.; RAMALHO, M. A. P.; SOUZA, J. C. Alterações nas propriedades genéticas da população CMS-39 submetidas à seleção massal para prolificidade. Revista Brasileira de Milho e Sorgo, v.1, n.3, p.89-1001, 2002.

ANJOS, M. H. G.; ANDRADE, J. A. C. Variabilidade genética no composto Flintisa de milho (Zea mays L.). CONGRESSO NACIONAL DE MILHO E SORGO, 23., Uberlândia, 2000. Resumos. Sete Lagoas: ABMS/Embrapa Milho e Sorgo/ Universidade Federal de Uberlândia, 2000. p.33.

ARIAS, C. A. A.; SOUZA JÚNIOR, C. L. Genetic variance and covariance components related to intra - and interpopulation recurrent selection in maize (Zea mays L.). Genetics and Molecular Biology, v.21, n.4, p.537-544, 1998.

ASTETE MALDONADO, F. A.. Endogamia e heterose em populações de tamanho reduzido de milho (Zea mays L.). Piracicaba, 2001. 170p. Tese (Doutorado) Escola Superior de Agricultura 'Luiz de Queiroz', Universidade de São Paulo.

BAKER, L. H.; CURNOW, R. N. Choice of populationsize and use of variation between replicate populations in plant breeding selection programs. Crop Science, v.9, p.555-560, 1969. 
BARBIN, D. Componentes de variância: teoria e aplicação. Piracicaba: FEALQ, 1998. 120p.

BELLUCI, A. A. Avaliação de populações derivadas de híbridos de milho (Zea mays L.) em cruzamentos nos esquemas dialélicos e top cross. Piracicaba, 1994. 133p. Dissertação (Mestrado) - Escola Superior de Agricultura 'Luiz de Queiroz', Universidade de São Paulo.

BENITEZ TORRES, L. Avaliação de progênies de irmãos germanos obtidos por cruzamento em cadeia em duas populações de milho (Zea mays L.). Piracicaba, 1986. 102p. Dissertação (Mestrado) - Escola Superior de Agricultura 'Luiz de Queiroz', Universidade de São Paulo.

CARRALES BLANDÓN, S. Efeito da deriva genética sobre caracteres quantitativos em uma população de milho (Zea mays L.). Piracicaba, 1996. 90p. Tese (Doutorado) - Escola Superior de Agricultura ' Luiz de Queiroz', Universidade de São Paulo.

CABALLERO, A. Developments in the prediction of effective population size. Heredity, v.73, p.657-679, 1994.

CARVALHO, H. W. L.; LEAL, M. L. S.; SANTOS, M. X. et al. Potencial genético da cultivar de milho BR-5011-Sertanejo nos tabuleiros costeiros do nordeste brasileiro. Pesquisa Agropecuária Brasileira, v.35, n.6, p.1169-1176, 2000.

COCKERHAM, C. C. An extension of the concept of partitioning hereditary variance for analysis of covariances among relatives when epistais is present. Genetics, v.39, p.859-882, 1954. 
COCKERHAM, C. C. Estimation of genetic variances. In: HANSON, W. D.; ROBINSON, H. F. (Ed) Statistical genetics and plant breeding. Washintgton: National Academy Science, 1963. p.53-94.

COMSTOCK, R. E.; ROBINSON, H. F. The components of genetic variance in population of biparental progenies and their use in estimating the average degree of dominance. Biometrics, v.4, p.254-256, 1948.

COSTA, F. M. P.; MIRANDA FILHO, J. B.; NASS, L. L. Valor genético de um composto selecionado para resistência à Phaeosferia maidis. In: CONGRESSO NACIONAL DE MILHO E SORGO, 23., Uberlândia, 2000. Resumos. Sete Lagoas: ABMS/Embrapa Milho e Sorgo/ Universidade Federal de Uberlândia, 2000. p.66.

DANTAS, J. L. L. Cruzamentos dialélicos parciais para avaliação de híbridos intermediários entre duas populações de milho (Zea mays L.). Piracicaba, 1992. 216p. Tese (Doutorado) - Escola Superior de Agricultura 'Luiz de Queiroz', Universidade de São Paulo.

EBERHART, S. A.; GARDNER, C. O. A general model for genetic effects. Biometrics, v.22, p.864-881, 1966.

FALCONER, D. S.; MACKAY, T. F. C. Quantitative genetics. 4.ed. Essex: Longman, 1996. 464p.

FISHER, W. R. Principes of cultivar development. New York: Macmillan Publishing Company, 1918. 536p.

FRANCELLI, A. L; DOURADO-NETO, D. Milho: Tecnologia e Produtividade. Piracicaba: ESALQ/LPV, 2001. 259p. 
FRANK, T. E.; HALLAUER, A. R. Inter and intrapopulation genetic variances after ten cycles of reciprocal full-sib recurrent selection in the BS10 and BS11 syntetic maize populations. Maydica, v.44, p.9-24, 1999.

GALAL, H. E.; ABD - ALLA, S. A.; KASSABY, Y. A. Effect of sample size on precision of the estimates of genetic variance in maize. I. Ear caracters. Egipty Journal Genetics Cytology, v.6, p.306-318, 1977.

GAMA, E. E. G.; VIANNA, R. T.; NASPOLINI FILHO,V.; et al. Efeito depressivo da endogamia em gerações avançadas de quatro tipos de híbridos de milho. Pesquisa Agropecuária Brasileira, v.20, p.1293-1300, 1985.

GARAY, G.; IGARTUA, E.; ALVAREZ, A. Responses to S1 selection in flint and dent synthetic maize populations. Crop science, v.36, p.1129-1134, 1996.

GARDNER, C. O.; EBERHART, S. A. Analysis and interpretation of the variety cross diallel and related population. Biometrics, v.22, p.439-425, 1966.

GERALDI, I. O.; MIRANDA FILHO, J. B. Adapted models for the analysis of combining ability of varieties in parcial diallel crosses. Revista Brasileira de Genética, v.11, n.2, p.419-430, 1988.

GORGULHO, E. P. Avaliação de variedades de milho (Zea mays L.) sob dois esquemas de cruzamento: dialélico parcial e 'topcross' intergrupos. Piracicaba, 1997. 117p. Tese (Doutorado) - Escola Superior de Agricultura ‘ Luiz de Queiroz’, Universidade de São Paulo. 
GORGULHO, E. P.; MIRANDA FILHO, J. B. Estudo da capacidade combinatória de variedades de milho no esquema de cruzamento dialélico parcial. Bragantia, v.60, n.1, p.1-8, 2001 .

GRIFFING, J. B. Concept of general and specific combining ability in relation to diaallel crossing system. Autralian Journal Biological Science, v.9, p.463-493, 1956.

GUL ZAFFAR, G. H. Z.; SHAFIQ, W. A. Estimation of genetic variances in a maize composite. Indian Journal Genetics, v.61, n.2, p.111-114, 2001.

GUZMAN, P. S.; LAMKEY, K. R. Effective population size and genetic variability in the BS11 maize population. Crop Science, v.40, p.338-346, 2000.

HALLAUER, A. R. Relation of quantitative genetics to applied maize breeding. Revista Brasileira de Genética, v.3, p.207-233, 1980.

HALLAUER, A. R. ; MIRANDA FILHO, J. B. Quantitative genetics in maize breeding. 2ed. Ames: Iowa State University Press., 1995. 468p.

HALlAUER, A. R. Recurrent selection in maize. Plant Breeding Reviews, v.9, p.115$179,1992$.

HARLAND, S. C. A new method of maize improvement. Tropical Agriculture, v.23, p.114, 1946.

HAYMAN, B. I. The teory and analysis of diallel crosses. Genetics, v.39, p.784-809, 1954. 
HELMS, T. C.; HALlAUER, A. R.; SMITH, O. S. Genetic drift and selection evaluated from recurrent selection programs in maize. Crop Science, v. 29, p.602$607,1989$.

HULL, F. H. Recurrent selection for specific combining ability in corn. Agronomy journal, v.37, p.134-145, 1945.

KEMPTHORNE, O. The correlations between relatives in a random mating population. Proceeding Royal Society London, v.143, p.103-113, 1954.

KEMPTHORNE, O. The theoretical values of correlations between relatives in random mating populations. Genetics, v.40, p.153-157, 1955.

KERR, W. E.; WRIGHT, S. Experimental studies of the distribution of gene frequencies in very small populations of Drosophila melanogaster: I. forked. Evolution, v.8, p. 293-302, 1954a.

KERR, W. E.; WRIGHT, S. Experimental studies of the distribution of gene frequencies in very small populations of Drosophila melanogaster: III. aristapedia and spineless. Evolution, v.8, p. 293-302, 1954 b.

KIMORA, M.; CROW, J. F. The measurement of effective population number. Evolution, v.17, p.279-288, 1963.

LIMA, M. Análise de cruzamentos intervarietais de milho (Zea mays L.) no esquema dialélico parcial. Piracicaba, 1982. 95p. Tese (Doutorado) - Escola Superior de Agricultura 'Luiz de Queiroz', Universidade de São Paulo.

LIMA, M.; MIRANDA FILHO, J. B.; GALLO, P. B. Inbreeding depression in Brazilian populations of maize (Zea mays L.). Maydica, v.29, p.203-215, 1984. 
LONNQUIST, J. H. Progress from recurrent selection procedures for the improvement of corn populations. Nebraska Agriculture Experimental Station Bulletin , n.197, p.1-33, 1961.

MALVAR, A. R.; ORDÁS, A.; REVILLA, P. et al. Estimates of genetic variances in two spanish populations of maize. Crop Science, v.36, p.291-295, 1996.

MARIANI, G.; DESIDERIO, E. Grain yield and PRificacy in maize. 2. A diallel analysis of eight inbreds from the O.P. variety Nostrano Dell'Isola at two densities. Maydica, v.20, p95-110, 1975.

MESQUITA, G.O.; BRASIL, E. M.; ZORZI, A. L. Estimação dos componentes de variância em duas populações de milho. IN: CONGRESSO NACIONAL DE MILHO E SORGO, 23., Uberlândia, 2000. Resumos. Sete Lagoas: ABMS/ Embrapa Milho e Sorgo/ Universidade Federal de Uberlândia, 2000. p.86.

MIRAND FILHO, J. B.; GORGULHO, E. P. Cruzamentos com testadores e dialelos. In: NASS, L. L.; VALOIS, A. C. C.; MELO, I. S.; VALADARES-INGLIS, M. C. Recursos Genéticos e Melhoramento - Plantas. Rondonópolis: Fundação MT, 2001. cap.21, p.649-671.

MIRANDA FILHO, J. B. Componentes da variância genética em progênies de cruzamentos em cadeia. Piracicaba: ESALQ, Dept. Gen., Inst. Genética, 1982. p.77-86 (Relatório Científico,16).

MIRANDA FILHO, J. B. Cruzamentos dialélicos e síntese de compostos de milho (Zea mays L.) com ênfase na produtividade e no porte da planta. Piracicaba, 1974. 116p. Tese (Doutorado) - Escola Superior de Agricultura 'Luiz de Queiroz' Universidade de São Paulo. 
MIRANDA FILHO, J. B.; ANDRADE, J. A. C. Quantitative traitss in the maize population ESALQ-PBI: parameters estimative. Brasilian Journal of Genetics, v.37, p.30-38, 1996.

MIRANDA FILHO, J. B.; GERALDI, I. O. An adapted model for the analysis of partial diallel crosses. Revista Brasileira de Genética, v.7, n.4, p.677-688, 1984.

MIRANDA FILHO, J. B.; VENCOVSKY, R. Analysis of diallel crosses among open pollinated varieties of maize (Zea mays L.). Maydica, v.29, p.271-234, 1984.

MIRANDA FILHO, J. B.; VENCOVSKY, R. Variance among testcrosses. Piracicaba: USP/ESALQ, Depto. De Genética, 2001. 11p. (Publicação Didática).

MOREIRA, R. M. P. Avaliação dos efeitos da deriva genética em duas gerações de amostragens nas populações de milho BR-105 e BR-106. Piracicaba, 1999. 120p. Tese (Doutorado) - Escola Superior de Agricultura 'Luiz de Queiroz', Universidade de São Paulo.

NASS, L. L. Variabilidade genética de populações semi-exóticas de milho (Zea mays L.). Piracicaba, 1992. 141p. Tese (Doutorado) - Escola Superior de Agricultura 'Luiz de Queiroz', Universidade de São Paulo.

NASS, L. L.; MIRANDA FILHO, J. B. Synthesis of new composites of maize (Zea mays L.) for population improvement in Brazil. In: REUNION LATINOAMERICANA DEL MAIZ, 18., Sete Lagoas, 1999. Memórias. Mexico: CIMMYT; EMBRAPA - CNPMS, 1999. p.309.

NASS, L. L.; MIRANDA FILHO, J. B.; COSTA, F. M. P.; Parâmetros genéticos em quatro compostos de milho. In: CONGRESSO NACIONAL DE MILHO E SORGO, 
23., Uberlândia, 2000. Resumos. Sete Lagoas: ABMS/Embrapa Milho e Sorgo/ Universidade Federal de Uberlândia, 2000. p.68.

OBILANA, A. T.; HALLAUER, A. R.; SMITH, O.S. Estimated genetic variability in a maize interpopulation. The Journal of Heredity, v.70, p.127-132, 1979.

ORDAS, A.; STUCKER, R. E. Effect of planting density on correlations among yield and its components in two corn populations. Crop Science, v.17, p.926-929, 1977.

PATERNIANI, E. Efeitos do tamanho de populações de milho (Zea mays L.). Piracicaba, 1995. 117p. Tese (Doutorado) - Escola Superior de Agricultura 'Luiz de Queiroz', Universidade de São Paulo.

PATERNIANI, E. Maize breeding in the tropics. CRC Critical reviews in Plant Science, v.9, p.125-154, 1990.

PATERNIANI, E.; MIRANDA FILHO, J. B. Melhoramento de populações. In: PATERNIANI, E.; VIÉGAS, G. P. (Ed.) Melhoramento e produção do milho. Campinas: Fundação Cargill, 1987. cap.6, p.217-274.

PATERNIANI, M. E. A. G. Z.; DUARTE, A. P.; LIMA, M. et al. Variedade de milho IAC V3: variabilidade genética e potencial de produção. In: CONGRESSO NACIONAL DE MILHO E SORGO, 23., Uberlândia, 2000. Resumos. Sete Lagoas: ABMS/Embrapa Milho e Sorgo/Universidade Federal de Uberlândia, 2000. p.87.

PIMENTEL-GOMES, F.; GARCIA, C. H. Estatística aplicada a experimentos agronômicos e florestais. Piracicaba: FEALQ, 2002. 309p. 
PIZAIA, A. Seleção para prolificidade em populção de milho (Zea mays L.). Piracicaba, 2000. 132p. Tese (Doutorado) - Escola Superior de Agricultura "Luiz de Queiroz", Universidade de São Paulo.

RAMALHO, M. A. P. Eficiência relativa de alguns processos de seleção intrapopulacional no milho baseados em famílias não endógamas. Piracicaba, 1977. 122p. Tese (Doutorado) - Escola Superior de Agricultura 'Luís de Queiroz', Universidade de São Paulo.

RAWLINGS, J. O.; THOMPSON, D.L. Performance level as criterion for for the choice of maize testers. Crop Science, v.2, p.217-220, 1962.

SAMPAIO, N. F. Propriedades genéticas e potencial para o melhoramento dos compostos de milho (Zea mays L.) ESALQ-PB4 e ESALQ-PB5. Piracicaba, 1986. 105p. Dissertação (Mestrado) - Escola Superior de Agricultura 'Luís de Queiroz', Universidade de São Paulo.

SANTOS, M. X. Estudo do potencial genético de duas raças brasileiras de milho (Zea mays L.) para fins de melhoramento. Piracicaba, 1985. 186p. Tese (Doutorado) Escola Superior de Agricultura 'Luiz de Queiroz', Universidade de São Paulo.

SCAPIM, C. A.; CARVALHO, C. G. P.; CRUZ, C. D. Uma proposta de classificação dos ceficientes de variação para a cultura do milho. Pesquisa Agropecuária Brasileira, v.30, n.5, p.683-686, 1995.

SILVA, S. O. Estimativas de parâmetros genéticos em populações de milho braquíticos, pelo delineamento I, de Comostock e Robonson. Piracicaba, 1990. 138p. Tese (Doutorado) - Escola Superior de Agricultura 'Luís de Queiroz', Universidade de São Paulo. 
SILVA, R. M. Valor genético e potencial heterótico de populações de milho (Zea mays). Piracicaba, 2001. 121p. Tese (Doutorado) - Escola Superior de Agricultura 'Luís de Queiroz', Universidade de São Paulo.

SMITH, O. S. Comparison of effects of reciprocal recurrent selection in the BSSS(R), BSCB1(R) and BS6 populations. Maydica, v.24, p.1-8, 1984.

SMITH, O. S. Evaluation of recurrent selection in BSSS, BSCB1, AND BS13 maize populations. Crop Science, v.23, p.35-40, 1983.

SOARES FILHO, W. S. Características fenotípicas e genéticas das populações de milho (Zea mays L.) braquítico Piranão VD2B e Piranão VF1B. Piracicaba, 1987. 185p. Tese (Doutorado) - Escola Superior de Agricultura 'Luiz de Queiroz', Universidade de São Paulo.

SOUZA JÚNIOR, C. L. Análise de cruzamentos dialélicos e predição de compostos de milho (Zea mays L.) braquítico. Piracicaba, 1981. 102p. Dissertação (Mestrado) Escola Superior de Agricultura 'Luiz de Queiroz', Universidade de São Paulo.

SOUZA JÚNIOR, C. L. Variâncias genéticas interpopulacionais e suas relações com a obtenção e seleção de híbridos. Piracicaba, 1988. 140p. Tese (Livre-Docência) Escola Superior de Agricultura 'Luís de Qeuiroz', Universidade de São Paulo.

SOUZA JÚNIOR, C. L.; GERALDI, O. I.; VENCOVSKY, R. Response to recurrent selection under small effective population size. Genetics and Molecular Biology, v.23, n.4, p.841-846, 2000.

SOUZA JÚNIOR, C.L. Variabilidade genética em milho (Zea mays L.) e relações com a seleção recorrente intra e interpopulacional. Piracicaba, 1983. 151p. Tese 
(Doutorado) - Escola Superior de Agricultura 'Luís de Queiroz', Universidade de São Paulo.

SPRAGUE, G. F.; TATUM, L. A. General vs. Specific combining ability in single crosses of corn. Journal of American Society of Agronomy, v.34, p.923-932, 1942.

STOJSIN, D.; KANNENBERG, L. W. Genetic chages associated with different methos of recorrent selection in five maize populations: II. Indirectly selected traits. Crop Science, v.34, p.1473-1479, 1994.

VALOIS, A. C. C. Eficiência comparativa de quatro métodos de seleção em uma população melhorada de milho (Zea mays L. ). Piracicaba, 1982. 119p. Tese (Doutorado) -Escola Superior de Agricultura 'Luiz de Queiroz', Universidade de São Paulo.

VALOIS, A.C.C.; MIRANDA FILHO, J.B. Comparação entre métodos de seleção em milho cv. Centralmex. Pesquisa Agropecuária Brasileira, v.19, p. 479-88, 1984.

VENCOVSKY, R. Alguns aspectos teóricos e aplicados relativos a cruzamentos dialélicos de variedades. Piracicaba, 1970. 110p. Tese (Livre Docência) - Escola Superior de Agicultura 'Luiz de Queiroz', Universidade de São Paulo.

VENCOVSKY, R. Efetive size of monoecious populations submitted to artificial selection. Revista Brasileira de Genética, v.1, n.3, p.181-191, 1978.

VENCOVSKY, R. Herança quantitativa. In: PATERNIANI, E.; VIÉGAS, G. P. (Ed) Melhoramento e produção do milho. Campinas: Fundação Cargill, 1987. cap.5, p.137-214. 
VENCOVSKY, R.; BARRIGA, P. Genética biométrica no fitomelhoramento. Ribeirão Preto: Sociedade Brasileira de Genética, 1992. 486p.

VENCOVSKY, R.; MIRANDA FILHO, J. B.; SOUZA JÚNIOR, C. L. Quantitative genetics and corn breeding in Brazil. In: INTERNATIONAL CONFERENCE ON QUANTITATIVE GENETICS, 2., Raleigh, 1987. Proceedings. Sunderland: Sinauer, 1988. 465-77.

VIANNA, R. T.; GAMA, E. E. G.; NASPOLINI FILHO, V.; et al. Inbreeding depression of several introduced populations of maize (Zea mays L.). Maydica, v.27, p.151-157, 1982.

WEYHRICH, R. A.; LAMKEY, K. R.; HALLAUER, A. R. Effective population size and Response to $\mathrm{S} 1$ - progeny selection in the BS11 maize population. Crop Science, v.38, p.1149-1158, 1998.

WOLF, D. P.; PETERNELLI, L. A.; HALLAUER, A. R. Estimates of genetic variance in an F2 maize population. The Journal of Heredity, v.91. n.5, p.384-391, 2000.

WRIGHT, S. Evolution in Mendelian populations. Genetics, v.16, p.97-159, 1931.

WRIGHT, S.; KERR, W. E. Experimental studies of the distribution of gene frequencies in very small populations of Drosophila melanogaster: II. Bar. Evolution, v.8, p. 225-240, 1954. 